\title{
ANÁliSE PARAMÉTRICA E DIMENSIONAMENTO DE POÇOS DE INFILTRAÇÃO PARA FINS DE DRENAGEM URBANA
}

Dissertação apresentada à Escola de Engenharia de São Carlos da Universidade de São Paulo, como parte dos requisitos para a obtenção do título de Mestre em Geotecnia

Versão Corrigida

Orientador: Prof. Dr. Orencio Monje Vilar 
AUTORIZO A REPRODUÇÃO E DIVULGAÇÃO TOTAL OU PARCIAL DESTE TRABALHO, POR QUALQUER MEIO CONVENCIONAL OU ELETRÔNICO, PARA FINS DE ESTUDO E PESQUISA, DESDE QUE CITADA A FONTE.

Ficha catalográfica preparada pela Seção de Tratamento da Informação do Serviço de Biblioteca - EESC/USP

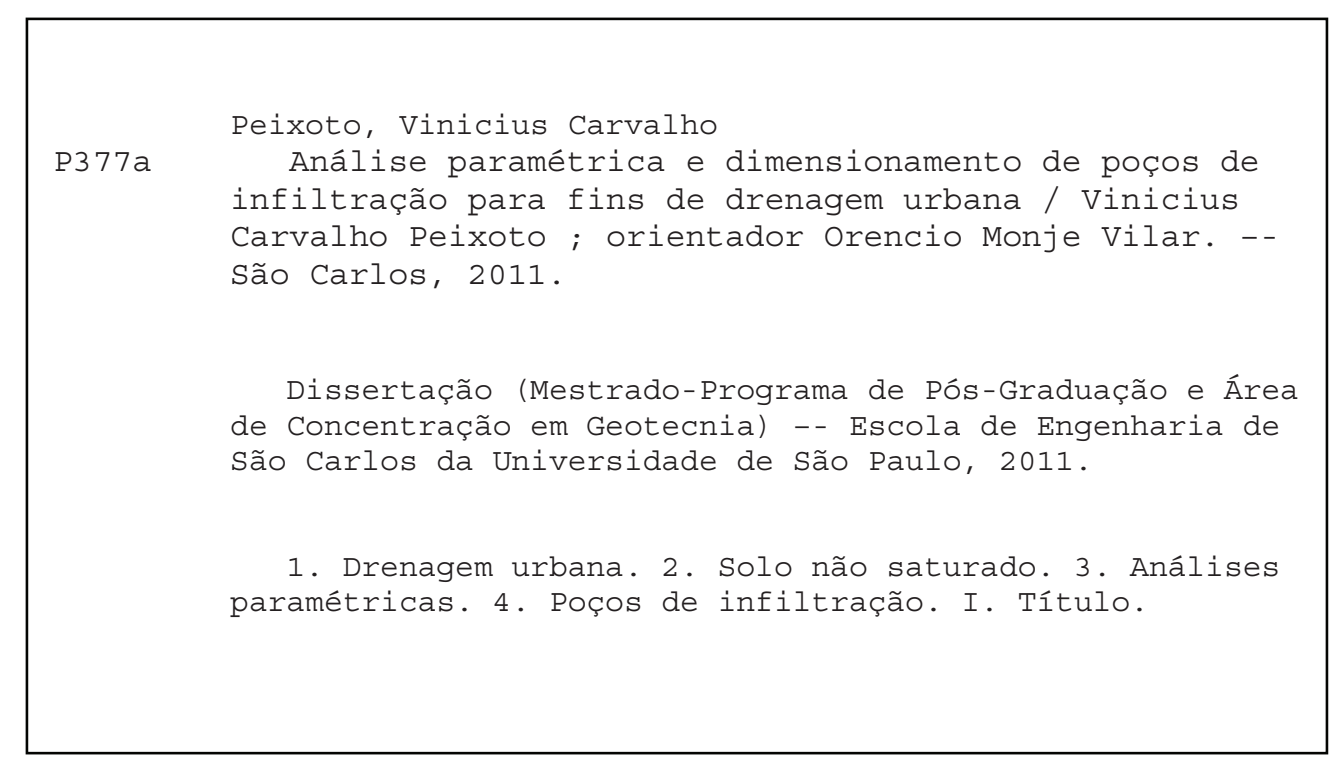


Candidato(a): Engenheiro VINICIUS CARVALHO PEIXOTO.

Dissertação defendida e julgada em 15/04/2011 perante a Comissão Julgadora:

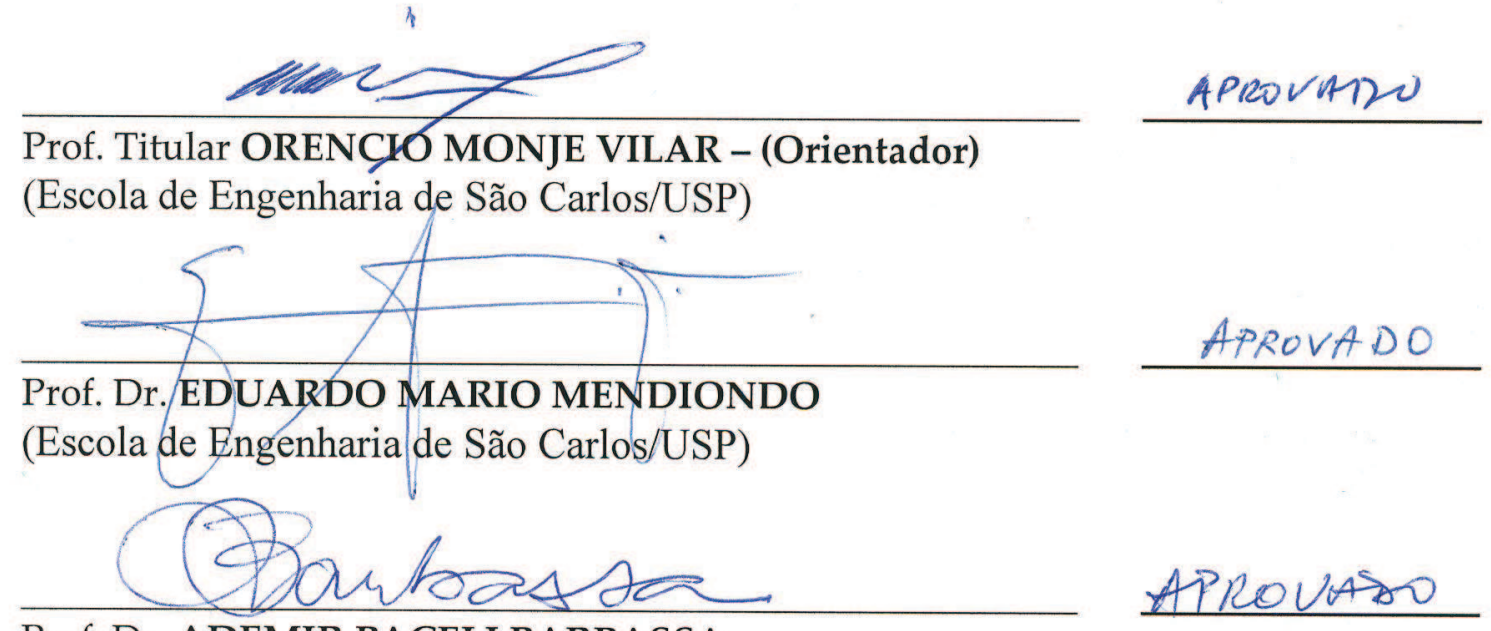

Prof. Dr. ADEMIR PACELI BARBASSA

(Universidade Federal de São Carlos/UFSCar)

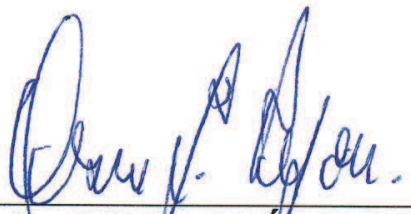

Prof. Titular OSN/ JOSÉ PEJON

Coordenador do Programa de Pós-Graduação em Geotecnia

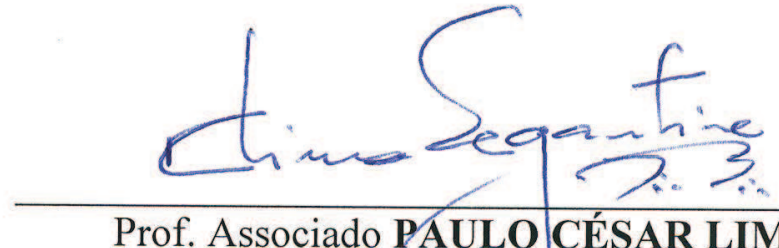

Prof. Associado PAULO CÉSAR LIMA SEGANTINE

Presidente da Comissã da Pós-Graduação da EESC 

Dedicatória

A minha família, em especial a minha esposa Amanda Maria Dantas de Jesus Peixoto, pelo incentivo e companheirismo. 



\section{AGRADECIMENTOS}

A Deus, mesmo que por inúmeras vezes eu tenha questionado a minha fé, sei que sem o Teu consentimento eu não teria alcançado tantas dádivas em minha vida.

A minha esposa Amanda Maria Dantas de Jesus Peixoto por todo amor, carinho e dedicação a mim concedidos.

Aos meus pais José Veríssimo Peixoto e Genilde Carvalho Peixoto e aos meus irmãos Thiago Carvalho Peixoto e Jacqueline Carvalho Peixoto por sempre terem me apoiado e incentivado nos momentos mais difíceis.

Pelas valiosas contribuições técnicas e auxílio fornecido para a elaboração deste trabalho, expresso minha imensa gratidão aos seguintes profissionais:

Ao professor Dr. Orencio Monje Vilar pela orientação e pelo apoio na realização deste trabalho.

Ao professor Dr. Benedito de Souza Bueno pelo exemplo de profissional íntegro e dedicado.

A todos os docentes do Departamento de Geotecnia.

A todos os amigos da pós-graduação. Cito em especial aqueles que fazem parte da turma de alunos de mestrado de 2009: Gian Franco Napa Garcia, Jenny Yuamiled Paricahua Jorge, Luis Miguel Cañabi Quispe, Mariana Alher Fernandes, Mercedes Liliana Prieto Castillo, Nestor Benedito Fracasse de Barros, Pablo César Trejo Noreña, Thiago Peixoto de Araújo, Tiago de Jesus Souza e Vivian Athaydes Canello.

Ao engenheiro Cláudio Rodrigues dos Santos pelas instruções no uso do SEEP/W.

Ao engenheiro Jude Christian Salles pela revisão do abstract.

Aos funcionários do Departamento de Geotecnia.

Aos companheiros do laboratório de Mecânica dos Solos, Giovana Bizão Georgetti, Oscar dos Santos Neto e José Luís Guerra.

Aos professores e amigos Carlos Rezende Cardoso Júnior, Demóstenes de Araújo Cavalcanti Júnior e Erinaldo Hilário Cavalcante, por terem me mostrado durante a minha formação como engenheiro civil o quão espetacular e fascinante é a Geotecnia.

Agradeço ainda, ao Conselho Nacional de Desenvolvimento Científico e Tecnológico (CNPq), pelo auxílio financeiro. 

Nada pode dar-nos uma satisfação mais profunda e maior felicidade do que o grande esforço de dar à luz alguma coisa que ainda não nasceu. Fazendo isso, nós ultrapassamos a fronteira estreita de nossa personalidade e, então, crescemos. O sentido da vida é a própria vida.

Trecho de uma carta de Karl Terzaghi enviada ao seu filho Eric Terzaghi em 1956. 



\section{RESUMO}

PEIXOTO, V. C. Análise Paramétrica e Dimensionamento de Poços de Infiltração para

Fins de Drenagem Urbana. 2011. 111p. Dissertação (Mestrado) - Escola de Engenharia de São Carlos, Universidade de São Paulo, São Carlos, 2010.

A combinação entre a falta de planejamento urbano e o crescimento indiscriminado de áreas impermeáveis é responsável pela ocorrência de enchentes em centros urbanos. O emprego de dispositivos de controle do escoamento superficial na fonte geradora, como poços e trincheiras de infiltração, pavimentos permeáveis e jardins de infiltração (rain gardens), é uma alternativa que permite restabelecer o processo de infiltração em áreas urbanas densamente impermeabilizadas. Neste contexto, efetuou-se uma análise paramétrica acerca da influência das funções condutividade hidráulica e das curvas de retenção dos solos no processo de infiltração de água em poços cilíndricos instalados em solos inicialmente não saturados. Para a realização das análises paramétricas, foi empregado o programa SEEP/W do pacote GeoStudio 2004, que utiliza a técnica dos elementos finitos na solução numérica da equação de Richards que rege o fluxo de água em meio não saturado. As análises paramétricas mostraram que o coeficiente de condutividade hidráulica saturada do solo é o parâmetro que apresenta maior relevância no processo de infiltração de água em poços. Com isto, desenvolveu-se uma técnica de dimensionamento de poços de infiltração que permite determinar o volume de água infiltrada em um dado poço em função do tempo de precipitação, do coeficiente de condutividade hidráulica saturada do solo e da área total do poço. Por fim, comparou-se o volume estimado de água infiltrada obtido através da técnica de dimensionamento com o volume medido em um ensaio de infiltração realizado por Lima (2009) em uma trincheira de pequenas dimensões e pôde-se constatar que o a técnica de dimensionamento desenvolvida é consistente com o ensaio de infiltração realizado em campo.

Palavras-chave: Solo não saturado; Drenagem urbana; Análises Paramétricas; Poços de infiltração. 



\begin{abstract}
PEIXOTO, V. C. Parametric Analysis and Design of Infiltration Wells for Urban Drainage. 2011. 111p. Dissertação (Mestrado) - Escola de Engenharia de São Carlos, Universidade de São Paulo, São Carlos, 2010.
\end{abstract}

The chief consequence of unplanned urban sprawl is the turning to impervious large tracts of land. Impervious developed areas are prone to floods during heavy rains. Flooding may be mitigated by installation of devices that can control runoff at the source. Examples of control devices are infiltration wells, infiltration trenches, permeable pavement, and rain gardens. By facilitating infiltration, such devices serve to return to the soil below the waterproofed area the waters that would otherwise be lost as runoff, which overloads urban drainage. A study of infiltration wells was conducted through parametric analyses of hydraulic conductivity function and soil-water characteristics curve of unsaturated soils in the process of infiltration. This research used the computer program SEEP/W by GeoStudio 2004 to carry out the parametric analysis. SEEP/W uses the finite element method for the numerical solution of Richards' equation, which describes water flow in the unsaturated zone. The parametric analysis showed that the saturated hydraulics conductivity of the soil is the parameter that has greater relevance in the process of infiltration of water into the soil surrounding the wells. Based on the results obtained, a technical procedure was developed to assist the consulting professional to size the infiltration wells. The variables employed in the proposed design procedure consist of time of precipitation, saturated hydraulic conductivity, and total surface area of well. Further, it was compared the estimated volume of infiltrated water obtained through this procedure to the measured volume obtained by Lima (2009) in a small trench. It was observed that the scaling procedure proposed by this work yields results consistent with infiltration field experiments such as that conducted by Lima (2009).

Key-words: Unsaturated soil; Urban drainage; Parametric analysis; Infiltration wells. 



\section{LISTA DE FIGURAS}

Figura 2.1 - Diagramas de fases, rigoroso e simplificado para um solo não saturado. (a) Sistema não saturado tetrafásico rigoroso do solo; (b) Diagrama trifásico simplificado. (modificado de FREDLUND \& RAHARDJO, 1993).

Figura 2.2 - Esquema ilustrativo da definição de potencial total da água no solo (VILAR, 2002).

Figura 2.3 - Definição de sucção total, matricial e osmótica (VILAR, 2002).

Figura 2.4 - Curva de retenção típica de solos siltosos ( $\theta_{r}$ é a umidade residual, $\theta_{s}^{*}$ é a umidade de saturação no processo de drenagem e $\theta_{s}^{* *}$ é a umidade de saturação no processo de sorção) (modificado de FREDLUND \& XING, 1994).

Figura 2.5 - Esquema da câmara com placa de alta pressão de entrada de ar (LIBARDI, 1995).

Figura 2.6 - Elemento de volume de solo, através do qual a água está fluindo (modificado de REICHARDT, 1996).

Figura 2.7 - Perfil de umedecimento do solo durante a infiltração ( $\theta_{0}$ é a umidade inicial do solo e $\theta_{s}$ a umidade do solo correspondente à saturação) (LIBARDI, 1995). .

Figura 2.8 - Curvas de infiltração instantânea e acumulada. 46

Figura 2.9 - Esquema do ensaio de infiltração horizontal (LIBARDI, 1995). .50

Figura 2.10 - Curva hipotética da umidade em função de $\eta$ (HILLEL, 1980). . .52

Figura 2.11 - Esquema do ensaio de infiltração vertical (LIBARDI, 1995). 52

Figura 2.12 - Esquema de uma barragem de terra ao fim da definição do problema (SEEP/W DEFINE). 57

Figura 2.13 - Termo $m_{w}$ da curva de retenção de água do solo. 58

Figura 2.14 - Visualização final da solução de um problema de fluxo permanente em uma barragem de terra (SEEP/W COUNTOUR).

Figura 2.15 - Diagrama conceitual de um jardim de infiltração (modificado de ARAVENA \& DUSSAILLANT, 2009).

Figura 2.16 - Corte com descrição das camadas dos pavimentos permeáveis. (a) Concreto ou asfalto porosos; (b) Piso de bloco de concreto vazado. (URBONAS \& STAHRE, 1993 apud ARAÚJO et al., 2000). 62

Figura 2.17 - Esquema típico de uma trincheira de infiltração. 64

Figura 2.18 - Esquema dos poços de infiltração. (a) Poço de infiltração revestido (modificado de REIS et al., 2005); (b) Poço de infiltração não revestido (modificado de SOUZA, 2002). 66 
Figura 3.1 - Domínio de referência típico ( $d$ e $h$ variam de acordo com cada poço).

Figura 3.2 - Perfil inicial de distribuição de pressões na água contida no solo, em todas as análises.

Figura 3.3 - (a) Curvas de retenção e (b) Funções condutividade hidráulica - Solos A, B e C.

Figura 3.4 - (a) Curvas de retenção e (b) Funções condutividade hidráulica - Solos D, E e F.

Figura 4.1 - Propriedades do solo utilizado no experimento de Vauclin et al. (1979). (a) curva de retenção de água e (b) função condutividade hidráulica (modificado de VAUCLIN et al., 1979).

Figura 4.2 - Distribuição de cargas totais após 8 horas de infiltração. (a) Vauclin et al. (1979) (valores assinalados com + são valores experimentais) - cargas totais em centímetros; (b) $\mathrm{SEEP} / \mathrm{W}$ - cargas totais em metros. .76

Figura 5.1 - Curva de retenção e função condutividade hidráulica do solo r.C-k.C $\left(10^{-5}\right) \ldots \ldots .77$ Figura 5.2 - (a) Volumes de água infiltrados em função da taxa de abastecimento dos poços; (b) Tempo de enchimento dos poços em função da taxa de abastecimento. 79 Figura 5.3 - (a) Curva de retenção r.C; (b) Funções condutividade hidráulica k.C $\left(10^{-5}\right)$, k.C e k.C $\left(10^{-7}\right)$.

Figura 5.4 - Variação das vazões infiltradas através da área lateral do poço (paredes e base) ao longo do tempo. (a) Solo C; (b) Solo r.C-k.C(10 $\left.{ }^{-5}\right)$; (c) Solo r.C-k.C(10 $\left.{ }^{-7}\right)$.

Figura 5.5 - Volumes infiltrados acumulados ao longo do tempo. (a) Solo C; (b) Solo r.Ck.C $\left(10^{-5}\right)$; (c) Solo r.C-k.C $\left(10^{-7}\right)$.

Figura 5.6 - (a) Curva de retenção r.C; (b) Funções condutividade hidráulica k.C(0,10), k.C e k.C $(0,20)$.

Figura 5.7 - Variação das vazões infiltradas através da área lateral do poço (paredes e base) ao longo do tempo. (a) Solo C; (b) Solo r.C-k.C(0,10); (c) Solo r.C-k.C(0,20). 84

Figura 5.8 - Volumes infiltrados acumulados ao longo do tempo. (a) Solo C; (b) Solo r.Ck.C(0,10); (c) Solo r.C-k.C(0,20).

Figura 5.9 - (a) Curva de retenção r.C; (b) Funções condutividade hidráulica k.A $\left(10^{-6}\right)$, k.C e k.B $\left(10^{-6}\right)$.

Figura 5.10 - Variação das vazões infiltradas através da área lateral do poço (paredes e base) ao longo do tempo. (a) Solo C; (b) Solo r.C-k.A(10-6); (c) Solo r.C-k.B $\left(10^{-6}\right)$.

Figura 5.11 - Volumes infiltrados acumulados ao longo do tempo. (a) Solo C; (b) Solo r.Ck.A $\left(10^{-6}\right)$; (c) Solo r.C-k.B $\left(10^{-6}\right)$. 
Figura 5.12 - (a) Curvas de retenção r.C(0,50), r.C e r.C(0,30); (b) Função condutividade hidráulica k.C.

Figura 5.13 - Variação das vazões infiltradas através da área lateral do poço (paredes e base) ao longo do tempo. (a) Solo C; (b) Solo r.C(0,30)-k.C; (c) Solo r.C(0,50)-k.C.

Figura 5.14 - Volumes infiltrados acumulados ao longo do tempo. (a) Solo C; (b) Solo r.C(0,30)-k.C; (c) Solo r.C(0,50)-k.C. 88

Figura 5.15 - (a) Curvas de retenção r.A(0,40), r.B(0,40) e r.C; (b) Função condutividade hidráulica k.C.

Figura 5.16 - Variação das vazões infiltradas através da área lateral do poço (paredes e base) ao longo do tempo. (a) Solo C; (b) Solo r.A(0,40)-k.C; (c) Solo r.B(0,40)-k.C.

Figura 5.17 - Volumes infiltrados acumulados ao longo do tempo. (a) Solo C; (b) Solo r.A(0,40)-k.C; (c) Solo r.B(0,40)-k.C.

Figura 5.18 - (a) Curvas de retenção r.C(a40), r.C(a10) e r.C; (b) Função condutividade hidráulica k.C. 90

Figura 5.19 - Variação das vazões infiltradas através da área lateral do poço (paredes e base) ao longo do tempo. (a) Solo C; (b) Solo r.C(a10)-k.C; (c) Solo r.C(a40)-k.C.

Figura 5.20 - Volumes infiltrados acumulados ao longo do tempo. (a) Solo C; (b) Solo r.C(a10)-k.C; (c) Solo r.C(a40)-k.C.

Figura 5.21 - (a) Curvas de retenção r.C , r.C(n3) e r.C(n10); (b) Função condutividade hidráulica k.C. 92

Figura 5.22 - Variação das vazões infiltradas através da área lateral do poço (paredes e base) ao longo do tempo. (a) Solo C; (b) Solo r.C(n3)-k.C; (c) Solo r.C(n10)-k.C. .93 Figura 5.23 - Volumes infiltrados acumulados ao longo do tempo. (a) Solo C; (b) Solo r.C(n3)-k.C; (c) Solo r.C(n10)-k.C.

Figura 5.24 - (a) Curvas de retenção r.C $(m 0.10)$, r.C $(m 0.30)$ e r.C; (b) Função condutividade hidráulica k.C. 94

Figura 5.25 - Variação das vazões infiltradas através da área lateral do poço (paredes e base) ao longo do tempo. (a) Solo C; (b) Solo r.C(m0,10)-k.C; (c) Solo r.C(m0,30)-k.C. 94 Figura 5.26 - Volumes infiltrados acumulados ao longo do tempo. (a) Solo C; (b) Solo r.C(m0,10)-k.C; (c) Solo r.C(m0,30)-k.C.

Figura 5.27 - Variação das vazões ao longo do tempo nos poços instalados no solo A, B, C, D, E e F. .96

Figura 5.28 - Ábacos que relacionam os parâmetros $\lambda$ com o tempo para os solos A, B, C, D, E e F. 97 
Figura 5.29 - Ábacos e equações de ajuste que relacionam as curvas médias dos parâmetros $\lambda$

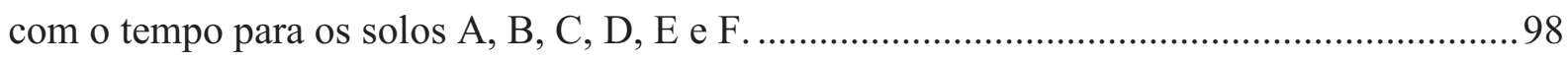

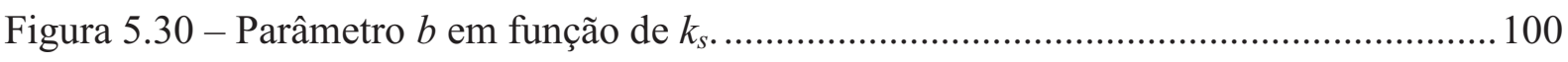

Figura 5.31 - Variação do volume de água infiltrada na trincheira durante a fase de abastecimento e recessão do primeiro experimento realizado por Lima (2009) (modificado de

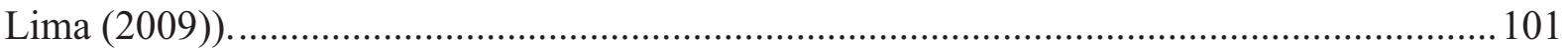




\section{LISTA DE TABELAS}

Tabela 2.1 - Síntese dos modelos matemáticos de curvas de retenção, segundo vários autores.

Tabela 2.2 - Síntese dos modelos matemáticos de funções condutividade hidráulica, segundo

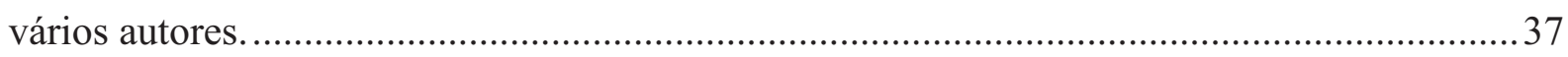

Tabela 3.1 - Geometria dos poços de infiltração.

Tabela 3.2 - Parâmetros das curvas de retenção e condutividades hidráulicas saturadas - Solos A, B e C. 72

Tabela 3.3 - Parâmetros das curvas de retenção e condutividades hidráulicas saturadas Solos D, E e F. 73

Tabela 5.1 - Taxa de ascensão do nível de água, tempos de enchimento e volumes de água

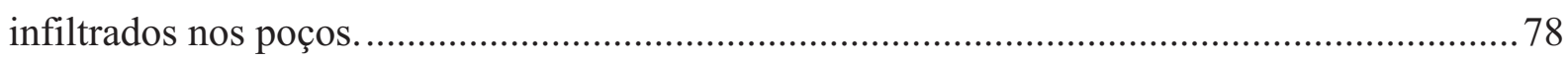

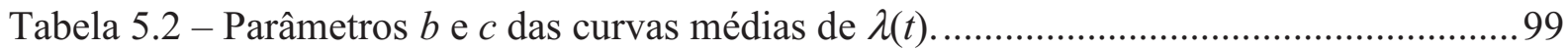

Tabela 5.3 - Exemplo de dimensionamento de poços de infiltração. 103 



\section{LISTA DE SÍMBOLOS}

\section{Símbolos do Alfabeto Latino}

a parâmetro de ajuste da curva de retenção (FREDLUND \& XING, 1994) $\left[\mathrm{FL}^{-2}\right]$;

$A \quad$ área de uma determinada seção transversal $\left[\mathrm{L}^{2}\right]$;

$A_{b} \quad$ área da base do poço de infiltração [ $\left[\mathrm{L}^{2}\right]$;

$A_{T} \quad$ área total do poço de infiltração (paredes e base) $\left[\mathrm{L}^{2}\right]$;

$b$ parâmetro de ajuste para o dimensionamento dos poços de infiltração [LT ${ }^{-1}$ ];

$c$ parâmetro de ajuste para o dimensionamento dos poços de infiltração;

d diâmetro do poço de infiltração [L];

$D(\theta) \quad$ difusividade da água no solo $\left[\mathrm{L}^{2} \mathrm{~T}^{-1}\right] ;$

e índice de vazios do solo $\left[\mathrm{L}^{3} \mathrm{~L}^{-3}\right]$;

$f \quad$ constante relacionada com a contribuição da gravidade para o movimento da água $\left[\mathrm{LT}^{-1}\right]$;

$h \quad$ profundidade do poço de infiltração [L];

$H \quad$ carga hidráulica [L];

$i \quad$ taxa de infiltração $\left[\mathrm{LT}^{-1}\right]$;

$i_{A b} \quad$ taxa de abastecimento do poço $\left[\mathrm{LT}^{-1}\right]$;

$i_{A s} \quad$ taxa de ascensão de água no poço $\left[\mathrm{LT}^{-1}\right]$;

$i_{P} \quad$ taxa de precipitação $\left[\mathrm{LT}^{-1}\right]$;

I $\quad$ infiltração acumulada [L];

$j \quad$ quantidade de poços;

$k_{r} \quad$ coeficiente de condutividade hidráulica relativa;

$k_{s} \quad$ coeficiente de condutividade hidráulica saturada $\left[\mathrm{LT}^{-1}\right]$;

$L \quad$ comprimento [L];

$m$ parâmetro de ajuste da curva de retenção (FREDLUND \& XING, 1994);

$m_{w} \quad$ inclinação da curva de retenção de água do solo entre dois pontos quaisquer $\left[\mathrm{F}^{-1} \mathrm{~L}^{2}\right]$;

$M_{S} \quad$ massa de partículas sólidas [M];

$M_{w} \quad$ massa de água presente no solo [M];

n parâmetro de ajuste da curva de retenção (FREDLUND \& XING, 1994);

$n$ porosidade [\%];

$q \quad$ densidade de fluxo $\left[\mathrm{LT}^{-1}\right]$;

$Q \quad$ vazão $\left[\mathrm{L}^{3} \mathrm{~T}^{-1}\right]$;

$r \quad$ porcentagem do volume de água precipitada que se deseja drenar [\%];

$S \quad$ sortividade do solo $\left[\mathrm{LT}^{-1 / 2}\right]$;

$S$ sucção total do solo $\left[\mathrm{FL}^{-2}\right]$;

$S_{m} \quad$ sucção matricial $\left[\mathrm{FL}^{-2}\right]$;

$S_{o s} \quad$ sucção osmótica $\left[\mathrm{FL}^{-2}\right]$;

$S_{R} \quad$ grau de saturação [\%];

$t$ tempo de duração de um determinado evento [T];

$t_{E} \quad$ tempo de enchimento de um poço de infiltração [T];

$u_{a}$ pressões no ar $\left[\mathrm{FL}^{-2}\right]$;

$u_{w} \quad$ pressões na água $\left[\mathrm{FL}^{-2}\right]$; 
$V \quad$ volume total da amostra de solo $\left[\mathrm{L}^{3}\right]$;

$V_{C} \quad$ volume total de água precipitada em uma dada área, ao fim de um evento de chuva $\left[\mathrm{L}^{3}\right]$;

$V_{i} \quad$ volume de água infiltrada $\left[\mathrm{L}^{3}\right] ;$

$V_{P} \quad$ volume interno do poço de infiltração $\left[\mathrm{L}^{3}\right]$;

$V_{w} \quad$ volume de água presente no solo $\left[\mathrm{L}^{3}\right]$;

$w \quad$ teor de umidade gravimétrica $\left[\mathrm{MM}^{-1}\right]$;

$w_{L} \quad$ limite de liquidez $\left[\mathrm{MM}^{-1}\right]$

$w_{P} \quad$ limite de plasticidade $\left[\mathrm{MM}^{-1}\right]$;

$x \quad$ eixo cartesiano;

$y \quad$ eixo cartesiano;

$z \quad$ eixo cartesiano;

\section{Símbolos do Alfabeto Grego}

$\alpha \quad$ parâmetro de ajuste da função condutividade hidráulica (GARDNER, 1958) $\left[\mathrm{F}^{-1} \mathrm{~L}^{2}\right]$;

$\Delta \quad$ símbolo indicador de diferença ou variação (sempre precede outro símbolo);

$\gamma_{w} \quad$ peso específico da água $\left[\mathrm{FL}^{-3}\right]$;

$\eta \quad$ variável da transformada de Boltzmann;

$\theta \quad$ teor de umidade volumétrica $\left[\mathrm{L}^{3} \mathrm{~L}^{-3}\right]$;

$\theta_{r} \quad$ teor de umidade volumétrica residual $\left[\mathrm{L}^{3} \mathrm{~L}^{-3}\right]$;

$\theta_{s} \quad$ teor de umidade volumétrica de saturação $\left[\mathrm{L}^{3} \mathrm{~L}^{-3}\right]$;

$\theta_{s}{ }^{*} \quad$ teor de umidade volumétrica de saturação no processo de drenagem $\left[\mathrm{L}^{3} \mathrm{~L}^{-3}\right]$;

$\theta_{s}^{* *} \quad$ teor de umidade volumétrica de saturação no processo de sorção $\left[\mathrm{L}^{3} \mathrm{~L}^{-3}\right]$;

$\Theta \quad$ teor de umidade volumétrica normalizada $\left[\mathrm{L}^{3} \mathrm{~L}^{-3}\right]$;

$\rho_{d} \quad$ massa específica seca do solo $\left[\mathrm{ML}^{-3}\right]$;

$\rho_{w} \quad$ massa específica da água $\left[\mathrm{ML}^{-3}\right]$;

$\psi \quad$ potencial total da água no solo [L];

$\psi_{b} \quad$ pressão de entrada de $\operatorname{ar}\left[\mathrm{FL}^{-2}\right]$;

$\psi_{m} \quad$ potencial matricial [L];

$\psi_{o s} \quad$ potencial osmótico [L];

$\psi_{p n} \quad$ potencial pneumático [L];

$\psi_{z} \quad$ potencial gravitacional [L];

\section{Operadores Matemáticos}

$\partial \quad$ símbolo operador de uma derivada parcial (sempre precede outro símbolo);

$\infty \quad$ infinito;

$\nabla \quad$ símbolo operador de um gradiente (sempre precede outro símbolo). 


\section{SUMÁRIO}

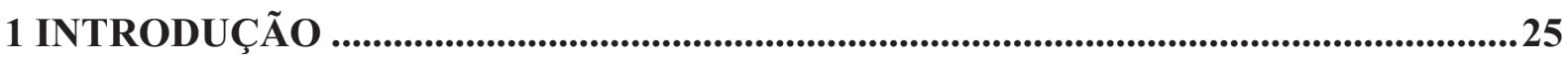

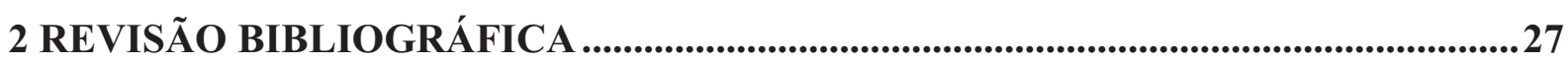

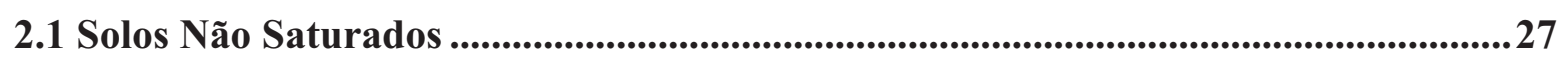

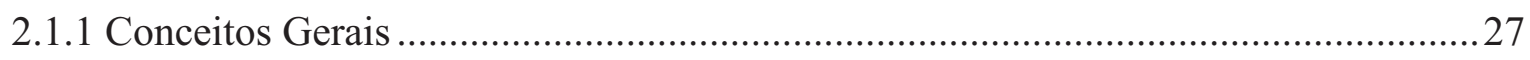

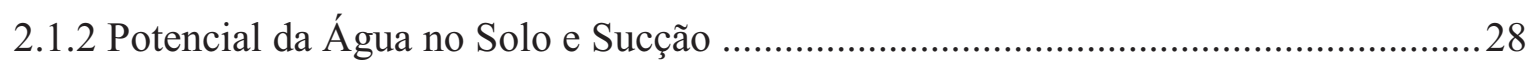

2.1.3 Comportamento Hidráulico do Solo Não Saturado .....................................................32

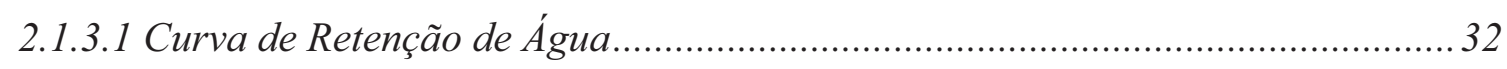

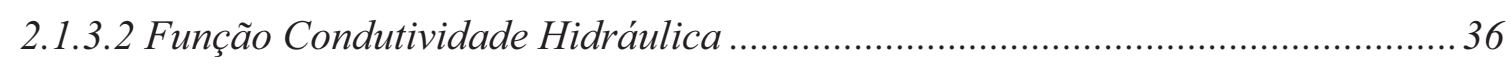

2.2 Movimento da Água no Solo .................................................................................................38

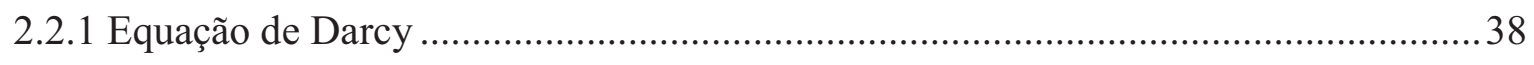

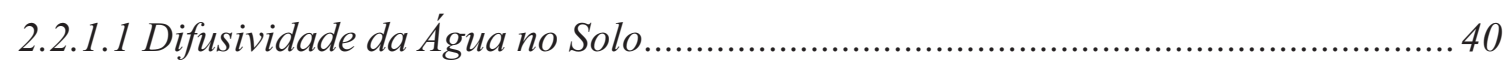

2.2.2 Equação da Continuidade ……………………………………………………....... 41

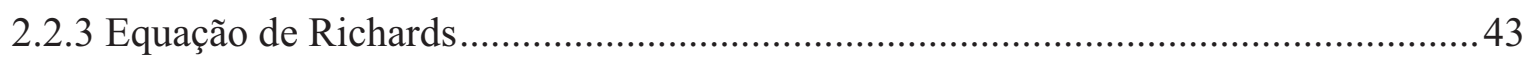

2.3 Infiltração .............................................................................................................................43

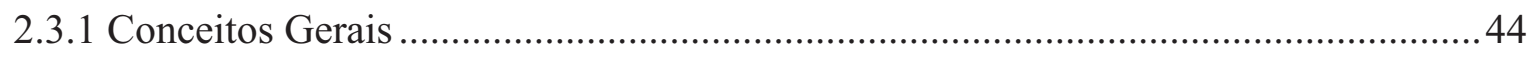

2.3.1.1 Capacidade de Infiltração e Taxa de Infiltração................................................ 45

2.4 Modelos de Infiltração........................................................................................................47

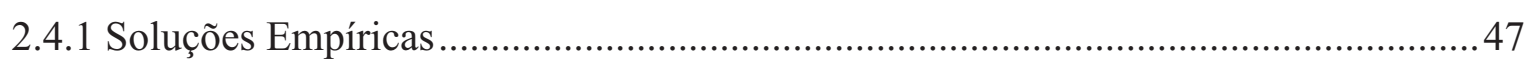

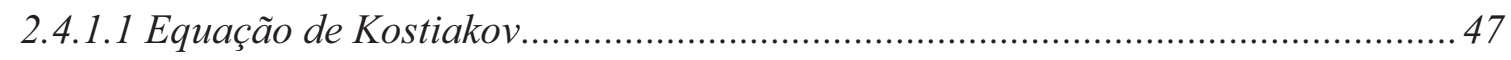

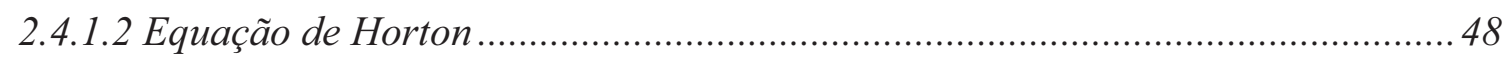

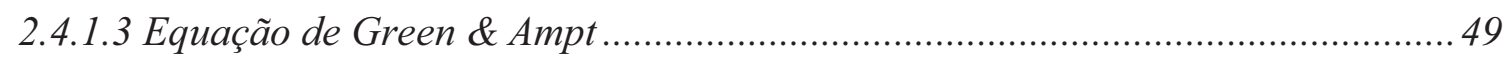

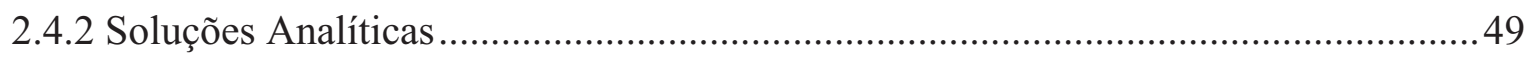

2.4.2.1 Infiltração Horizontal - Philip (1955)..............................................................50

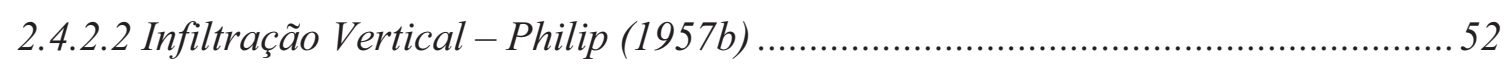

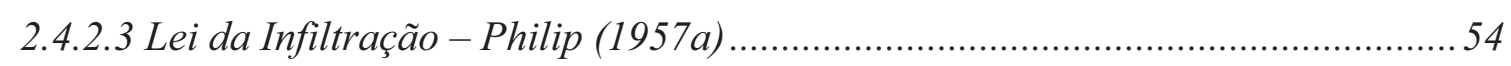

2.4.3 Solução Numérica da Equação de Richards no Programa SEEP/W...…………….....54

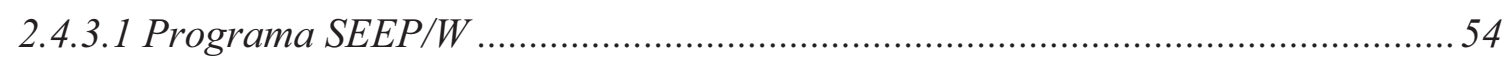

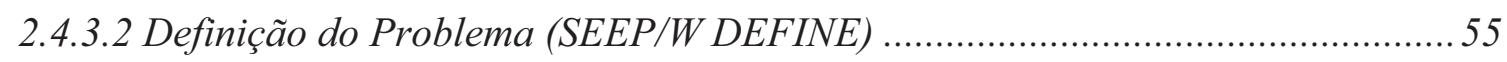

2.4.3.3 Resolução do Problema por Processo Iterativo (SEEP/W SOLVE) e Visualização

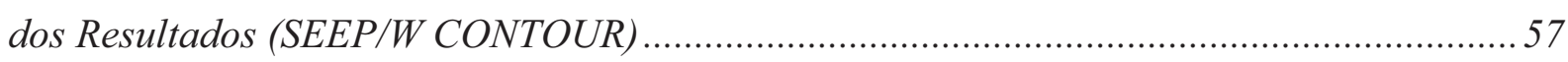

2.5 Soluções Práticas de Drenagem Urbana com Uso de Técnicas de Infiltração ..........60

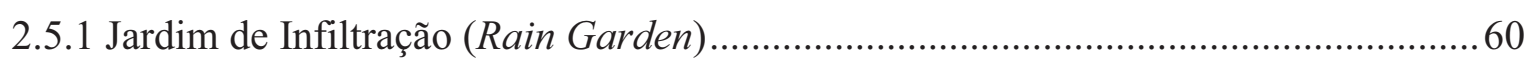


2.5.2 Pavimento Permeável

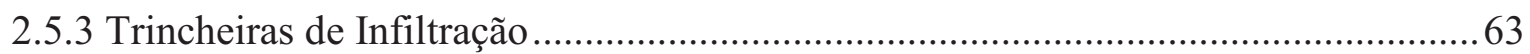

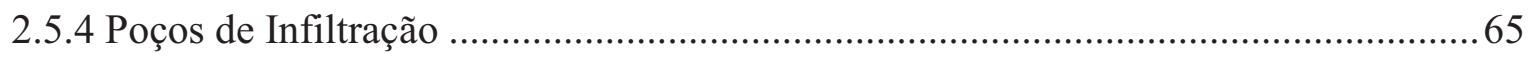

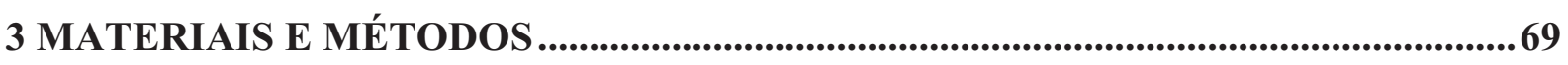

3.1 Geometria dos Poços e Domínios de Referência ...............................................................69

3.2 Condições de Contorno Iniciais - Fluxo Permanente .................................................... 70

3.3 Características dos Solos que Compõem os Domínios. .................................................. 71

3.3.1 Solos Empregados nas Análises Paramétricas .......................................................... 71

3.3.2 Solos Empregados na Técnica de Dimensionamento de Poços de Infiltração ........... 72

3.4 Ascensão do Nível de Água no Interior dos Poços .................................................73

3.5 Condições de Contorno - Fluxo Transiente .................................................................74

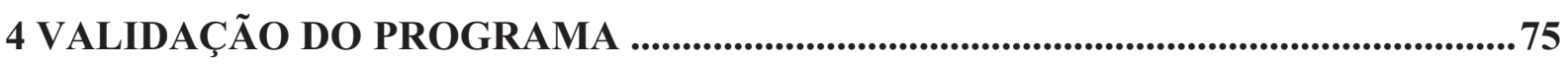

5 RESULTADOS E DISCUSSÕES ................................................................................. 77

5.1 Avaliação da Condição de Poço Preenchido por Água Instantaneamente................. 77

5.2 Análise Paramétrica das Funções Condutividade Hidráulica dos Solos ...................80

5.2.1 Influência da Condutividade Hidráulica Saturada .................................................... 80

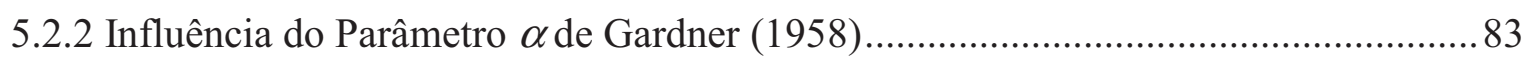

5.2.3 Influência do Formato da Função Condutividade Hidráulica.................................... 84

5.3 Análise Paramétrica das Curvas de Retenção dos Solos.............................................86

5.3.1 Influência do Teor de Umidade Volumétrica na Condição Saturada ......................... 86

5.3.2 Influência do Formato da Curva de Retenção............................................................ 88

5.3.3 Influência do Parâmetro $a$ da Curva de Retenção de Fredlund \& Xing (1994)......... 90

5.3.4 Influência do Parâmetro $n$ da Curva de Retenção de Fredlund \& Xing (1994)......... 92

5.3.5 Influência do Parâmetro $m$ da Curva de Retenção de Fredlund \& Xing (1994)........ 94

5.4 Dimensionamento de Poços de Infilttração ...........................................................................95

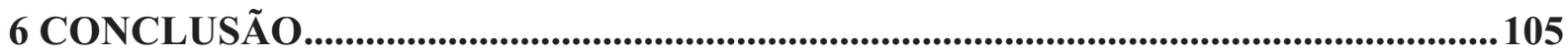

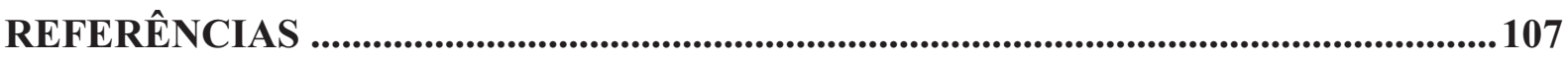




\section{INTRODUÇÃO}

Na ocorrência de uma precipitação, toda água que chega ao solo é infiltrada até o instante em que ocorre a saturação da sua superfície. A partir desse instante, a água continua a infiltrar, entretanto inicia-se o processo de escoamento superficial, que de modo simplificado é o deflúvio excedente do processo de infiltração. Desse modo, esses dois componentes do ciclo hidrológico - infiltração e escoamento superficial - estão intimamente ligados. O impedimento do primeiro componente implica o excesso do segundo.

A ocupação irregular de áreas de risco combinada à falta de planejamento urbano tem gerado, nos centros urbanos de todo Brasil, uma série de problemas, dentre os quais a ocorrência de enchentes é um dos mais graves e recorrentes. As regiões sul e sudeste são as mais vitimadas pelas inundações durante os meses do verão, devido aos elevados índices pluviométricos característicos desta estação, nesta porção do país. $O$ crescimento indiscriminado de áreas impermeáveis, proporcionadas pelos pavimentos e telhados, impede a infiltração das águas pluviais. Desse modo, em regiões impermeabilizadas o volume de água infiltrada é mínimo e praticamente toda a água precipitada transforma-se em escoamento superficial, o que contribui para o aumento dos volumes das cheias e para a redução do tempo que vai do início da precipitação até a ocorrência da vazão máxima na calha do rio para uma dada precipitação.

Atualmente, a prática de projetos de drenagem urbana tem por característica transportar todo excesso de água superficial, gerado pela precipitação sobre áreas impermeáveis, para canais e rios da forma mais rápida possível. Assim, é evidente que esta filosofia de projeto sobrecarrega as seções das calhas, localizadas no sentido das cotas mais baixas no sistema de drenagem, gerando as enchentes que trazem uma série de prejuízos financeiros e sociais.

O emprego de medidas estruturais - que consistem em intervenções por meio de obras hidráulicas, tais como construção de diques, barragens, ampliação de calhas de rios, entre outras - não resolvem a problemática das enchentes de forma definitiva, uma vez que estas medidas tornam-se defasadas ao longo do tempo devido ao crescimento ininterrupto das cidades. Além disso, medidas estruturais possuem um custo bastante elevado, o que muitas vezes impossibilita a realização das mesmas por parte do poder público.

Com o exposto, parece evidente que o sistema de drenagem urbana carece de dispositivos que permitam a redução do volume de água escoada superficialmente e que evitem, ou reduzam, a sobrecarga dos trechos dos canais e rios localizados mais à jusante. A 
construção de poços e trincheiras de infiltração, pavimentos permeáveis, jardins de infiltração (rain gardens), entre outras, em lotes são medidas de controle do escoamento superficial na fonte geradora e que apresentam os benefícios que os sistemas de drenagem convencionais não dispõem.

Para que se torne possível o uso de dispositivos de drenagem urbana que permitam o controle do escoamento superficial na fonte geradora é necessário, antes de tudo, a determinação de parâmetros de projeto que levem em conta as características geométricas e as propriedades hidráulicas do solo no qual o dispositivo será instalado. Porém, vários fatores interferem no processo de infiltração podendo-se citar a intensidade de precipitação, a duração da mesma, a curva de retenção e a função condutividade hidráulica do solo, como sendo os principais. Vale ressaltar que os dois últimos fatores citados são diretamente relacionados ao tipo de solo e ao nível de sucção atuante no mesmo. Logo, a capacidade de infiltração de um solo, em grande parte dos processos, trata-se de um problema de fluxo transiente em meio não saturado.

Neste contexto, este trabalho tem o objetivo de realizar uma análise paramétrica acerca da influência das funções condutividade hidráulica e das curvas de retenção dos solos no processo de infiltração de água em poços cilíndricos instalados em solos inicialmente não saturados. Para a realização das análises paramétricas, foi utilizado o programa SEEP/W do pacote GeoStudio 2004, que emprega a técnica dos elementos finitos na solução numérica da Equação de Richards que rege o fluxo de água em meio não saturado. Com isto, esta pesquisa se propõe a determinar parâmetros de projeto de poços de infiltração, de modo a estabelecer um método prático de dimensionamento, que necessite de poucos parâmetros e que exclua a interferência de parâmetros que possuem pequena influência no processo de infiltração de água em poços. 


\section{REVISÃO BIBLIOGRÁFICA}

\subsection{Solos Não Saturados}

\subsubsection{Conceitos Gerais}

O solo não saturado é denotado geralmente como um sistema trifásico, composto pelas fases sólida, líquida e gasosa. Entretanto, de acordo com Fredlund \& Rahardjo (1993) o importante papel da interface entre o ar e a água (membrana contrátil) permite sua inclusão como uma fase adicional. Quando a fase ar é contínua, a membrana contráctil interage com as partículas do solo e influencia diretamente o comportamento mecânico do mesmo.

A massa e o volume de cada fase podem ser esquematicamente representados por um diagrama de fases. A Figura 2.1(a) mostra um diagrama tetrafásico rigoroso para um solo não saturado. A espessura da membrana contráctil é da ordem, somente, de algumas camadas moleculares. Consequentemente, a subdivisão física da membrana contráctil é desnecessária ao estabelecer relações de massa e volume para um solo não saturado. A membrana contráctil é considerada como parte da fase água sem erro significativo. Um diagrama trifásico simplificado, descrito na Figura 2.1(b), pode ser usado para escrever as relações entre massa e volume. O termo matriz é usado quando se refere à soma das massas e dos volumes de todas as partículas sólidas do solo (FREDLUND \& RAHARDJO, 1993).

\section{Membrana Contrátil}

Volume

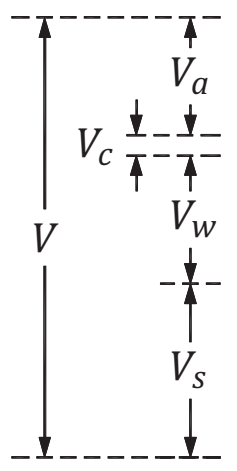

Massa

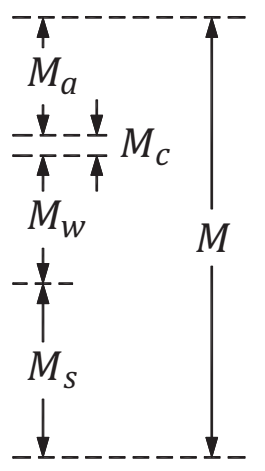

(a)

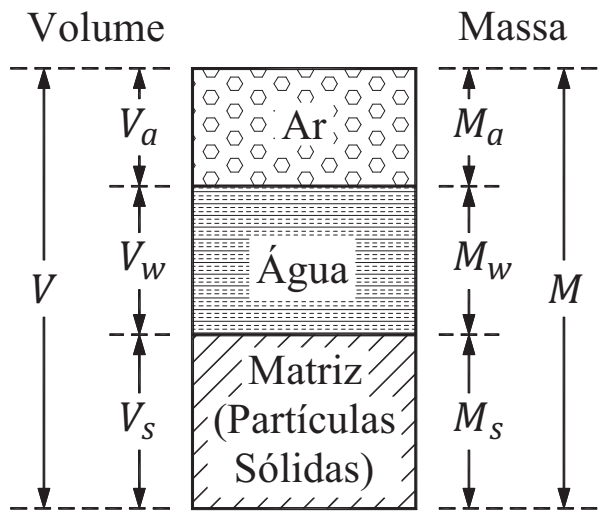

(b)

Figura 2.1 - Diagramas de fases, rigoroso e simplificado para um solo não saturado. (a) Sistema não saturado tetrafásico rigoroso do solo; (b) Diagrama trifásico simplificado. (modificado de FREDLUND \& RAHARDJO, 1993). 
No estudo de solos não saturados é extremamente importante conhecer a quantidade de água presente no solo. O teor de umidade gravimétrica $w$ é a razão entre a massa de água presente no solo $\left(M_{w}\right)$ e a massa de partículas sólidas $\left(M_{s}\right)$. Outra medida da quantidade de água presente em um solo é o teor de umidade volumétrica $\theta$ que é a razão entre o volume de água presente no solo $\left(V_{w}\right)$ e o volume total da amostra de solo $(V)$.

A relação entre os teores de umidades, gravimétrica e volumétrica é extremamente simples:

$$
\theta=\frac{V_{w}}{V} \Rightarrow \theta=\frac{M_{w} / \rho_{w}}{V} \Rightarrow \theta=w \cdot \frac{M_{s}}{\rho_{w} \cdot V} \Rightarrow \theta=w \cdot \frac{\rho_{d}}{\rho_{w}}
$$

em que: $\rho_{d}=M_{s} / V$, é a massa específica seca do solo;

$\rho_{w}=M_{w} / V_{w}$, é a massa específica da água.

\subsubsection{Potencial da Água no Solo e Sucção}

A água presente no solo, assim como qualquer corpo na natureza, pode ser caracterizada por um estado de energia. Este estado é determinado por diferentes formas e quantidades de energia. A física clássica reconhece duas formas principais de energia, a potencial e a cinética, sendo que esta é proporcional ao quadrado da velocidade, e como o movimento da água no solo é muito lento, sua energia cinética é desprezível na maioria dos casos. Entretanto, a energia potencial, que é uma função da posição e condição interna da água no ponto em consideração, é de primordial importância na caracterização de seu estado de energia (REICHARDT, 1985).

Analisando-se a Figura 2.2, o trabalho útil que deve ser realizado em uma quantidade infinitesimal de água pura, para conduzi-la, reversível e isotermicamente, de um dado reservatório em uma determinada cota sujeita à pressão atmosférica (ponto A) até a água no solo, na cota de interesse (ponto B) é chamado de Potencial Total da Água no Solo $(\psi)$ (VILAR, 2002). A água tende, espontaneamente, a se mover de modo a assumir um estado de menor energia, sendo que esta é a condição mais estável. Desse modo, se o potencial da água no solo define seu estado de energia no ponto considerado, então, conhecendo-se os potenciais da água em diferentes pontos no solo, pode-se determinar sua tendência de movimento. 
O potencial total é composto principalmente pelos potenciais pneumático, gravitacional, matricial, osmótico e térmico. Entretanto, os processos que ocorrem no solo são aproximadamente isotérmicos, logo a componente térmica pode ser desprezada.

Transporte Reversível e Isotérmico

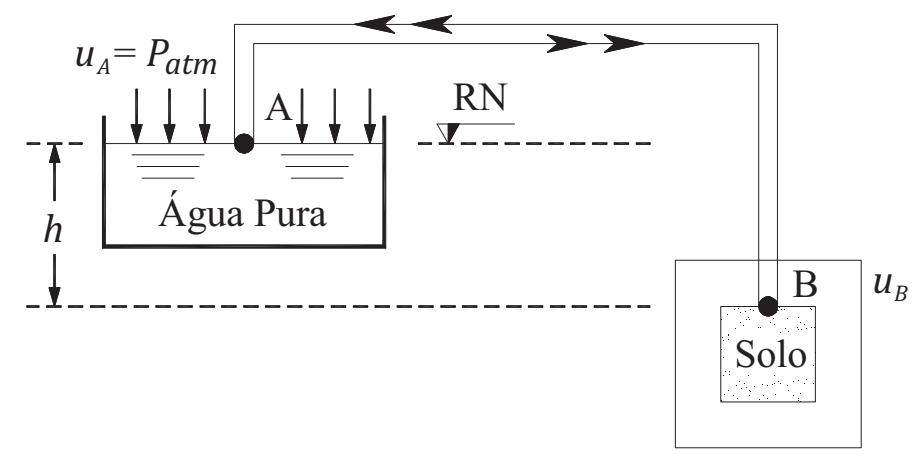

Figura 2.2 - Esquema ilustrativo da definição de potencial total da água no solo (VILAR, 2002).

O Potencial Pneumático $\left(\psi_{p n}\right)$ ocorre sempre que existir uma diferença entre a pressão do ar atuante no solo e a pressão do ar atuante no reservatório padrão e é de extrema importância em ensaios de câmaras de pressão de placa porosa e na técnica de translação de eixos. Em outras palavras, de acordo com a Figura 2.2, o potencial pneumático será igual ao total quando a água do solo for idêntica à do reservatório padrão, $h$ for igual a zero e $u_{B}$ for diferente da pressão atmosférica (VILAR, 2002).

O Potencial Gravitacional $\left(\psi_{z}\right)$ é dado pelo produto da aceleração da gravidade pela diferença de cotas entre o reservatório padrão e a amostra de solo (diferença de cotas entre os pontos A e B na Figura 2.2). Esta definição do potencial gravitacional é evidente, pois se a fase sólidos-água-ar do solo estiver a uma altura, em relação a um plano de referência horizontal arbitrário, diferente da altura da fase estado padrão, em relação ao mesmo plano, a influência do campo gravitacional será diferente nas duas fases (LIBARDI, 1995).

De acordo com Vilar (2002), o potencial gravitacional é igual ao total quando a água do solo é idêntica à do reservatório - quer seja se a água for pura ou no caso de uma solução com mesma composição -, está à mesma pressão e o solo está saturado.

O Potencial Matricial $\left(\psi_{m}\right)$ é o componente do potencial da água no solo que relaciona as interações entre a matriz do solo e a água, que decorrem de forças associadas com a adsorção e a capilaridade. Segundo Libardi (1995), é necessário despender energia para remover a água retida no solo por estas forças, sendo que tanto maior é a energia despendida quanto mais baixo for o teor de umidade do solo, em outras palavras, $\psi_{m}$ é função do teor de umidade do solo, $\psi_{m}(\theta)$. 
Para solos não saturados, os efeitos das forças de capilaridade provocam a formação de meniscos (interfaces líquido-gás), e há a presença de superfícies de adsorção (interfaces sólido-líquido), tais fenômenos atraem e fixam a água em estados de energia menores que o estado livre (sob pressão atmosférica). Sempre que a pressão atmosférica, adotada como sendo nula, for tomada como referência, o potencial matricial será negativo (REICHARDT, 1996). Logo, é óbvio que o potencial matricial atinge o seu valor máximo quando da saturação do solo, ou seja, potencial matricial nulo. O potencial matricial pode ser medido diretamente em campo com o auxílio de tensiômetros, ou em laboratório por meio de câmaras com placa de alta pressão de entrada de ar, do funil de pedra porosa, da técnica do papel filtro e dos princípios osmóticos.

O Potencial Osmótico $\left(\psi_{o s}\right)$ reflete a influência da presença de sais minerais e substâncias orgânicas na solução da água do solo. O potencial osmótico equivale ao total $(\psi)$ já definido, quando tanto a água do reservatório padrão quanto a solução de água do solo encontram-se na mesma cota $(h=0)$, à mesma pressão $\left(u_{B}=P_{a t m}\right)$ e não ocorrem efeitos da matriz do solo (solo saturado) (VILAR, 2002). Segundo Reichardt (1996), a componente osmótica não possui grande relevância no que se refere ao movimento da água, a não ser que exista uma membrana semipermeável no sistema (membrana de celulose seletiva). Quando existem diferenças de concentração salina sem a presença de membranas, o movimento de sais é muito mais importante que o da água, que chega a ser desprezível.

Com o exposto, pode-se escrever:

$$
\psi=\psi_{p n}+\psi_{z}+\psi_{m}+\psi_{o s}
$$

A partir dos conceitos dos componentes do potencial total da água no solo, pode-se definir o que vem a ser a Sucção Total do Solo $(S)$. Conforme Vilar (2002), a sucção total do solo é a pressão manométrica negativa, em relação à pressão externa de gás sobre a água do solo, que deve ser aplicada a um reservatório de água pura (à mesma cota e temperatura) de modo que se mantenha o equilíbrio, através de uma membrana semipermeável, entre a água do solo e a do reservatório. Sempre que ambos os componentes, gravitacional e pneumático, do potencial total podem ser desprezados há uma correspondência direta entre a sucção total do solo e o potencial total. Logo a sucção total é separada em sucção osmótica $\left(S_{o s}\right)$ e em sucção matricial $\left(S_{m}\right)$, as quais são grandezas positivas que correspondem respectivamente, ao potencial osmótico e ao potencial matricial, que são grandezas negativas. A Figura 2.3 apresenta conceitualmente a sucção total e suas componentes.

$$
S=S_{m}+S_{o s}
$$




$$
S=\left(u_{a}-u_{w}\right)+\pi
$$

em que: $S_{m}=\left(u_{a}-u_{w}\right)$, é a diferença entre as pressões no ar $\left(u_{a}\right)$ e na água $\left(u_{w}\right)$ necessária para não haver fluxo através de uma membrana permeável tanto à água quanto aos solutos;

$S_{o s}=\pi$, é a pressão que deve ser aplicada à solução mais concentrada de solutos, de modo que seja evitado o fluxo entre a mesma e uma outra solução menos concentrada, que se encontra separada da primeira por uma membrana semipermeável que permita o fluxo de água, porém não o de solutos.

Membrana Permeável

(Permite o fluxo de água e de solutos)
Membrana Semipermeável (Permite apenas o fluxo de água)

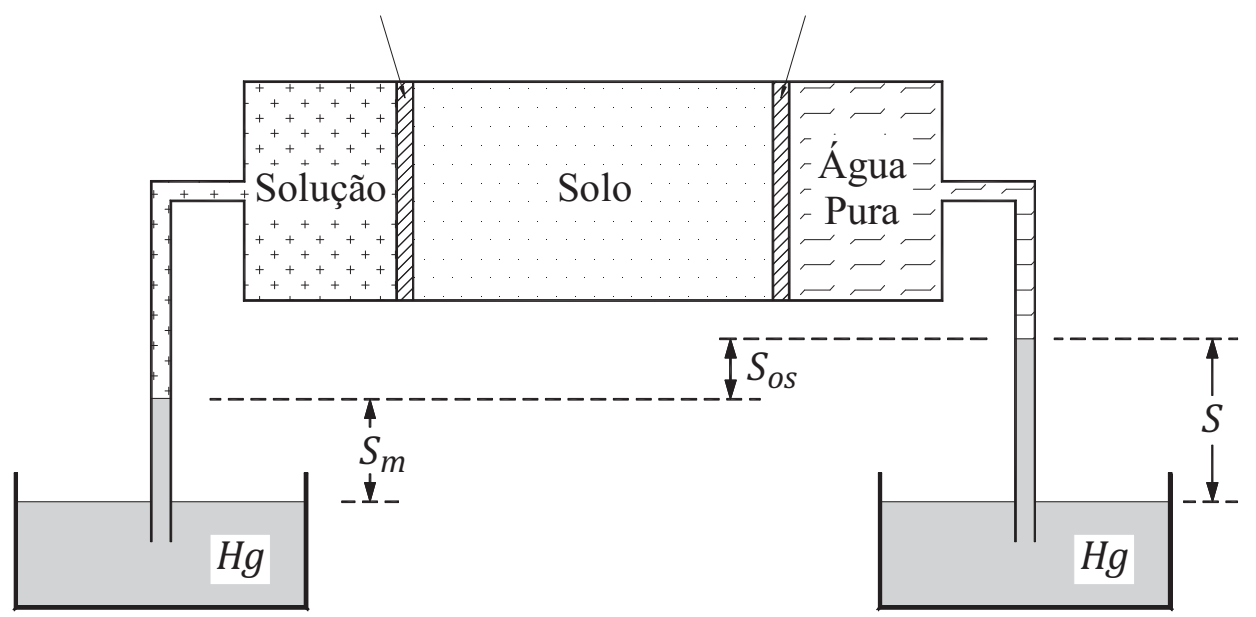

Figura 2.3 - Definição de sucção total, matricial e osmótica (VILAR, 2002).

As mudanças ambientais e mudanças de pressões aplicadas na água do solo produzem mudanças no seu teor de umidade. $\mathrm{O}$ teor de umidade inicial de solos compactados parece ter uma relação direta com o componente de sucção matricial. Por outro lado, a sucção osmótica não parece ser sensível às mudanças no teor de umidade do solo. Como resultado, uma mudança na sucção total é bastante representativa de uma mudança na sucção matricial. Portanto, as medições de sucção total, são de grande importância, especialmente nos intervalos de aspiração, onde as medições de sucção matricial são difíceis de obter (FREDLUND \& RAHARDJO, 1993).

Deste modo, segundo Vilar (2002), em Mecânica dos Solos, qualquer alusão que se faça à sucção do solo, se refere na verdade à sucção matricial, a menos que seja feita alguma citação específica. Em outras palavras, o uso do termo sucção, não só neste trabalho como na literatura específica em geral, se refere à sucção matricial. 


\subsubsection{Comportamento Hidráulico do Solo Não Saturado}

O comportamento hidráulico dos solos não saturados interfere diretamente em sua capacidade de infiltração. Logo, é imprescindível o conhecimento dos elementos que interferem diretamente no comportamento hidráulico dos solos, para que se torne possível o desenvolvimento de técnicas de projeto de sistemas de drenagem que se apóiem no processo de infiltração. Com relação ao comportamento hidráulico, é evidente que a condutividade hidráulica do solo não saturado governa a facilidade da penetração da água no interior do mesmo (infiltração) e consequentemente influencia diretamente a alteração da quantidade de água nos poros do solo (teor de umidade volumétrica). $\mathrm{O}$ acréscimo do teor de umidade do solo, a partir do processo de infiltração, torna-o cada vez menos ávido por água, haja vista a relação inversamente proporcional entre o teor de umidade do solo e sua sucção, sendo que tal relação é representada por meio da curva de retenção de água, ou curva característica da umidade do solo.

\subsubsection{Curva de Retenção de Água}

A curva de retenção de água de um solo é definida como sendo a relação entre o teor de umidade e a sucção do solo. Em tal curva, o teor de umidade pode ser expresso na forma gravimétrica $(w)$, ou volumétrica $(\theta)$, ou ainda utilizando-se o grau de saturação do solo $\left(S_{r}\right)$, de modo a expressar a relação entre a quantidade de água presente no solo e sua energia. A Figura 2.4 apresenta uma curva de retenção típica, e a partir da mesma serão definidos alguns conceitos.

A pressão de entrada de ar representa a diferença de pressão entre o ar e a água que é necessária para a drenagem do maior poro do solo. O valor da pressão de entrada de ar é obtido estendendo-se o trecho de maior declividade da curva de retenção até a intersecção com a horizontal que corresponde a 100\% de saturação, ou com a horizontal que corresponde à umidade de saturação. A coordenada do ponto dado pela intersecção das duas retas corresponde à sucção que equivale à pressão de entrada de ar do solo (VANAPALLI et al., 1999). 


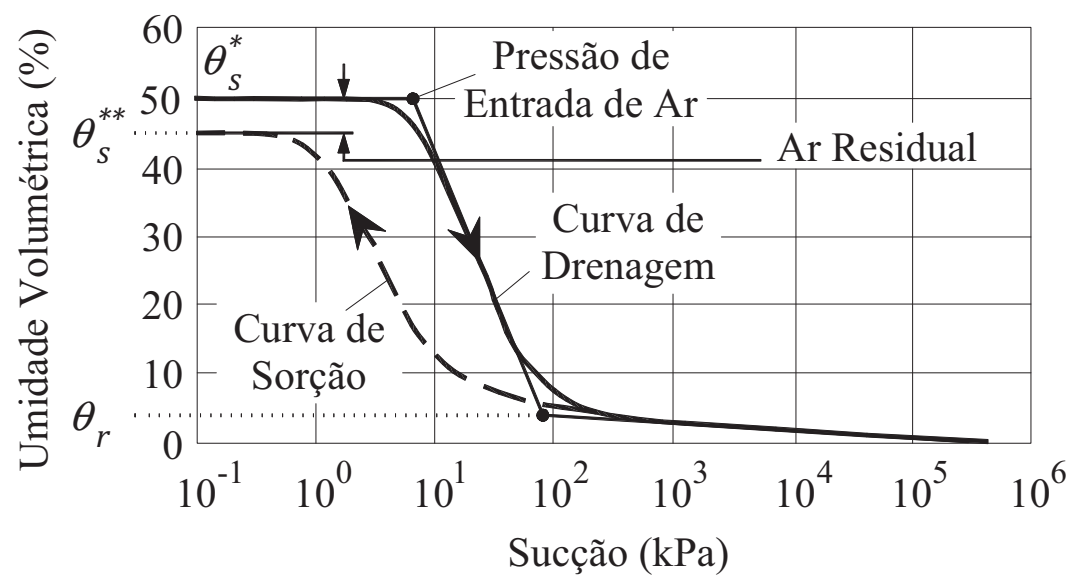

Figura 2.4 - Curva de retenção típica de solos siltosos ( $\theta_{r}$ é a umidade residual, $\theta_{s}^{*}$ é a umidade de saturação no processo de drenagem e $\theta_{s}^{* *}$ é a umidade de saturação no processo de sorção) (modificado de FREDLUND \& XING, 1994).

A umidade residual do solo corresponde a um grau de saturação abaixo do qual há a descontinuidade da fase líquida. Consequentemente, a partir da umidade residual, um acréscimo de sucção não provoca alteração significativa no teor de umidade. A circulação de água além da condição residual é, sobretudo, o resultado da migração de vapor de água (FREDLUND \& RAHARDJO, 1993; VANAPALLI et al.,1999 e MIGUEL \& VILAR, 2009).

Percebe-se na Figura 2.4 que a determinação da curva de retenção através do processo de drenagem apresenta comportamento distinto da determinação através do processo de umedecimento do solo. Tal diferença de comportamento é chamada de histerese. Segundo Reichardt (1985), Vilar (2002) e Miguel \& Vilar (2009), este fenômeno se deve principalmente à variação do diâmetro dos poros do solo que interfere diretamente nos fenômenos capilares, ao aprisionamento de ar no interior do solo, à variação do ângulo de molhamento em processos de drenagem e à contração e a expansão das argilas durante o seu secamento e molhamento.

A curva de retenção de um solo pode ser obtida em laboratório através do uso de câmara com placa de alta pressão de entrada de ar. Este dispositivo consiste em uma câmara construída para suportar alta pressão, com uma placa porosa de alta pressão de entrada de ar em seu interior, provida em sua parte inferior de um diafragma de borracha selado em sua borda. Este diafragma possui um tubo de saída de água aberto para atmosfera. O esquema do equipamento é mostrado na Figura 2.5. 


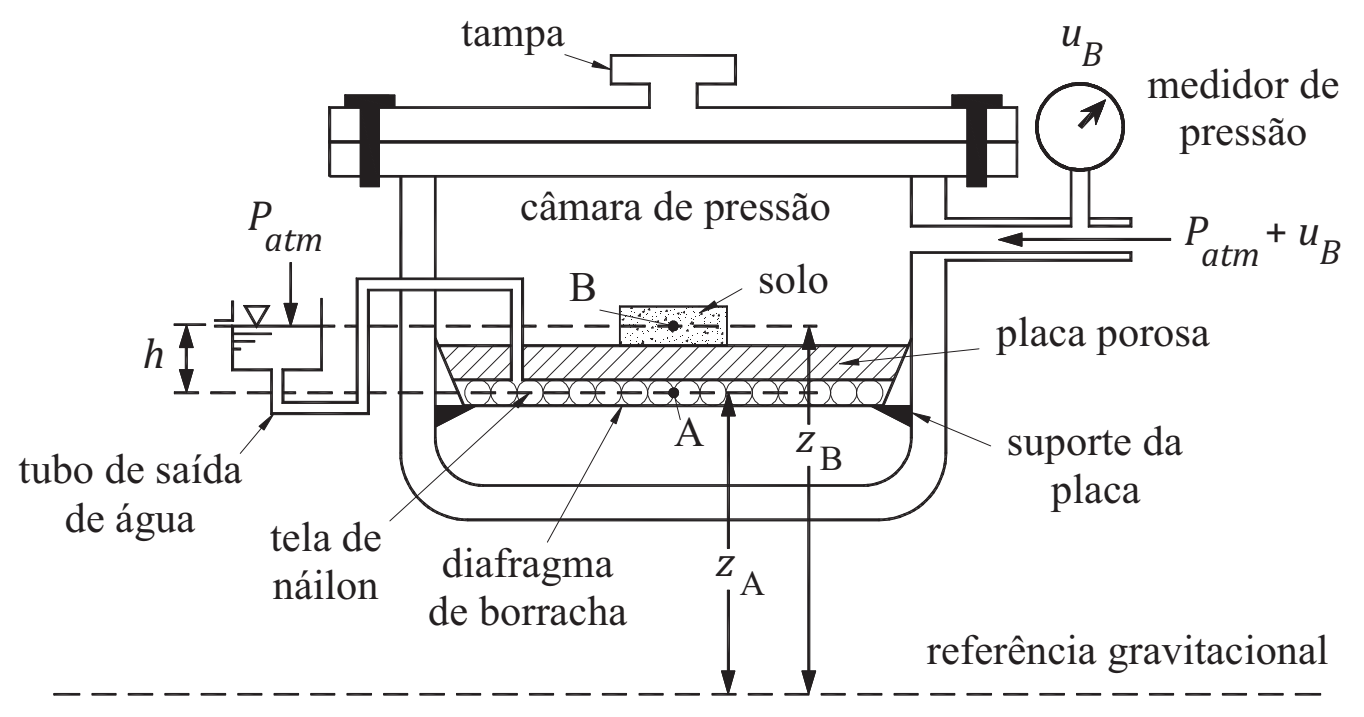

Figura 2.5 - Esquema da câmara com placa de alta pressão de entrada de ar (LIBARDI, 1995).

O corpo de prova saturado é colocado em contato com a placa porosa, também saturada, de modo que se garanta a continuidade da fase água no solo e em sua interface com a placa. Aplica-se, então, uma pressão $u_{B}$ no interior da câmara, fazendo com que a água se mova do interior do solo para o diafragma de borracha, em seguida a água começa a gotejar no tubo de saída até um determinado instante em que a drenagem do solo é cessada. Nesta condição de equilíbrio, pode-se afirmar que a pressão $u_{B}$ aplicada à câmara é igual ao potencial total da água no solo que por sua vez é igual à sucção atuante no mesmo. Repete-se este processo, aumentando-se a pressão $u_{B}$ até que seja alcançado o equilíbrio do sistema. Sempre, ao fim destes processos, mede-se a massa do corpo de prova $\left(M=M_{s}+M_{w}\right)$ e ao fim de todo o ensaio seca-se o corpo de prova em estufa de modo que seja medida a massa de suas partículas sólidas $\left(M_{s}\right)$. Com tais medidas de massa do corpo de prova obtém-se facilmente o teor de umidade do mesmo ao fim de cada processo, possibilitando confeccionar a curva de retenção do solo.

Uma série de autores desenvolveu modelos matemáticos para o ajuste da curva de retenção do solo, obtida experimentalmente, à uma equação. Leong \& Rahardjo (1997a) apresentaram uma revisão das principais equações que servem de ajuste à curva de retenção obtida experimentalmente. A Tabela 2.1 foi confeccionada com base no trabalho de Leong \& Rahardjo (1997a), e sintetiza os principais modelos matemáticos que servem ao ajuste da curva de retenção.

O formato típico da curva de retenção de um solo é sigmóide. Entretanto, segundo Leong \& Rahardjo (1997a) as equações de Gardner (1958), Brooks \& Corey (1964), Williams et al. (1983) e McKee \& Bumb (1984) não possibilitam a obtenção de um ajuste sigmóide da 
curva de retenção. Das equações apresentadas na Tabela 2.1, apenas as de McKee \& Bumb (1987), van Genuchten (1980) e Fredlund \& Xing (1994) apresentam comportamento sigmóide.

Leong \& Rahardjo (1997a) atentam para o fato de que os termos $q$, $p$ e $a$ das equações de Gardner (1958), van Genuchten (1980) e Fredlund \& Xing (1994), respectivamente, não devem ser interpretados com a pressão de entrada de ar, apesar de serem relacionados com a mesma. Além disso, Leong \& Rahardjo (1997a) afirmam que a equação da curva de retenção proposta por Fredlund \& Xing (1994) apresenta, para os dados por eles estudados, melhores ajustes que as demais equações.

Tabela 2.1 - Síntese dos modelos matemáticos de curvas de retenção, segundo vários autores.

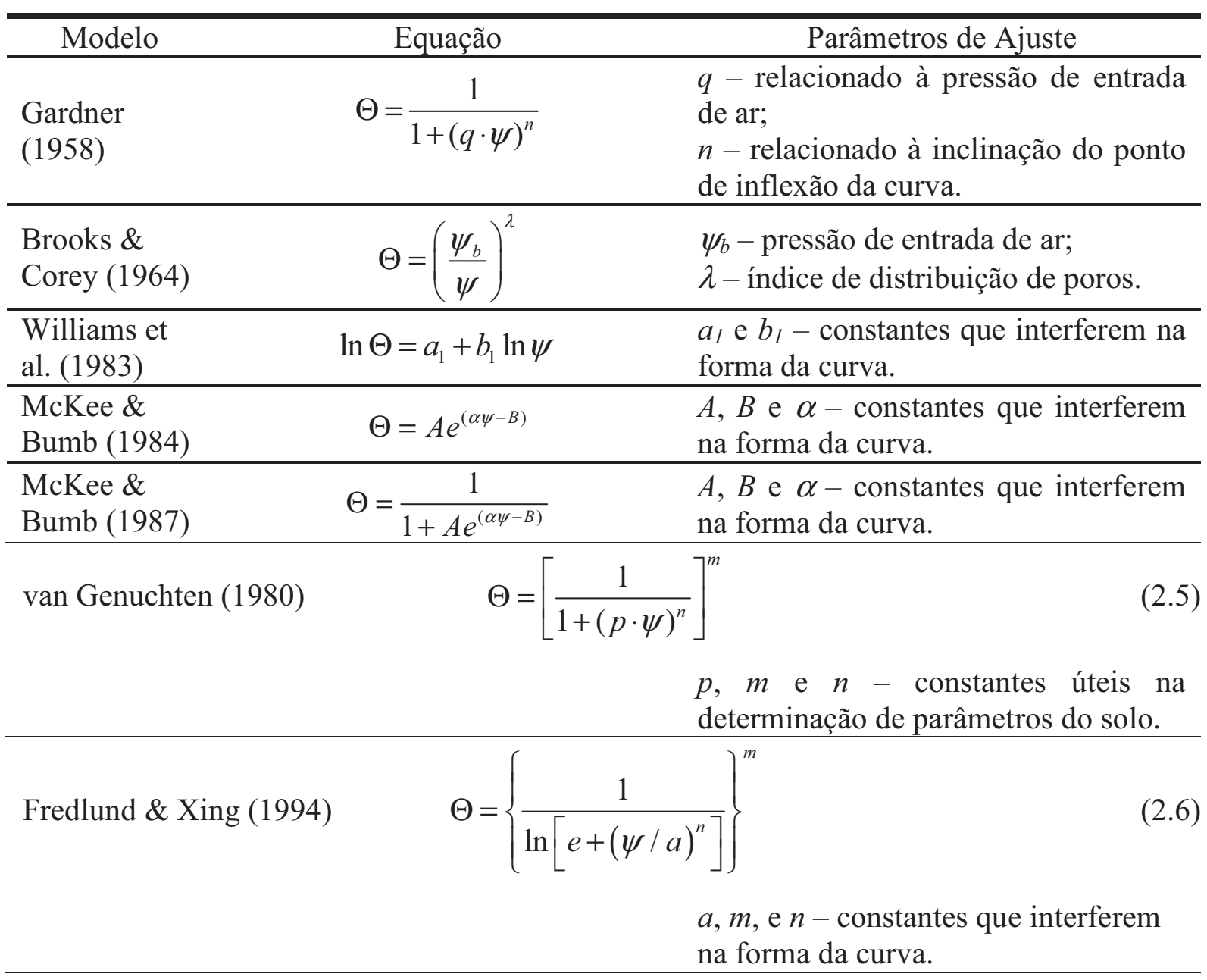

Nota: $\Theta$ é a umidade volumétrica normalizada e é dada por:

$$
\Theta=\frac{\theta-\theta_{r}}{\theta_{s}-\theta_{r}}
$$




\subsubsection{Função Condutividade Hidráulica}

$\mathrm{Na}$ Geotecnia, nenhuma propriedade do solo varia de forma tão ampla quanto a condutividade hidráulica. Para solos saturados, o coeficiente de condutividade hidráulica pode variar em mais de dez ordens de grandeza, quando se considera solos que variam de um pedregulho para uma argila. Para solos não saturados, essa mesma ordem de grandeza na variação da condutividade hidráulica pode ocorrer em um mesmo solo, a depender no nível de sucção atuante (FREDLUND et al., 1994).

Costuma-se representar o coeficiente de condutividade hidráulica saturada $k_{s}$ como função do índice de vazios $e$, principalmente em solos granulares. Para solos não saturados, o coeficiente de condutividade hidráulica é função tanto do índice de vazios quanto do teor de umidade. Caso a estrutura do solo seja considerada como incompressível, é possível dissociar os dois parâmetros em apenas um. Desse modo, $k_{s}$ pode ser quantificado em relação ao índice de vazios e a função condutividade hidráulica em relação ao teor de umidade $k(\theta)$.

Medidas diretas da condutividade hidráulica em laboratório podem consumir bastante tempo. O ensaio torna-se mais demorado à medida que o teor de umidade do solo decresce. Ainda, os valores das condutividades hidráulicas, em um mesmo ensaio, podem variar em muitas ordens de grandeza, o que é um problema em qualquer medição direta já que nenhum aparelho pode medir uma variedade tão grande de valores de condutividade de forma eficiente. Desse modo, medidas indiretas da condutividade hidráulica são comumente realizadas através das funções condutividade hidráulica, que estão relacionadas com a curva de retenção do solo. Em geral, as funções condutividade hidráulica podem ser separadas em três grupos: empíricas, macroscópicas e modelos estatísticos (LEONG \& RAHARDJO, 1997b).

Uma série de autores desenvolveu modelos matemáticos empíricos para a previsão da função condutividade hidráulica do solo. A Tabela 2.2 sintetiza os principais modelos matemáticos que servem à previsão da função condutividade hidráulica do solo. A mesma, foi confeccionada com base no trabalho de Fredlund et al. (1994), porém acrescenta alguns modelos matemáticos que não constam em seu trabalho. 
Tabela 2.2 - Síntese dos modelos matemáticos de funções condutividade hidráulica, segundo vários autores.

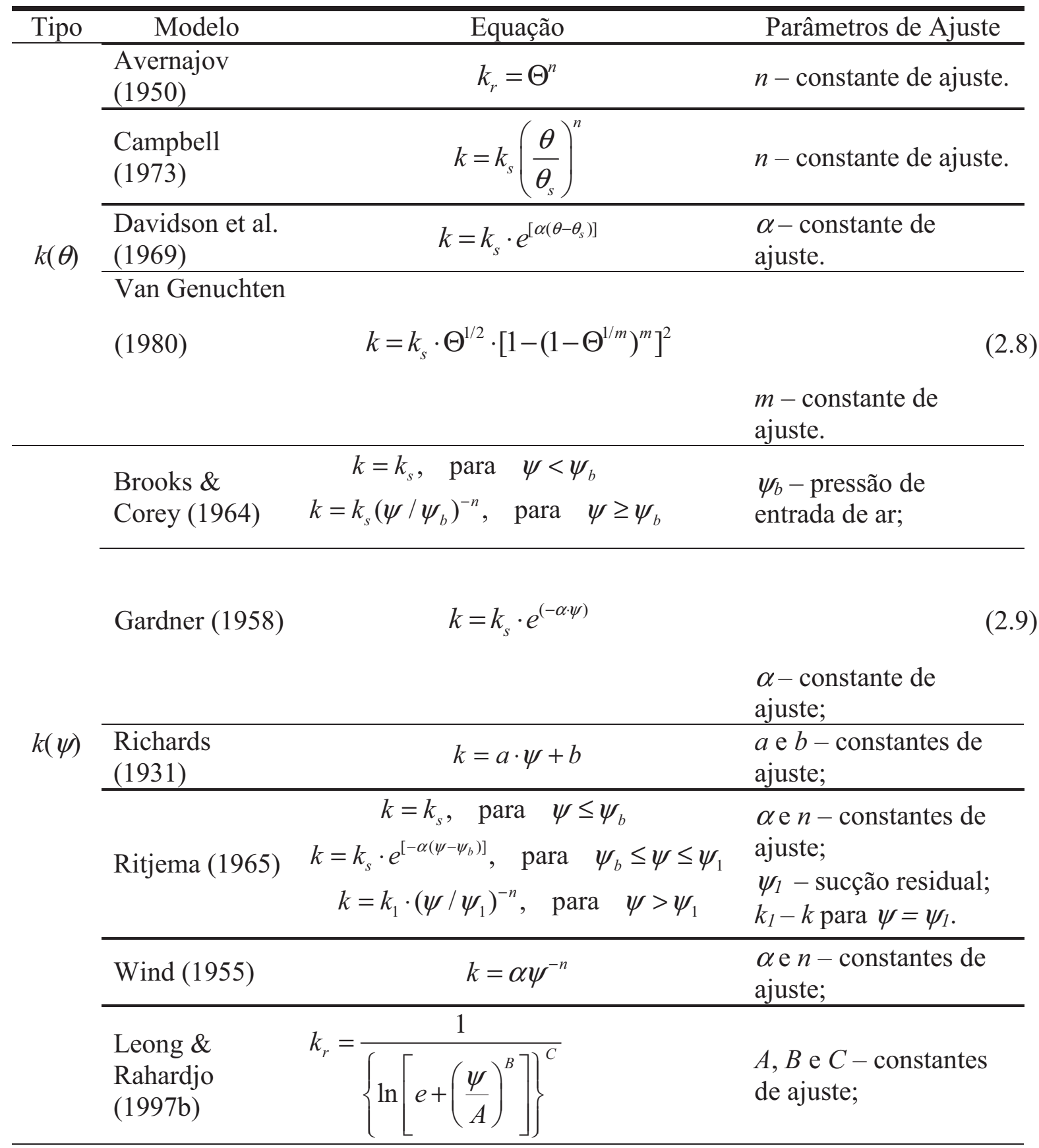

Nota: $k_{r}$ é o coeficiente de condutividade hidráulica relativa:

$$
k_{r}=k / k_{s}
$$


Leong \& Rahardjo (1997b) concluem que, fazendo-se algumas hipóteses simplificadoras, os modelos estatísticos são oriundos dos modelos macroscópicos e estes por sua vez, provêm da equação analítica da função condutividade hidráulica de Mualem ${ }^{1}$ (1986) que é baseada em equações empíricas. Logo, dispondo de um banco de dados de coeficiente de condutividade hidráulica de um dado solo, é mais conveniente a utilização de equações empíricas para a determinação da função condutividade hidráulica.

Ainda, van Genuchten (1980) obteve excelentes ajustes para as funções condutividade hidráulica - obtidas a partir da sua equação para a curva de retenção -, em relação às funções condutividade hidráulica, obtidas experimentalmente, de cinco tipos de solo distintos com condutividades hidráulicas saturadas variando de 303,0 a 0,082 cm/dia.

\subsection{Movimento da Água no Solo}

A Equação de Darcy, ou de Darcy-Buckingham, rege o fluxo de água no solo na condição saturada e não saturada na condição de equilíbrio dinâmico, em outras palavras, regime permanente. Entretanto, em várias situações o fluxo em meios porosos varia em função da posição e do tempo, ou seja, não há o equilíbrio dinâmico e o regime de fluxo passa a ser chamado transiente. Neste caso deve-se recorrer às leis gerais da Física como a da continuidade da massa, para a descrição matemática do fenômeno.

Assim, para que haja o devido entendimento do processo de infiltração, bem como da sua formulação matemática, esta seção se dedica a mostrar as equações de Darcy, da Continuidade e de Richards, de modo que se possa descrever o fluxo de água no solo nos regimes permanente e transiente.

\subsubsection{Equação de Darcy}

Em 1856 foi realizada uma série de experimentos sobre infiltração pelo engenheiro hidráulico Henry Darcy, que confeccionou filtros (colunas) verticais e verificou o processo de infiltração em areia homogênea sob condições de saturação. Segundo Libardi (1995), os ensaios realizados por Darcy permitiram-lhe concluir que a vazão do fluxo $Q\left[\mathrm{~L}^{3} \mathrm{~T}^{-1}\right]$ é diretamente proporcional tanto à área da seção transversal $A\left[\mathrm{~L}^{2}\right]$ da coluna, quanto à

1 MUALEM, Y. (1986). Hydraulic Conductivity of Unsaturated Soils: Prediction and Formulas. In: Methods of soil analysis. Part 1. Physical and mineralogical methods. 2nd ed. Agronomy Monograph No. 9. Ed. A. Klute. American Society of Agronomy, Inc. and Soil Science Society of America, Inc. Madison, WI, USA, pp. 799- 823 . 
diferença de potencial hidráulico total $-\Delta \psi=H_{1}-H_{2}=\psi_{1}-\psi_{2}$, em condição de saturação, em unidades de altura de coluna de água [L] - entre as extremidades do filtro de areia, enquanto que é inversamente proporcional ao comprimento $L$ do filtro.

Darcy estabeleceu uma constante de proporcionalidade à vazão, sendo que esta constante recebe atualmente o nome de coeficiente de condutividade hidráulica saturada $k_{s}$, a qual reflete o grau de dificuldade da água em fluir em um meio poroso. Assim, solos mais permeáveis (solos arenosos) devem apresentar condutividades hidráulicas saturadas maiores que solos menos permeáveis (solos argilosos).

$$
Q=-k_{s} \cdot A \cdot \frac{\Delta \psi}{L}
$$

O sinal negativo na Equação (2.11) indica apenas que o fluxo se dá no sentido em que o potencial hidráulico decresce.

A razão entre $\Delta \psi$ e $L$ é o gradiente de potencial hidráulico total, ou simplesmente gradiente hidráulico total $\nabla \psi\left[\mathrm{LL}^{-1}\right]$, atuante no solo e trata-se de uma grandeza vetorial que pode ser definida no sistema cartesiano de três dimensões, pela Equação (2.12). Fisicamente, este gradiente representa a força que atua na unidade de massa da solução fazendo-a mover (LIBARDI, 1995).

$$
\nabla \psi=\frac{\partial \psi}{\partial x}+\frac{\partial \psi}{\partial y}+\frac{\partial \psi}{\partial z}
$$

Assim, é fácil perceber que $\nabla \psi$ representa a variação do potencial $\psi$ ao longo de uma direção $x, y$ ou $z$, qualquer (REICHARDT, 1985).

Se ambos os membros da Equação (2.11) forem divididos por $A$, obteremos o vetor densidade de fluxo $q\left[\mathrm{LT}^{-1}\right]$, com direção e sentido iguais ao do gradiente hidráulico e módulo igual a $Q / A$.

$$
q=-k_{s} \cdot \nabla \psi
$$

Apesar do módulo de $q$ ter dimensões de velocidade, ele não é a velocidade com que a água se move no interior do solo, já que a velocidade real da água no solo é a vazão do fluxo que passa por uma área de fluxo disponível, isto é, seção transversal de poros ocupados pela água (REICHARDT, 1996). A Equação (2.13) obtida por Darcy é, na verdade, um caso particular que rege o fluxo em meio poroso saturado. Entretanto, nas condições naturais de infiltração, o início do fluxo ocorre em meio não saturado. Atento a esta limitação da equação 
de Darcy, Buckingham² (1907 apud LIBARDI, 1995) propôs a Equação (2.15), que foi o primeiro passo na quantificação do movimento de uma solução em um meio não saturado.

$$
\begin{gathered}
q=-k(\theta) \cdot\left[\frac{\partial \psi_{m}(\theta)}{\partial x}+\frac{\partial \psi_{m}(\theta)}{\partial y}+\frac{\partial \psi_{m}(\theta)}{\partial z}\right] \\
q=-k(\theta) \cdot \nabla \psi_{m}(\theta)
\end{gathered}
$$

Entretanto, a Equação (2.15) não se aplica a um meio com potencial gravitacional diferente de zero, logo a mesma só é válida para o fluxo de água nas direções horizontais.

Richards $^{3}$ (1928 apud LIBARDI, 1995) adicionou o potencial gravitacional $\psi_{z}$ à Equação (2.14), obtendo-se assim o potencial hidráulico total $\psi$.

$$
\begin{gathered}
q=-k(\theta) \cdot\left\{\frac{\partial\left[\psi_{z}+\psi_{m}(\theta)\right]}{\partial x}+\frac{\partial\left[\psi_{z}+\psi_{m}(\theta)\right]}{\partial y}+\frac{\partial\left[\psi_{z}+\psi_{m}(\theta)\right]}{\partial z}\right\} \\
q=-k(\theta) \cdot\left(\frac{\partial \psi}{\partial x}+\frac{\partial \psi}{\partial y}+\frac{\partial \psi}{\partial z}\right) \\
q=-k(\theta) \cdot \nabla \psi
\end{gathered}
$$

A Equação (2.18) é o caso geral da Equação de Darcy, que rege o fluxo de água no solo sob a condição saturada ou não saturada.

Neste caso, é evidente que:

$$
\nabla \psi=\nabla \psi_{m}(\theta)+\nabla \psi_{z}
$$

\subsubsection{Difusividade da Água no Solo}

Antes de apresentar o conceito de difusividade da água no solo, serão mostrados os processos matemáticos que levam a tal conceito. Portanto, substituindo-se a Equação (2.19) em (2.18) pode-se reescrever (2.18) como:

$$
q=-k(\theta) \cdot\left[\nabla \psi_{m}(\theta)+\nabla \psi_{z}\right]
$$

Igualando-se as equações (2.14) e (2.15) tem-se que:

$$
\nabla \psi_{m}(\theta)=\frac{\partial \psi_{m}(\theta)}{\partial x}+\frac{\partial \psi_{m}(\theta)}{\partial y}+\frac{\partial \psi_{m}(\theta)}{\partial z}
$$

O termo $\nabla \psi_{m}(\theta)$ pode ser estendido pela regra da cadeia, chegando-se a:

\footnotetext{
2 BUCKINGHAN, E. (1907) Studies of the movement of soil moisture. USDA Bur. Soil Bull. 38 . US. Government Printing Office, Washington D.C.

${ }^{3}$ RICHARDS, L. A. (1928). The usefulness of capillary potential to soil moisture and plant investigators. Journal of Agricultural Research, v.37, p.719-742.
} 


$$
\nabla \psi_{m}(\theta)=\frac{d \psi_{m}(\theta)}{d \theta} \cdot \frac{\partial \theta}{\partial x}+\frac{d \psi_{m}(\theta)}{d \theta} \cdot \frac{\partial \theta}{\partial y}+\frac{d \psi_{m}(\theta)}{d \theta} \cdot \frac{\partial \theta}{\partial z}
$$

Substituindo-se (2.22) em (2.20) e simplificando os termos das equações, obtém-se:

$$
q=-\left[k(\theta) \cdot \frac{d \psi_{m}(\theta)}{d \theta} \cdot \nabla \theta+k(\theta) \cdot \nabla \psi_{z}\right]
$$

O termo da Equação (2.23) que apresenta o produto de $k(\theta)$ por $d \psi_{m}(\theta) / d \theta$ é conhecido como coeficiente de difusão ou difusividade da água no solo $D(\theta)\left[\mathrm{L}^{2} \mathrm{~T}^{-1}\right]$. A obtenção da função $D(\theta)$ pode ser facilmente realizada conhecendo-se a função condutividade hidráulica $k(\theta)$ de um dado solo e sua curva de retenção $\psi_{m}(\theta)$, já que o produto da derivada primeira desta, em relação à $\theta$, por $k(\theta)$ nada mais é que a difusividade da água no solo.

$$
D(\theta)=k(\theta) \cdot \frac{d \psi_{m}(\theta)}{d \theta}
$$

Substituindo-se a Equação (2.24) em (2.23) obtém-se a Equação de Darcy empregando-se a definição de difusividade da água no solo.

$$
q=-\left[D(\theta) \cdot \nabla \theta+k(\theta) \cdot \nabla \psi_{z}\right]
$$

\subsubsection{Equação da Continuidade}

Para que se obtenha a Equação da Continuidade, considere o elemento de volume $d V$, apresentado na Figura 2.6, que possui dimensões $d x, d y$ e $d z$. Sabendo-se que a densidade de fluxo na direção $x$ é dada pelo vetor $q_{x}$ e que ao longo de $d x$ pode haver uma variação de $q_{x}$, a uma taxa igual a $\partial q_{x} / \partial x$, pode-se afirmar que a densidade de fluxo que sai $q_{x}^{\prime}$ do elemento de volume $d V$ é dada por:

$$
q^{\prime}{ }_{x}=q_{x}+\left(\frac{\partial q_{x}}{\partial x}\right) d x
$$

Estudando-se ainda a direção $x$, a variação do volume de água por unidade de tempo $\partial V_{w_{x}} / \partial t$ é dada pela diferença entre o volume de água que entra $V_{w_{x}}$ e o volume de água que sai $V_{w_{x}}^{\prime}$ do elemento, dividida pela unidade de tempo $\partial t$. Assim:

$$
\begin{gathered}
\frac{\partial V_{w_{x}}}{\partial t}=\left(\frac{V_{w_{x}}-V_{w_{x}}^{\prime}}{\partial t}\right) \\
\frac{\partial V_{w_{x}}}{\partial t}=q_{x} d y d z-\left[q_{x}+\left(\frac{\partial q_{x}}{\partial x}\right) d x\right] d y d z
\end{gathered}
$$




$$
\begin{gathered}
\frac{\partial V_{w_{x}}}{\partial t}=-\left(\frac{\partial q_{x}}{\partial x}\right) d x d y d z \\
\frac{\partial V_{w_{x}}}{\partial t}=-\left(\frac{\partial q_{x}}{\partial x}\right) d V
\end{gathered}
$$

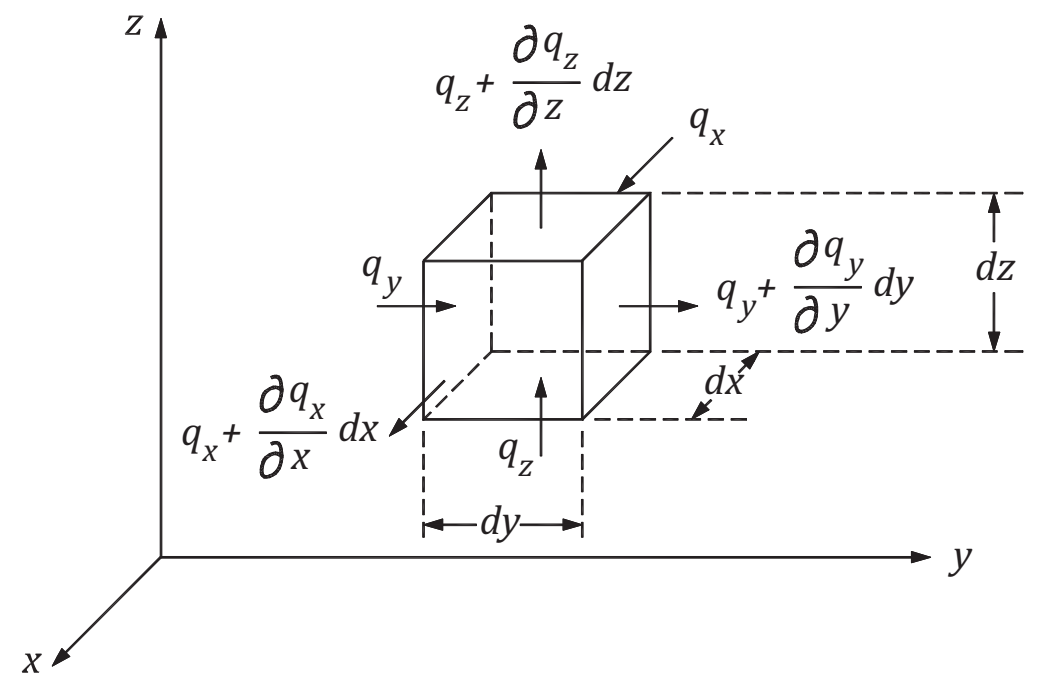

Figura 2.6 - Elemento de volume de solo, através do qual a água está fluindo (modificado de REICHARDT, 1996).

A mesma analogia empregada para a obtenção da Equação (2.30) pode ser empregada para as demais direções $\left(y\right.$ e $z$ ). Portanto, a variação total $\partial V_{w} / \partial t$ no elemento $d V$ será a soma das variações nas três direções.

$$
\frac{\partial V_{w}}{\partial t}=-\left(\frac{\partial q_{x}}{\partial x}+\frac{\partial q_{y}}{\partial y}+\frac{\partial q_{z}}{\partial z}\right) d V
$$

Como $\theta=V_{w} / V$, pode-se dividir ambos os lados da igualdade da Equação (2.31) por $d V$ e teremos a chamada Equação da Continuidade.

$$
\begin{gathered}
\frac{\partial \theta}{\partial t}=-\left(\frac{\partial q_{x}}{\partial x}+\frac{\partial q_{y}}{\partial y}+\frac{\partial q_{z}}{\partial z}\right) \\
\frac{\partial \theta}{\partial t}=-\nabla q
\end{gathered}
$$

A equação da continuidade nos diz que a variação de umidade volumétrica $\theta$ com o tempo $t$ é igual às variações das densidades de fluxo $q_{x}, q_{y}$ e $q_{z}$ nas direções $x, y$ e $z$, respectivamente. Parece lógico que se ao longo de uma direção qualquer a densidade de fluxo (nesta direção) varia, isto fará com que a umidade volumétrica do elemento de solo varie ao longo do tempo. Por exemplo, se a densidade de fluxo que entra em um elemento de solo, em uma direção qualquer, é maior que a que sai, significa que o elemento de solo está 
acumulando água e assim a umidade volumétrica do mesmo aumenta ao longo do tempo, no caso contrário o solo está perdendo água e a umidade volumétrica do elemento de solo diminui com o tempo.

\subsubsection{Equação de Richards}

Richards (1931) analisou a Equação da Continuidade a partir de $k$ e de $\psi_{m}$, e percebeu que o uso de $\psi_{m}$ e $k\left(\psi_{m}\right)$ ou de $\theta$ e $k(\theta)$ é estritamente uma questão de conveniência matemática, desde que $\psi_{m}(\theta)$ seja único.

Assim, Richards (1931) substituiu a Equação de Darcy (2.18) na Equação da Continuidade (2.33) e obteve a equação diferencial geral que rege o movimento da água em solos isotrópicos com relação a sua função condutividade hidráulica:

$$
\begin{gathered}
\frac{\partial \theta}{\partial t}=\nabla[k(\theta) \cdot \nabla \psi] \\
\frac{\partial \theta}{\partial t}=\frac{\partial}{\partial x}\left[k(\theta) \cdot \frac{\partial \psi}{\partial x}\right]+\frac{\partial}{\partial y}\left[k(\theta) \cdot \frac{\partial \psi}{\partial y}\right]+\frac{\partial}{\partial z}\left[k(\theta) \cdot \frac{\partial \psi}{\partial z}\right]
\end{gathered}
$$

A Equação (2.35) é apropriadamente denominada Equação de Richards.

Substituindo-se a Equação de Darcy, em termos de difusividade (Equação (2.25)), na Equação (2.33) obtém-se a Equação de Richards, também em termos de difusividade:

$$
\begin{gathered}
\frac{\partial \theta}{\partial t}=\nabla\left[D(\theta) \cdot \nabla \theta+k(\theta) \cdot \nabla \psi_{z}\right] \\
\frac{\partial \theta}{\partial t}=\frac{\partial}{\partial x} \cdot\left[D(\theta) \cdot \frac{\partial \theta}{\partial x}\right]+\frac{\partial}{\partial y} \cdot\left[D(\theta) \cdot \frac{\partial \theta}{\partial y}\right]+\frac{\partial}{\partial z} \cdot\left[D(\theta) \cdot \frac{\partial \theta}{\partial z}\right]+\frac{\partial k(\theta)}{\partial z}
\end{gathered}
$$

\subsection{Infiltração}

Conhecer o processo de infiltração é extremamente importante para que se possa empregar este componente do ciclo hidrológico de forma a atenuar os problemas das inundações nos centros urbanos e prevenir os problemas futuros. Para tal, se faz necessário conhecer seus conceitos básicos além da compreensão matemática de como se dá o processo de infiltração. Portanto, esta seção apresenta as ferramentas necessárias ao entendimento do processo de infiltração, física e matematicamente. 


\subsubsection{Conceitos Gerais}

O conceito de infiltração é extremamente intuitivo e nada mais é que a penetração da água nos poros do solo através da sua superfície, ou seja, a entrada de água se dá através da interface solo-atmosfera (LIBARDI, 1995). Este fenômeno é facilmente constatado quando da ocorrência de uma precipitação, entretanto a formulação matemática do processo de infiltração é dada por leis físicas complexas, que são alcançadas por meio de leis empíricas, experimentos e solução de equações diferenciais que regem o fluxo da água no solo (RIGHETTO, 1998). A infiltração de água, através da superfície, umedece gradativamente as camadas superiores do perfil de solo de cima para baixo, o que faz com que a umidade seja aumentada no mesmo sentido. Normalmente, eventos naturais de precipitação não são capazes de saturar, via infiltração, todo o solo. Tais eventos restringem-se em saturar o solo em superfície, de modo a conformar um perfil típico em que o teor de umidade decresce com a profundidade (SILVEIRA et al., 2004).

Bodman \& Colman (1944) realizaram experimentos de infiltração vertical em solos siltosos e arenosos, ambos com presença de matéria orgânica, típicos do condado de Yolo na Califórnia. Os experimentos tiveram como objetivo a determinação da distribuição do teor de umidade da coluna de solo durante o processo de infiltração. A Figura 2.7 apresenta um perfil de umidade genérico semelhante aos encontrados por Bodman \& Colman (1944).
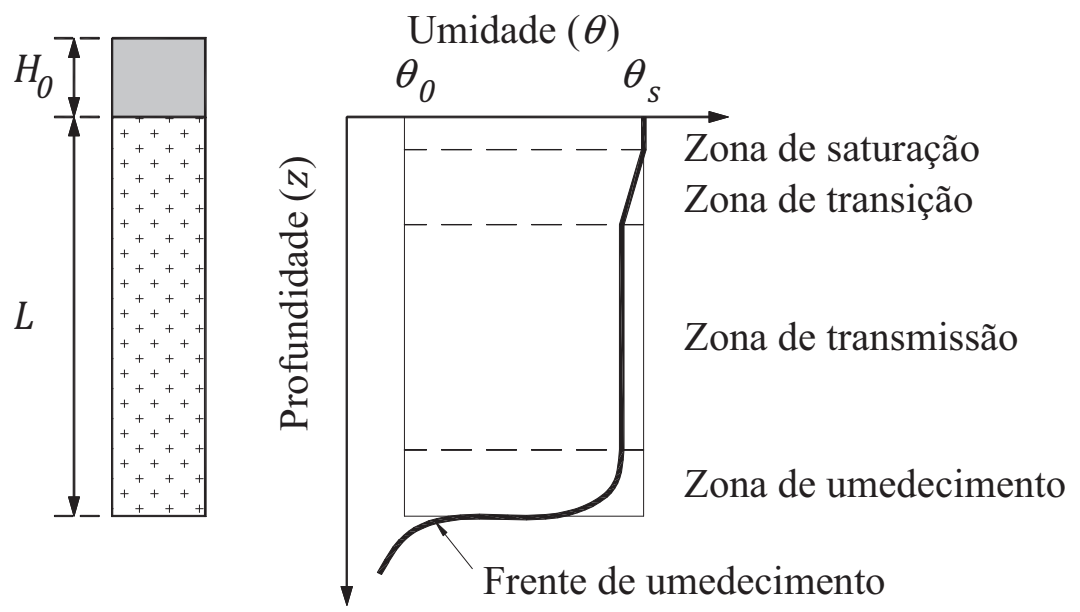

Figura 2.7 - Perfil de umedecimento do solo durante a infiltração ( $\theta_{0}$ é a umidade inicial do solo e $\theta_{s}$ a umidade do solo correspondente à saturação) (LIBARDI, 1995).

Bodman \& Colman (1944) distinguiram quatro zonas no perfil de umidade. A primeira é a zona de saturação, a qual, em seus experimentos, se estendeu frequentemente em uma estreita faixa de $1,5 \mathrm{~cm}$ abaixo da superfície. A zona de transição apresentou espessura em torno de $6 \mathrm{~cm}$, no momento em que a frente de umedecimento se encontrava $15 \mathrm{~cm}$ abaixo da 
superfície; nesta zona percebeu-se um decréscimo acentuado do teor de umidade do solo. A zona de transmissão não apresentou espessura constante, já que a mesma aumentou continuamente com a aplicação de água, nesta camada ocorreu pequena variação da umidade em relação ao espaço e tempo. Na zona de umedecimento, pouco espessa, ocorreu grande redução da umidade com o aumento da profundidade e a frente de umedecimento foi distinguida pelo limite visível da movimentação da água no solo.

Os processos de infiltração que ocorrem na natureza, muitas vezes possuem certas particularidades tais como a infiltração em "fingers", em fendas e macroporos ou o fluxo por caminhos preferenciais nos contatos entre solos com condutividades hidráulicas distintas. Desse modo, o comportamento de um solo idealizado (homogêneo e isotrópico) pelas leis de fluxo nem sempre corresponde ao comportamento real na natureza (SANTOS, 2004).

$\mathrm{Na}$ hidrologia, Horton (1933) mostrou que uma precipitação, quando alcança a superfície do solo, infiltra a partir desta a uma taxa que diminui com o tempo e ressaltou que para um dado solo há uma curva limite que define as possíveis taxas de infiltração versus o tempo.

\subsubsection{Capacidade de Infiltração e Taxa de Infiltração}

A taxa máxima de água, em unidades de altura de coluna de água por unidade de tempo $\left[\mathrm{LT}^{-1}\right]$, que um dado solo pode absorver, a partir da sua superfície, em uma dada condição é conceituada como capacidade de infiltração (HORTON, 1933). Segundo Silveira et al. (2004), o uso do conceito de capacidade de infiltração é útil na hidrologia para que seja diferenciado o potencial de absorção de água de um solo da taxa de infiltração $i\left[\mathrm{LT}^{-1}\right.$ ] real que ocorre quando há disponibilidade de água para penetrar no solo.

Após o início da precipitação, a capacidade de infiltração decresce com o tempo, e com o passar deste alcança uma razão constante. O decréscimo da curva de capacidade de infiltração é causado principalmente pelo preenchimento dos poros do solo por água. Ensaios controlados, realizados em vários tipos de solos, mostram que para argilas (menor porosidade) o declínio da curva de capacidade de infiltração versus o tempo é mais rápido e no seu trecho constante, apresenta menor taxa de infiltração do que para solos arenosos (maior porosidade). Durante um evento de chuva, se em algum momento a intensidade da precipitação ultrapassar a capacidade de infiltração do solo, formar-se-á na superfície um excesso de água, a qual escoará, gerando um dos componentes básicos do ciclo hidrológico que é o escoamento superficial (FREEZE \& CHERRY, 1979). 
Para um dado solo, sua capacidade de infiltração varia entre um valor máximo quando o solo está seco e um valor mínimo quando está saturado. A capacidade de infiltração atinge, geralmente, valores próximos aos máximos durante curtas tempestades após períodos de seca e valores próximos ao mínimo durante períodos prolongados de chuvas (HORTON, 1933). Desse modo, fica claro que ao fim de um evento de precipitação, considerando-se que não há lâmina de água em superfície, a taxa real de infiltração tende a ser reduzida rapidamente, enquanto que a capacidade de infiltração tende a crescer, já que há a perda de umidade para camadas de solo mais profundas e por evapotranspiração.

Outra variável importante ao processo de infiltração é a que corresponde ao volume de água infiltrada em uma determinada unidade de área ao longo do tempo que é chamada de infiltração acumulada $I[\mathrm{~L}]$. De forma generalizada, o comportamento da taxa de infiltração e da infiltração acumulada segue o esquema da Figura 2.8.

Segundo Rubin et al. ${ }^{4,5}$ (1963, 1964 apud FREEZE \& CHERRY, 1979), a constante no final da curva de taxa de infiltração é numericamente igual à condutividade hidráulica saturada do solo, em outras palavras, o limite da curva de taxa de infiltração para o tempo tendendo ao infinito é igual à condutividade hidráulica saturada do solo. Freeze \& Cherry (1979) afirmam que Rubin et al. ${ }^{4,5}(1963,1964)$ também identificaram as duas condições necessárias para a formação de poças: (1) a intensidade da chuva deve ser maior que a condutividade hidráulica saturada do solo, e (2) o período de duração da chuva deve ser maior que o tempo necessário para que o solo se torne saturado na superfície.

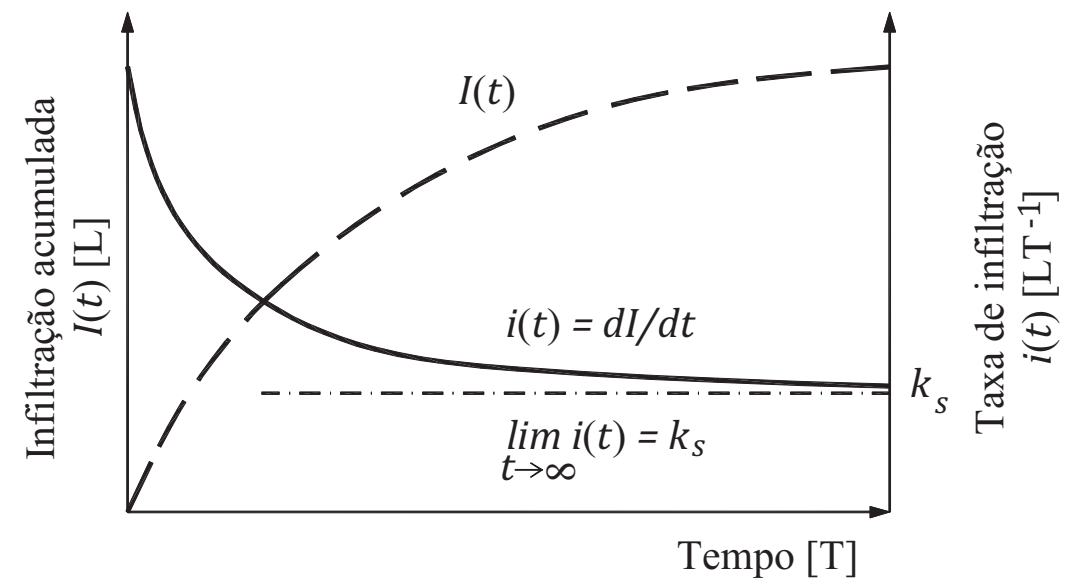

Figura 2.8 - Curvas de infiltração instantânea e acumulada.

\footnotetext{
${ }^{4}$ RUBIN, J.; STEINHARDT, R. (1963). Soil water relations during rain infiltration: I Theory. Soil Sci. Soc. Amer. Proc., v.27, p.246-251.

${ }^{5}$ RUBIN, J.; STEINHARDT, R.; REINIGER, P. (1964). Soil water relations during rain infiltration: II Moisture content profiles during rains of low intensities. Soil Sci. Soc. Amer. Proc., v.28, p.1-5.
} 


\subsection{Modelos de Infiltração}

Segundo Chahinian et al. (2005), a maioria dos modelos de simulação do escoamento superficial transforma o excesso da infiltração em escoamento. Desse modo, para fins de drenagem urbana, é imprescindível o conhecimento dos modelos de infiltração.

Os modelos de infiltração são frequentemente classificados como empíricos e teóricos. Os empíricos permitem o ajuste do modelo, a partir dos seus parâmetros, às características do solo, de modo a englobar na determinação de suas constantes alguns fatores que são difíceis de serem considerados nos modelos teóricos, mesmo que tais constantes não possuam obrigatoriamente significado físico. Entretanto estes modelos só são válidos para as condições em que foram determinados, ou seja, não podem ser adotados em outros tipos de solo. Já os modelos teóricos têm a vantagem de poderem ser utilizados para diferentes condições de solo, visto que são baseados na teoria física da dinâmica da água em meios porosos, empregando os conceitos advindos da Equação de Darcy e de Richards (BRANDÃO et al., 2009).

\subsubsection{Soluções Empíricas}

\subsubsection{Equação de Kostiakov}

Kostiakov $^{6}$ (1932, apud LIBARDI, 1995) desenvolveu uma equação totalmente empírica, da seguinte forma:

$$
i=i_{i} \cdot t^{-a}
$$

em que $i_{i}$ é a taxa de infiltração no início do processo, ou seja, em $t=0$, e $a$ é uma constante. Tanto $i_{i}$ quanto $a$ são obtidos empiricamente a partir da observação de valores de dois pares de $i$ e de $t$.

A partir da Equação (2.38) chega-se à infiltração acumulada $I$ até um dado instante $t$ :

$$
I=i_{i} \cdot \frac{t^{(1-a)}}{1-a}
$$

A equação de Kostiakov (1932) tem a vantagem de ser bastante simples e descreve a infiltração no trecho mais baixo da escala de tempo $t$ extremamente bem. A maior desvantagem consiste no fato de que o limite de $i$, quando $t$ tende ao infinito é igual a zero.

\footnotetext{
${ }^{6}$ KOSTIAKOV, A. N. (1932). On the dynamics of the coefficient of water-percolation in soils and on the necessity of studying it from a dynamic point of view for purposes of amelioration. Transactions Communications for the Society of Soil Science 6th Conference, Moscow, Part A, p. 17-21.
} 
Assim, a equação de Kostiakov (1932) possui baixa acurácia para grandes valores de $t$ (PHILIP, 1957a).

De modo a corrigir essa deficiência da equação de Kostiakov (1932), pode-se estabelecer, através de uma condição, um intervalo de validez das equações (2.38) e (2.39). A condição é que o modelo de Kostiakov (1932) só é válido para os tempos $t$ menores que $(t<T)$, em que:

$$
T=\left(\frac{i_{i}}{k_{s}}\right)^{1 / a}
$$

Esta condição é necessária, para que $i$ tenda a $k_{s}\left(i \rightarrow k_{s}\right)$ quando $t$ tender ao infinito $(t \rightarrow \infty)$.

\subsubsection{Equação de Horton}

Horton (1940) apresentou a equação empírica (2.41), através da qual a taxa de infiltração $i$ pode ser representada em função do tempo de infiltração $t$.

$$
i=i_{f}+\left(i_{i}-i_{f}\right) \cdot e^{-C \cdot t}
$$

em que: $i_{f}$, é a taxa de infiltração para um tempo infinito $(t \rightarrow \infty)\left[\mathrm{LT}^{-1}\right]$;

$i_{i}$, é a taxa de infiltração inicial $(t=0)\left[\mathrm{LT}^{-1}\right]$;

$C$, é uma constante de ajuste da equação $\left[\mathrm{T}^{-1}\right]$.

Esta equação é a denominada Equação de Horton, sendo que os parâmetros $i_{i}, i_{f}$ e $C$ podem ser obtidos a partir de quaisquer três observações separadas de pares de valores simultâneos de $i$ e $t$.

A redução da taxa de infiltração $i$ com a ocorrência de uma chuva prolongada é representada como sendo um processo de exaustão muito comum na natureza. Assim, a taxa de infiltração $i$ pode ser interpretada como um processo de decaimento que obedece à lei de que a taxa de variação de uma determinada grandeza que se aproxima de um valor final constante, aqui representado por $i_{f}$, é proporcional à diferença entre seu valor em um determinado tempo e o valor final constante (HORTON, 1940; LIBARDI, 1995).

Segundo Philip (1957a) o ponto básico a favor da formulação de Horton (1940) é que o limite de $i$, quando $t$ tende ao infinito é diferente de zero. As desvantagens incluem o fato de que a Equação (2.41) é incapaz de representar adequadamente a diminuição muito rápida de $i$ 
com a variação dos pequenos valores de $t$, e a necessidade da determinação de três parâmetros.

\subsubsection{Equação de Green \& Ampt}

Green \& Ampt (1911) desenvolveram teoricamente uma equação de fluxo com base na equação de Darcy, de modo que seja necessário considerar: (1) infiltração ocorre sob uma carga hidráulica $H_{0}$ constante na superfície do solo, (2) a frente de umedecimento é extremamente nítida e atrás da mesma o solo está saturado com condutividade hidráulica $k_{s}$, e (3) o solo nesta frente encontra-se com potencial matricial e, consequentemente, umidade volumétrica iguais aos que eram apresentados antes da infiltração. Neste caso, fica claro que a densidade de fluxo $q$ é igual à taxa de infiltração $i$, e adotando-se a frente de molhamento como referencial gravitacional, empregando-se a Equação (2.18) tem-se:

$$
i=\frac{d I}{d t}=-k_{s}\left(\frac{H_{0}+L+H_{f}}{L}\right)
$$

em que, $H_{f}=-\psi_{m}$ e $\psi_{m}$ é o potencial matricial na frente de umedecimento em unidades de altura de coluna de água [L].

A partir da Equação (2.43) pode-se determinar a infiltração acumulada $I$. Para tal, basta que se obtenham os valores das constantes $A, B$ e $C$, a partir das observações da taxa de infiltração em duas profundidades $L$ conhecidas (LIBARDI, 1995).

$$
I=t \cdot A-C \cdot \ln \left(1+\frac{I}{C}\right)
$$

em que: $A=-k_{s}$;

$$
\begin{aligned}
& C=\left(\theta_{s}-\theta_{0}\right) \frac{B}{A} ; \\
& B=-k_{s}\left(H_{0}+H_{f}\right) .
\end{aligned}
$$

\subsubsection{Soluções Analíticas}

Philip (1955, 1957a e 1957b), desenvolveu soluções da Equação de Richards, para obtenção da equação do perfil de umidade - Philip (1955 e 1957b) - e, então, a da lei de infiltração - Philip (1957a). 


\subsubsection{Infiltração Horizontal - Philip (1955)}

A Figura 2.9 apresenta um arranjo experimental de um ensaio de infiltração horizontal em solo homogêneo com umidade inicial uniforme $\theta_{0}$. No instante $t=0$ (início do processo de infiltração), uma placa porosa de resistência desprezível, ligada a uma bureta de Mariotte preenchida com água, é colocada em contato com uma das extremidades da coluna, em $x=0$. Nestas condições, a umidade volumétrica na extremidade $x=0$, se eleva para $\theta_{l}$ próxima à saturação, mantendo-se a entrada de ar da bureta de Mariotte um pouco abaixo do centro da coluna (LIBARDI, 1995).

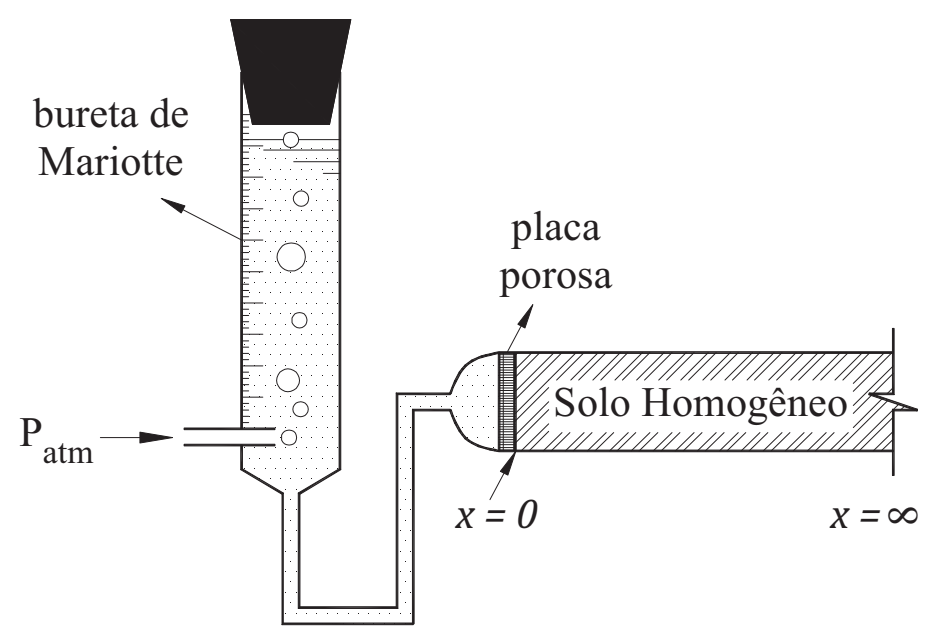

Figura 2.9 - Esquema do ensaio de infiltração horizontal (LIBARDI, 1995).

Neste caso, a Equação de Richards (Equação (2.37)) é a utilizada para descrever o processo de infiltração. Por se tratar de fluxo horizontal, considera-se apenas a sua primeira parcela (direção $x$ ). Logo, tem-se:

$$
\frac{\partial \theta}{\partial t}=\frac{\partial}{\partial x}\left[D(\theta) \frac{\partial \theta}{\partial x}\right]
$$

que está sujeita às condições:

$$
\left.\begin{array}{c}
\theta=\theta_{0}, \quad x \geq 0, \quad t=0 \quad \text { (inicial) } \\
\theta=\theta_{1}, \quad x=0, \quad t>0 \quad \text { (de contorno) } \\
\theta=\theta_{0}, \quad x=\infty, \quad t>0 \quad \text { (de contorno) }
\end{array}\right\}
$$

A solução da Equação (2.44) é do tipo $\theta=\theta(x, t)$, esta função permite calcular $\theta$ em qualquer ponto $x$ da coluna a qualquer instante $t$. Entretanto, esta solução é de difícil obtenção e só é possível de ser utilizada em alguns casos específicos em que se conhece $D(\theta)$ (REICHARDT, 1996). A solução da Equação (2.44) pode ser obtida por meio da técnica das 
variáveis separáveis, se $x$ for transformada em variável dependente, isto é $x=x(\theta, t)$ (SWARTZENDRUBER, 1969).

Através do cálculo elementar, pode-se fazer a transformação de $\theta=\theta(x, t)$ para $x=x(\theta, t)$, de modo que a Equação (2.44) possa ser escrita como:

$$
-\frac{\partial x}{\partial t}=\frac{\partial}{\partial \theta}\left[\frac{D(\theta)}{\partial x / \partial \theta}\right]
$$

A solução da Equação (2.46) é dada por:

$$
\eta(\theta)=x \cdot t^{-1 / 2}
$$

que é conhecida como transformação de Boltzmann.

A Equação (2.47) permite que a Equação (2.44) seja reduzida à equação diferencial ordinária:

$$
-\frac{\eta}{2}=\frac{d}{d \theta}\left[D(\theta) \frac{d \theta}{d \eta}\right]
$$

Obviamente, a introdução da transformação de Boltzmann na Equação (2.44) implica na alteração das condições de contorno. Assim, as condições (2.45) tornam-se:

$$
\theta=\theta_{1}, \quad \eta=0 \quad \text { e } \theta=\theta_{0}, \quad \eta \rightarrow \infty
$$

que implica $\theta \rightarrow \theta_{0}, d \theta / d \eta \rightarrow 0$ (HILLEL, 1980).

Para que se obtenha a solução da Equação (2.46), que permite conhecer $x$ para uma dada umidade $\theta$ em um instante $t$ qualquer, basta que o termo $\eta(\theta)$ da Equação (2.47) seja resolvido. Com a integração da Equação (2.48), sujeita às condições (2.49), chega-se a:

$$
\int_{\theta_{0}}^{\theta} \eta d \theta=-2 D(\theta)\left(\frac{d \theta}{d \eta}\right)
$$

A solução de (PHILIP, 1955) consiste basicamente em dividir a faixa de umidade entre $\theta_{0}$ e $\theta_{1}$ em intervalos iguais a $\Delta \theta$ e reescrever a Equação (2.50) na forma de diferença finita, que pode ser empregada conhecendo-se apenas $\theta_{0}, \theta_{1}$ e $D(\theta)$. Neste caso, $D(\theta)$ não precisa ser conhecida analiticamente, basta obtê-lo na forma numérica. Segundo Hillel (1980), a solução de Philip (1955) resume-se à determinação apropriada de áreas e inclinações na curva $\theta(\eta)$ (ver a Figura 2.10). 


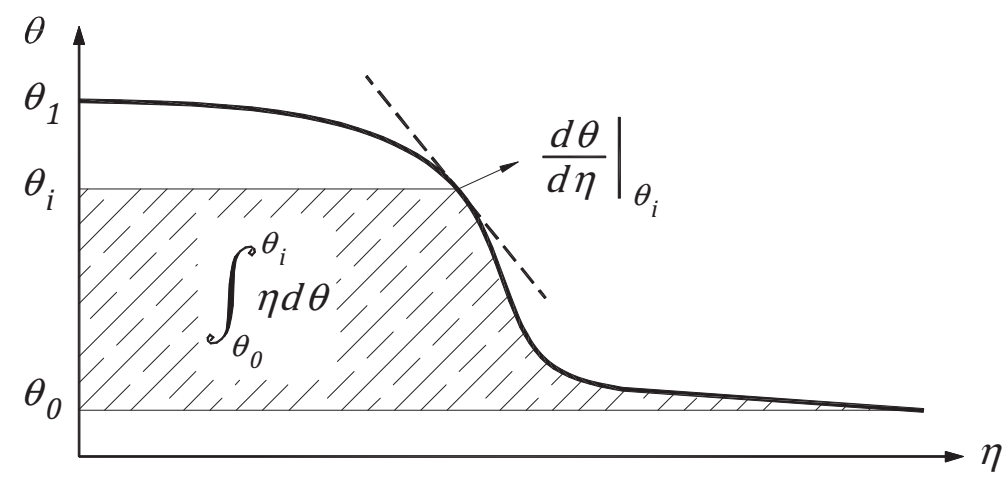

Figura 2.10 - Curva hipotética da umidade em função de $\eta$ (HILLEL, 1980).

\subsubsection{Infiltração Vertical - Philip (1957b)}

A Figura 2.11 apresenta um arranjo experimental semelhante ao da Figura 2.9, sendo a posição da coluna de solo na vertical a única diferença. Logo, as condições de contorno deste experimento são exatamente as mesmas da infiltração horizontal (condições (2.45)), alterando-se apenas a direção do eixo da coluna.

$$
\left.\begin{array}{c}
\theta=\theta_{0}, \quad z \geq 0, \quad t=0 \quad \text { (inicial) } \\
\theta=\theta_{1}, \quad z=0, \quad t>0 \quad \text { (de contorno) } \\
\theta=\theta_{0}, \quad z=\infty, \quad t>0 \quad \text { (de contorno) }
\end{array}\right\}
$$

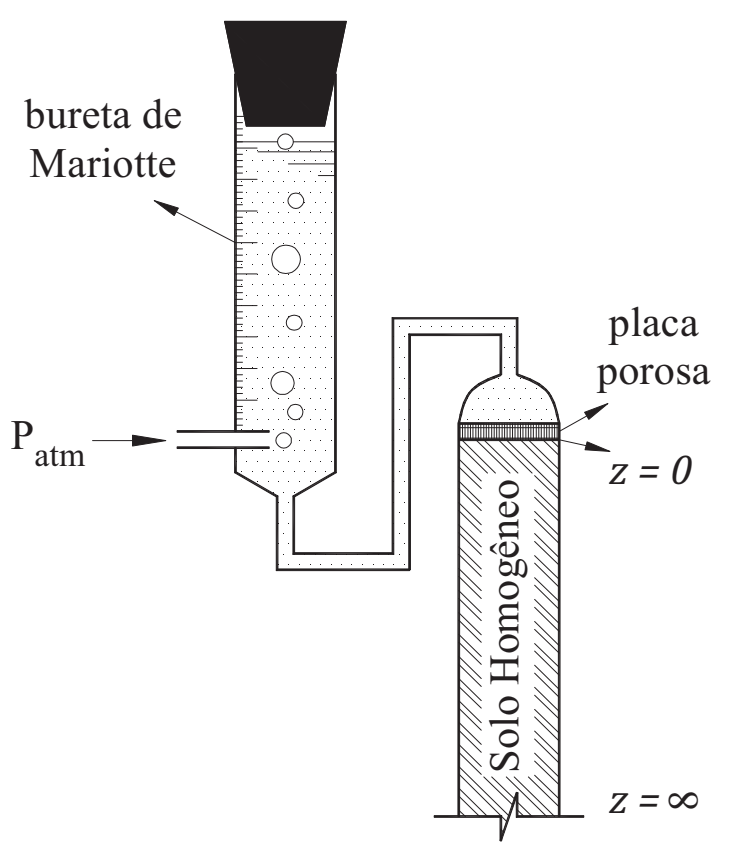

Figura 2.11 - Esquema do ensaio de infiltração vertical (LIBARDI, 1995). 
A Equação de Richards (Equação (2.37)) é a utilizada mais uma vez para descrever o processo de infiltração. Por se tratar de fluxo vertical, considera-se apenas a sua última parcela (direção $z$ ). Logo, tem-se:

$$
\frac{\partial \theta}{\partial t}=\frac{\partial}{\partial z} \cdot\left[D(\theta) \cdot \frac{\partial \theta}{\partial z}\right]+\frac{\partial k(\theta)}{\partial z}
$$

Novamente, pode-se fazer a transformação da solução da Equação (2.52) do tipo $\theta=\theta(z, t)$ para $z=z(\theta, t)$, de modo que a Equação (2.52) possa ser escrita como:

$$
-\frac{\partial z}{\partial t}=\frac{\partial}{\partial \theta}\left[\frac{D(\theta)}{\partial z / \partial \theta}\right]+\frac{k(\theta)}{\partial \theta}
$$

A Equação (2.53) possui duas soluções, uma delas é empregada para um tempo de infiltração $t$ bem pequeno, e a segunda para um tempo $t$ não pequeno (LIBARDI, 1995). Para tempos bem pequenos o efeito da gravidade é desprezível. Assim, a solução da Equação (2.53) para $t$ bem pequeno é idêntica à solução dada ao caso de infiltração horizontal (REICHARDT, 1996):

$$
\begin{gathered}
\eta(\theta)=z \cdot t^{-1 / 2} \\
z(\theta, t)=\eta(\theta) \cdot t^{1 / 2}
\end{gathered}
$$

do mesmo modo, pode ser resolvida pelo processo iterativo de Philip (1955).

Para valores de $t$ não pequeno, a técnica de variáveis separáveis não soluciona a equação diferencial (2.53), sujeita às condições (2.51). Uma formulação alternativa que pode ser tentada, e que tem excelente precedente na solução de equações diferenciais, é assumir a solução na forma de uma série infinita (SWARTZENDRUBER, 1969):

$$
z(\theta, t)=f_{0}+f_{1} t^{m}+f_{2} t^{2 m}+f_{3} t^{3 m}+\cdots=\sum_{i=0}^{\infty} f_{i} t^{i m}
$$

em que, $m$ é uma constante positiva e $f_{i}=f_{i}(\theta)$.

Para que se possa utilizar (2.56) como solução de (2.53), (2.56) deve valer também para valores de $t$ bem pequenos. Nota-se facilmente que para pequenos valores de $t$ (valores de $t$ menores que uma determinada unidade de tempo, $t<1$ ), quanto maior for o expoente $i$, menor será o valor de $t^{i m}$. Desse modo, para $t$ bem pequeno, pode-se reescrever a Equação (2.56) desprezando-se os termos $i$ maiores que um ( $i>1)$ (REICHARDT, 1996).

$$
z(\theta, t)=f_{0}+f_{1} t^{m}
$$

Comparando-se (2.57) e (2.55), chega-se à conclusão de que $f_{0}=0, f_{1}=\eta(\theta)$ e $m=1 / 2$. Conhecendo-se estes três parâmetros, para que a Equação (2.56) seja 
completamente solucionada, basta que se conheça os demais termos $f_{i}$ para $i \geq 2$ (PHILIP, 1957b).

Philip (1957b) propôs então, um método numérico capaz de determinar as funções $f_{i}$ para $i \geq 2$, a partir da integração da Equação (2.53). Para que este método possa ser utilizado, é necessário que as funções $D(\theta)$ e $k(\theta)$ sejam conhecidas ou adotadas e que a função $\eta(\theta)$ seja avaliada inicialmente pela solução da Equação (2.50), sujeita à condição de que $\eta\left(\theta_{1}\right)=0$.

\subsubsection{Lei da Infiltração - Philip (1957a)}

Muitas situações aplicadas à hidrologia requerem que a dinâmica da infiltração seja caracterizada por um pequeno número de parâmetros. Estes parâmetros são mais apropriadamente os coeficientes de uma equação algébrica representada pela variação de $i$ com $t$ (PHILIP, 1957a). Assim, este mesmo autor propôs uma equação que permite descrever o processo de infiltração ao longo do tempo:

$$
I=s \cdot t^{1 / 2}+f \cdot t
$$

em que: $s$, é a sortividade do solo, que é um indicador da capacidade que o solo homogêneo tem de absorver água $\left[\mathrm{LT}^{-1 / 2}\right]$;

$f$, é uma constante relacionada com a contribuição da gravidade para o movimento da água $\left[\mathrm{LT}^{-1}\right]$.

Os valores de $s$ e $f$ tanto podem ser calculados a partir de equações teóricas, quanto podem ser determinados por meio da medida de infiltração em dois tempos distintos (LIBARDI, 1995).

\subsubsection{Solução Numérica da Equação de Richards no Programa SEEP/W}

\subsubsection{Programa SEEP/W}

O SEEP/W 2004 é um software do pacote GeoStudio 2004, e trata-se de um programa que permite a modelagem e a análise numéricas do escoamento das águas subterrâneas e dos problemas de dissipação do excesso de pressão neutra em materiais porosos, tais como os solos e as rochas. A técnica empregada na solução de tais problemas é a dos elementos finitos. O SEEP/W é uma ferramenta matemática extremamente potente que permite a solução 
numérica da Equação de Richards. Deste modo, através do SEEP/W pode-se realizar análises que vão desde os simples problemas de fluxo em regime permanente até as mais complexas análises em regime transiente. Entretanto, vale destacar que a obtenção de resultados úteis e significativos a partir desta ferramenta, depende das orientações e dos dados fornecidos pelo usuário. Isto implica dizer que a capacidade do usuário em fornecer e interpretar os dados é o que torna o SEEP/W uma ferramenta poderosa (GEOSTUDIO, 2004).

De acordo com Santos (2004), as principais limitações desse programa são:

- suposição da homogeneidade do solo;

- é formulado para condição de tensão total constante;

- há dificuldades na convergência de problemas de solos com função condutividade hidráulica com grande declividade (materiais arenosos);

- esta dificuldade também ocorre em problemas com nível de água profundo.

Além das limitações intrínsecas ao programa há ainda, as limitações e falhas do usuário. Estas podem ser minimizadas seguindo-se as seguintes estratégias necessárias a uma boa modelagem:

- estimar manualmente o possível resultado da solução de um determinado problema que será modelado;

- simplificar a geometria do modelo em relação aos aspectos geométricos naturais do problema;

- aumentar a complexidade do problema gradativamente, de modo que se possa ganhar confiança nos resultados obtidos em cada estágio;

- questionar os resultados obtidos;

- avaliar os resultados obtidos no âmbito dos resultados esperados.

Os procedimentos que vão desde a modelagem de um problema no SEEP/W até a obtenção da sua solução, são compreendidos em três etapas: (1) Definição do Problema (SEEP/W DEFINE), (2) Resolução do Problema por Processo Iterativo (SEEP/W SOLVE) e (3) Visualização dos Resultados (SEEP/W CONTOUR). Na sequência, são apresentados resumidamente os detalhes pertinentes a cada uma dessas etapas.

\subsubsection{Definição do Problema (SEEP/W DEFINE)}

Os métodos numéricos que envolvem elementos finitos consistem em subdividir uma região contínua em pequenos elementos, que descrevam os seus comportamentos individuais e o somatório dos comportamentos individuais representa o comportamento do todo (região 
contínua). A subdivisão de uma região contínua em elementos menores é chamada de discretização e os elementos são os chamados elementos finitos (GEOSTUDIO, 2004). Evidentemente, para que se possa discretizar uma região é necessário defini-la. Assim, o problema é inicialmente definido no SEEP/W DEFINE. Para tal, de acordo com Santos (2004) é necessário seguir as seguintes etapas:

a) definição do espaço de trabalho no qual o problema será esquematizado graficamente;

b) desenho do problema e determinação de regiões;

c) especificação dos materiais;

d) discretização das regiões em elementos finitos;

e) definição das condições de contorno.

Na etapa a) define-se o tamanho do papel, a escala do desenho e a origem do sistema de coordenadas. A etapa b) inicia-se com a determinação da geometria básica para a visualização do problema e é encerrada com a divisão da geometria do problema em regiões. O emprego de regiões oferece todas as vantagens da divisão de um grande domínio em partes menores - facilidade das análises de partes menores. A união destas regiões representa 0 comportamento de todo o domínio, exatamente como o conceito de elementos finitos. As características dos diversos tipos de materiais (camadas de solos, camadas impermeáveis, filtros, etc.) presentes no problema são especificados na etapa c). Nesta, são determinadas as propriedades dos materiais porosos como a curva de retenção e a função condutividade hidráulica.

A etapa d) consiste na discretização das regiões em elementos finitos. No GeoStudio 2004 a geração da malha da região discretizada é realizada automaticamente. Entretanto, pode-se alterar o tamanho dos elementos a um nível global para toda a malha, em qualquer uma das regiões, ou ao longo de uma linha ou em torno de um ponto. Ainda, pode-se especificar a densidade da malha como uma unidade de comprimento real, como uma razão do tamanho da malha global, ou como o número de divisões ao longo de uma linha de borda. Finalmente, na etapa e) são determinadas as condições de contorno. A solução de um problema numérico é uma resposta direta às condições de contorno impostas. As condições de contorno podem ser: a diferença de carga hidráulica total entre dois pontos, ou a densidade de fluxo do sistema, ou a determinação de uma face de fluxo, entre outras. Além disso, as condições de contorno podem mudar com o tempo durante uma análise transiente, podendo haver o incremento de complexidade com o tempo. 
A Figura 2.12 apresenta o esquema da solução de um problema de fluxo permanente ao fim da etapa SEEP/W DEFINE - de uma barragem de terra sujeita a uma carga hidráulica total de $11 \mathrm{~m}$ à montante, carga hidráulica total de jusante nula e toda a face de jusante disponível para o fluxo de água. Neste caso, a malha foi gerada com elementos quadriláteros e triangulares de $1 \mathrm{~m}$ de lado.

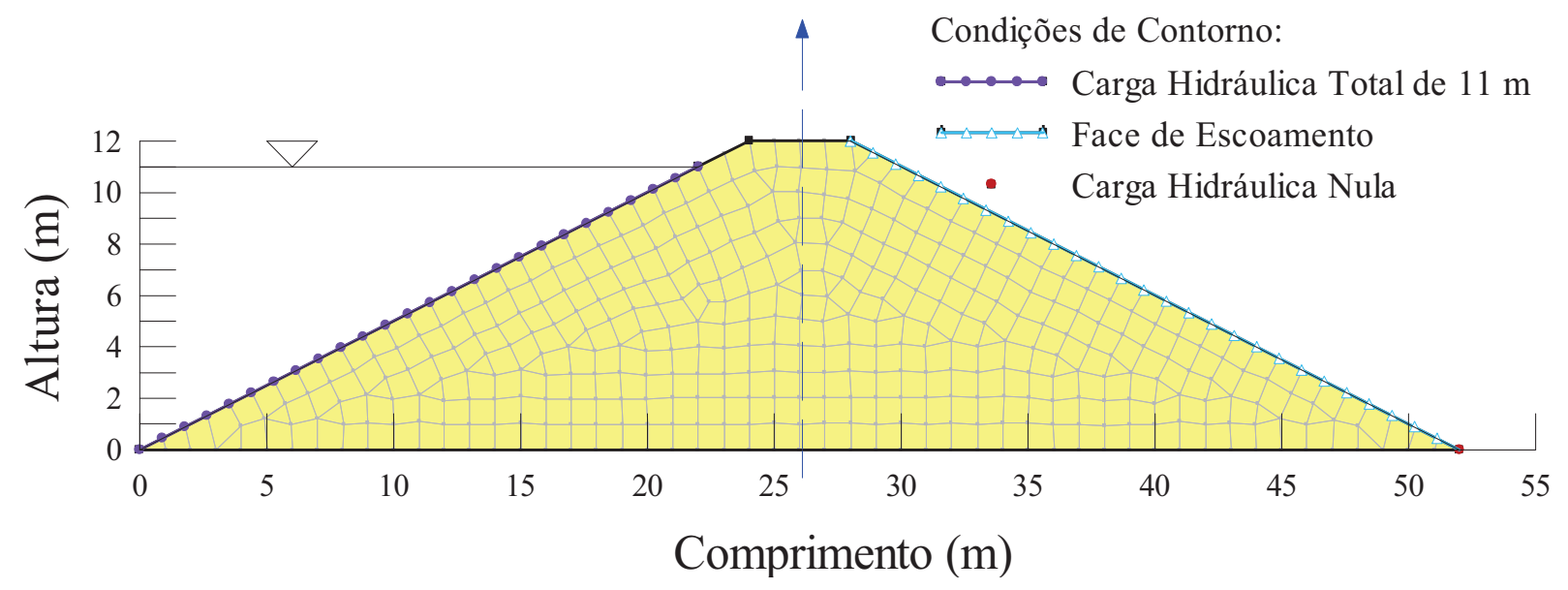

Figura 2.12 - Esquema de uma barragem de terra ao fim da definição do problema (SEEP/W DEFINE).

\subsubsection{Resolução do Problema por Processo Iterativo (SEEP/W SOLVE) e Visualização dos Resultados (SEEP/W CONTOUR)}

O SEEP/W SOLVE soluciona a Equação de Richards numericamente, a partir das características geométricas, das especificações dos materiais, das condições de contorno e da discretização do problema, anteriormente definidas no SEEP/W DEFINE. Em seguida, é mostrada sucintamente a forma como a Equação de Richards é resolvida do SEEP/W SOLVE. Tal processo pode ser apreciado detalhadamente em GEOSTUDIO (2004).

A solução parte da Equação de Richards para o fluxo em duas dimensões, análoga a Equação (2.35) já apresentada, expressa como:

$$
\frac{\partial \theta}{\partial t}=\frac{\partial}{\partial x}\left[k(\theta) \cdot \frac{\partial \psi}{\partial x}\right]+\frac{\partial}{\partial y}\left[k(\theta) \cdot \frac{\partial \psi}{\partial y}\right]+F_{C}
$$

em que: $F_{C}$ é o fluxo externo aplicado na fronteira, ao elemento de solo.

O SEEP/W é formulado para condições de tensão total constante. Ainda, é assumido no SEEP/W que a pressão do ar presente nos poros do solo - durante os processos de fluxo transiente - permanece constante e igual à pressão atmosférica. Logo, a variável de estado $\left(\sigma-u_{a}\right)$ permanece constante e não influencia na variação da umidade volumétrica do solo. 
As alterações na umidade volumétrica do solo são, consequentemente, dependentes apenas das variações na variável de estado $\left(u_{a}-u_{w}\right)$. Esta, por sua vez, depende apenas da variação de $u_{w}$, já que $u_{a}$ permanece constante durante todo processo (GEOSTUDIO, 2004). Assim, no SEEP/W a variação do teor de umidade volumétrica de um solo é função da variação da pressão da água no solo:

$$
\partial \theta=m_{w} \cdot \partial u_{w}
$$

em que: $m_{w}$ é a inclinação da curva de retenção de água do solo entre dois pontos quaisquer (ver a Figura 2.13).

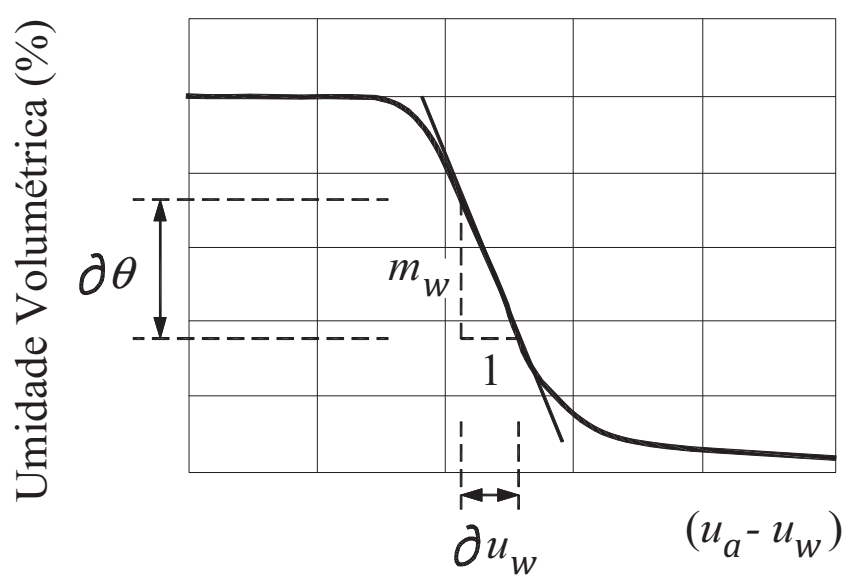

Figura 2.13 - Termo $m_{w}$ da curva de retenção de água do solo.

A carga hidráulica total é definida por:

$$
\psi=\frac{u_{w}}{\gamma_{w}}+\psi_{z}
$$

que pode ser reescrita como:

$$
u_{w}=\gamma_{w} \cdot\left(\psi-\psi_{z}\right)
$$

em que $\gamma_{w}$ é o peso específico da água $\left[\mathrm{FL}^{-3}\right]$.

Substituindo-se a Equação (2.62) na Equação (2.60) e esta, por sua vez, na Equação (2.59), obtém-se:

$$
m_{w} \gamma_{w} \frac{\partial\left(\psi-\psi_{z}\right)}{\partial t}=\frac{\partial}{\partial x}\left[k(\theta) \frac{\partial \psi}{\partial x}\right]+\frac{\partial}{\partial y}\left[k(\theta) \frac{\partial \psi}{\partial y}\right]+F_{C}
$$

Sabendo-se que o potencial gravitacional $\psi_{z}$ é constante, sua derivada ao longo do tempo é nula. Assim, obtém-se a formulação, empregada no SEEP/W, da equação diferencial do fluxo de água no solo, que é resolvida por elementos finitos. 


$$
m_{w} \gamma_{w} \frac{\partial \psi}{\partial t}=\frac{\partial}{\partial x}\left[k(\theta) \frac{\partial \psi}{\partial x}\right]+\frac{\partial}{\partial y}\left[k(\theta) \frac{\partial \psi}{\partial y}\right]+F_{C}
$$

Nas análises de fluxo em meios porosos, o SEEP/W SOLVE aplica a equação geral do elemento finito para a análise de fluxo transiente. A obtenção desta equação geral é realizada a partir da Equação (2.64) com o emprego do Método dos Resíduos Ponderados de Galerkin. Para casos de fluxo transiente o SEEP/W promove a integração temporal da equação geral do elemento finito para a análise de fluxo transiente. Para a solução da equação, resultante da integração temporal, é necessário que se conheça a carga hidráulica inicial de um determinado elemento no início de um determinado incremento de tempo, para que se possa obter a carga hidráulica ao final deste incremento de tempo. Em seguida, o SEEP/W SOLVE realiza a integração numérica Gaussiana, sendo que tal integração é avaliada pela amostragem das propriedades do elemento em pontos definidos especificamente, e depois somadas para todo o elemento (GEOSTUDIO, 2004).

Finalmente, os resultados são apresentados ao usuário do programa no SEEP/W CONTOUR. Nesta etapa, pode-se visualizar a solução final por meio do próprio esquema gráfico do problema (determinado no SEEP/W DEFINE), gráficos, tabelas de valores, superfícies freáticas, entre outras formas de apresentação.

A Figura 2.14 apresenta a visualização da solução final do problema de fluxo permanente através de uma barragem de terra, apresentada na subseção 2.4.3.2 (Figura 2.12). Tal visualização é possível no SEEP/W CONTOUR, após a solução numérica do problema no SEEP/W SOLVE.

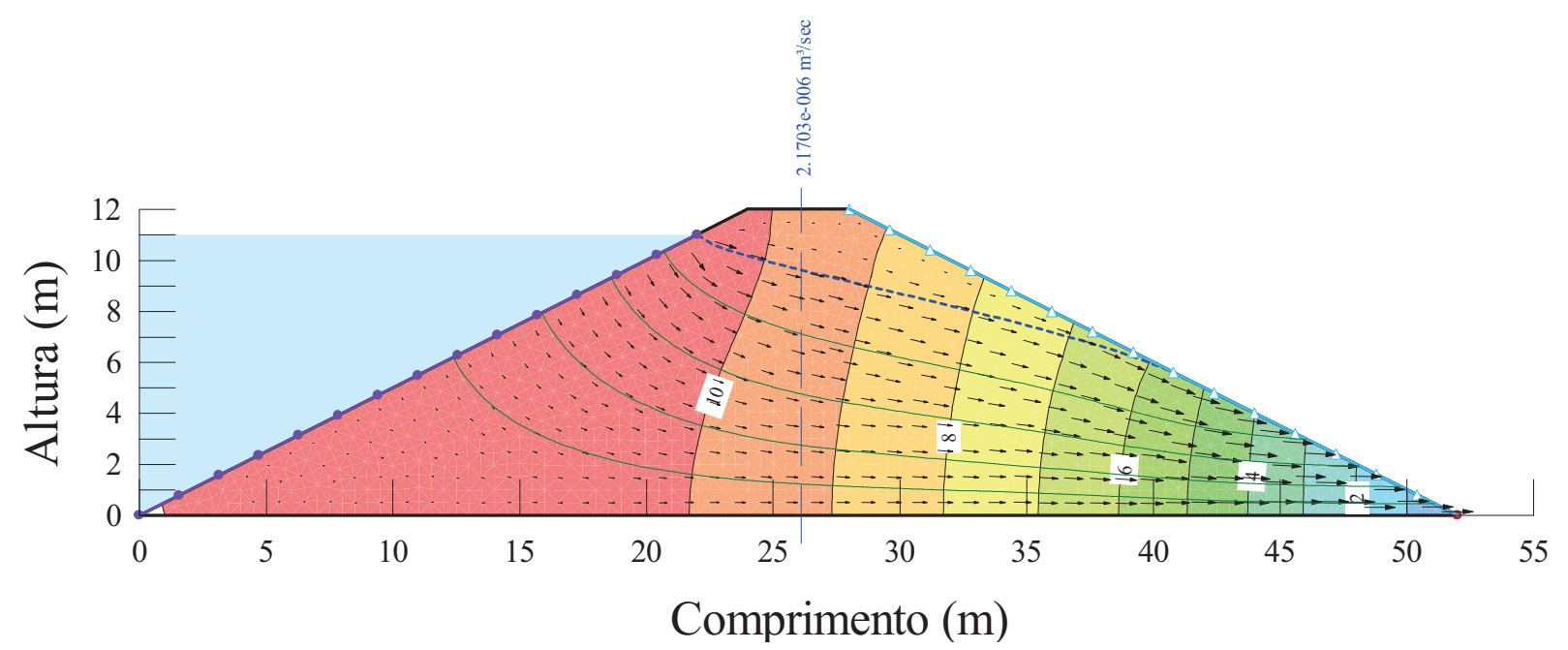

Figura 2.14 - Visualização final da solução de um problema de fluxo permanente em uma barragem de terra (SEEP/W COUNTOUR). 


\subsection{Soluções Práticas de Drenagem Urbana com Uso de Técnicas de Infiltração}

Aravena \& Dussaillant (2009) afirmam que as práticas de infiltração são uma excelente alternativa para a drenagem urbana, por permitirem uma abordagem descentralizada da mesma. Tais práticas permitem a redução da necessidade da construção de grandes e caras estruturas de drenagem à jusante das fontes produtoras do escoamento superficial. O baixo custo aliado à possibilidade de reter o escoamento das águas pluviais na própria fonte geradora faz com que as técnicas de infiltração despontem como soluções atraentes do ponto de vista técnico e financeiro. Desse modo, esta seção se dispõe a apresentar algumas soluções práticas de drenagem urbana que empregam técnicas de infiltração.

\subsubsection{Jardim de Infiltração (Rain Garden)}

As práticas de infiltração, tais como jardins de infiltração, oferecem uma abordagem potencialmente eficaz para lidar com o esgotamento das águas pluviais. Um jardim de infiltração é um jardim paisagístico localizado em uma depressão, que recebe as águas pluviais das superfícies impermeáveis em suas proximidades (ARAVENA \& DUSSAILLANT, 2009). Este tipo de jardim é geralmente composto por uma camada inicial de solo que possibilita o desenvolvimento da vegetação, seguida de uma camada de material granular que atua como uma zona de armazenamento de água. A Figura 2.15 apresenta um diagrama conceitual de um jardim de infiltração e do seu funcionamento.

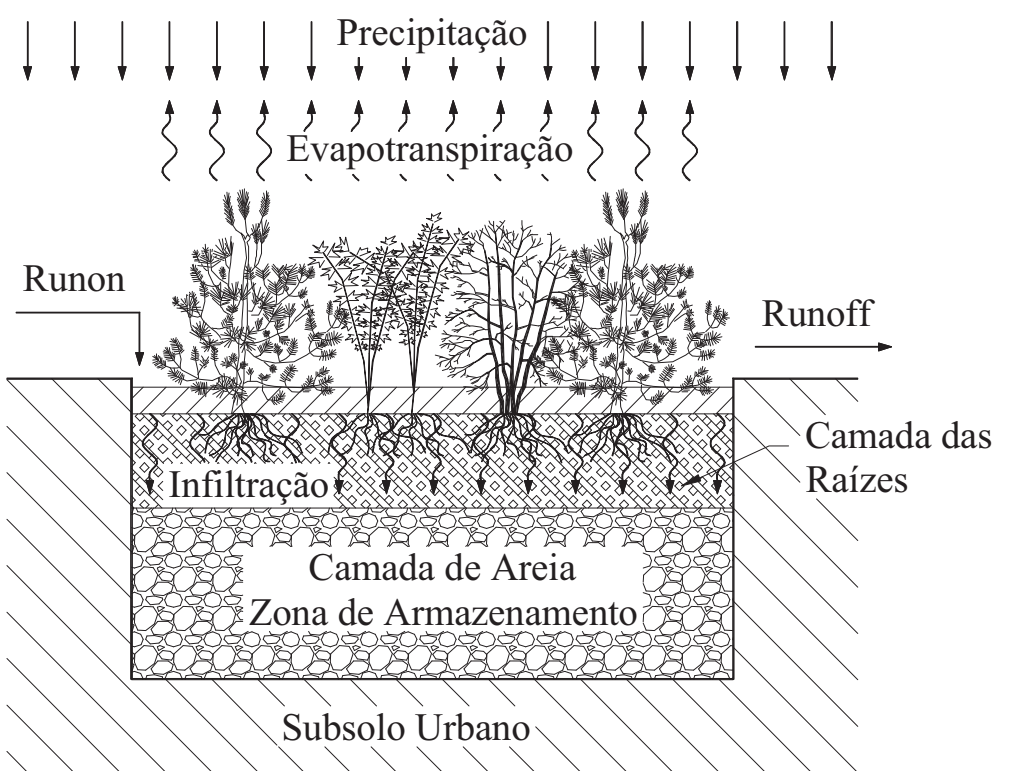

Figura 2.15 - Diagrama conceitual de um jardim de infiltração (modificado de ARAVENA \& DUSSAILLANT, 2009). 
Dussaillant et al. (2004) desenvolveram um modelo numérico focado na recarga de águas subterrâneas, chamado de RECHARGE, que pode ser aplicado no projeto e avaliação de jardins de infiltração. O modelo é baseado na equação de Richards e inclui os processos mais relevantes de interceptação e armazenamento, de infiltração da água precipitada sobre uma ou mais superfícies impermeáveis, da formação da lâmina de água e infiltração através das camadas do solo e da evapotranspiração. Tais processos são avaliados de um modo contínuo, em que as simulações das águas de superfície e do fluxo de água no solo são acopladas.

Para a validação do modelo RECHARGE, Dussaillant et al. (2004) modelaram uma série de frentes de umedecimento a partir das condições iniciais verificadas nos experimentos de Celia et al. ${ }^{7}$ (1990). As frentes de umedecimento modeladas por Dussaillant et al. (2004) se ajustaram perfeitamente às obtidas experimentalmente por Celia et al. ${ }^{7}$ (1990). Ainda, Dussaillant et al. (2004) puderam concluir que o emprego de jardins de infiltração, para fins de recarga de aquífero - para as condições climáticas da cidade de Madison no estado de Wisconsin nos Estados Unidos -, pode ser otimizado nos seguintes casos: (1) para jardins com área em planta de 10 a 20\% da área impermeável que é drenada para o mesmo, (2) para maiores profundidades de depressão da superfície do jardim e (3) para camadas de solo abaixo da zona de armazenamento (material granular) com altos valores de condutividade hidráulica saturada.

Asleson et al. (2009) desenvolveram três aproximações para a avaliação do desempenho de jardins de infiltração: inspeção visual, teste da taxa de infiltração, e teste sintético de rebaixamento. As inspeções visuais da vegetação e do solo de um jardim de infiltração forneceram uma indicação preliminar da capacidade do mesmo em infiltrar a água escoada. $\mathrm{O}$ teste de taxa de infiltração apresentou informações sobre a variabilidade espacial de $k_{s}$ e uma estimativa do tempo de drenagem geral do jardim da infiltração. Este teste se mostrou útil na identificação de pontos específicos que devem receber serviços de manutenção, e na garantia da correta construção do jardim. Através do teste sintético de rebaixamento, Asleson et al. (2009) puderam medir o tempo de drenagem, rapidamente e com pouco esforço, quando a disponibilidade de água foi o suficiente para encher a bacia e determinar um tempo de drenagem. Tal condição restringiu este teste a jardins de infiltração com áreas em planta menores que $80 \mathrm{~m}^{2}$. Finalmente, Asleson et al. (2009) concluíram que a

\footnotetext{
${ }^{7}$ CEliA, M. A.; BOUloutAS, E. T.; ZARBA, R. L. (1990). A General Mass-Conservative NumericalSolution for the Unsaturated Flow Equation. Water Resources Research, v.26, n.7, p.1483-1496.
} 
avaliação dos jardins de infiltração em vários níveis permite a identificação de problemas nos mesmos, as potenciais causas e as possíveis soluções.

\subsubsection{Pavimento Permeável}

O princípio geral dos pavimentos permeáveis é simplesmente recolher, tratar e permitir a livre infiltração de qualquer escoamento superficial, em apoio à recarga dos aquíferos. Em comparação aos sistemas tradicionais de drenagem, a retenção de águas pluviais e sua infiltração é um processo barato, eficaz, sustentável e é apropriado para áreas urbanas. Além disso, os pavimentos permeáveis apresentam vários benefícios como a redução do escoamento superficial, a recarga das águas subterrâneas, a economia de água através da reciclagem e a prevenção da poluição. Embora os pavimentos permeáveis sejam adequados para uma grande variedade de edifícios residenciais, comerciais e aplicações industriais, o seu uso ainda é pouco freqüente (SCHOLZ \& GRABOWLECKI, 2007).

Os pavimentos permeáveis podem ser superfícies segmentadas e perfuradas (piso de bloco de concreto vazado) ou contínuas e porosas (asfalto ou concreto porosos) que permitem parte da infiltração da água no solo. A Figura 2.16 esquematiza os dois tipos de pavimentos permeáveis.

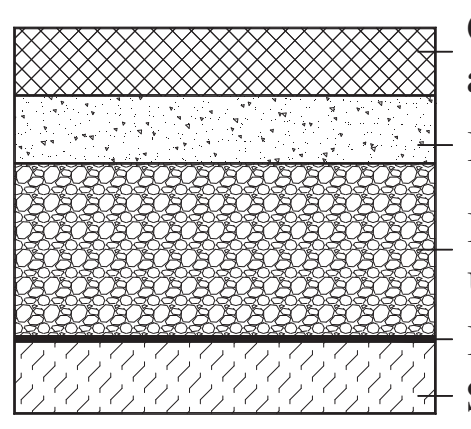

(a)

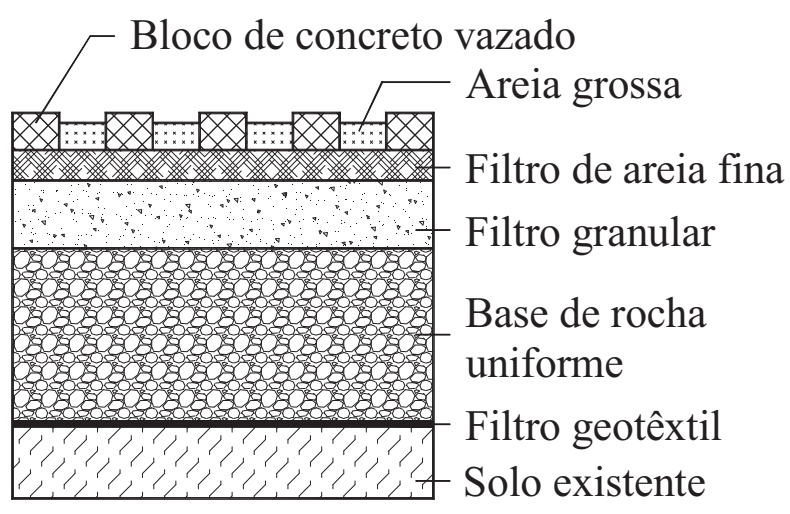

(b)

Figura 2.16 - Corte com descrição das camadas dos pavimentos permeáveis. (a) Concreto ou asfalto porosos; (b) Piso de bloco de concreto vazado. (URBONAS \& STAHRE $^{8}, 1993$ apud ARAÚJO et al., 2000).

Nos pavimentos permeáveis, o escoamento infiltra rapidamente através do revestimento, com espessura entre 5 e $10 \mathrm{~cm}$, passa por um filtro de agregado com aproximadamente $2,5 \mathrm{~cm}$ de espessura e com agregados de $1,25 \mathrm{~cm}$ de diâmetro. $\mathrm{O}$

\footnotetext{
${ }^{8}$ URBOnAS, B.; STAHRE, P. (1993). Stormwater Best Management Practices and Detention. New Jersey: Prentice-Hall, Englewood Cliffs, 1993. 450 pp.
} 
escoamento segue para um reservatório, ou base de rocha uniforme, com agregados de 3,8 a $7,6 \mathrm{~cm}$ de diâmetro. $\mathrm{O}$ revestimento permeável somente age como um conduto rápido para o escoamento chegar à base de rocha (reservatório). A água armazenada no reservatório poderá então ser infiltrada para o subsolo ou ser coletada por tubos de drenagem. Em termos gerais, a capacidade de armazenamento dos pavimentos permeáveis é determinada pela soma entre o volume de água que pode ser retido na base de rocha e o volume que é infiltrado no subsolo, durante o evento de precipitação (ARAÚJO et al., 2000).

Brattebo \& Booth (2003) examinaram a eficácia, em longo prazo, de quatro sistemas de pavimentos permeáveis disponíveis comercialmente, como uma alternativa ao asfalto tradicional (impermeável) em uma área de estacionamento. Os sistemas foram avaliados, após 6 anos de uso diário do estacionamento, em relação à durabilidade estrutural, à capacidade de infiltração da água precipitada, e aos impactos sobre a qualidade da água infiltrada. Todos os quatro sistemas de pavimento permeável não mostraram sinais de grande desgaste. Os pavimentos, praticamente não perderam rendimento em relação à infiltração, já que o escoamento superficial gerado, após os 6 anos de uso, continuou insignificante. O nível de contaminação das águas infiltradas, em todos os sistemas de pavimento permeável, se mostrou significantemente mais baixos que o das águas escoadas superficialmente.

\subsubsection{Trincheiras de Infiltração}

As trincheiras de infiltração, assim como as demais soluções apresentadas, são elementos de drenagem do tipo controle na fonte e o seu funcionamento possibilita o armazenamento temporário da água até que ela se infiltre no solo, permitindo a redução dos volumes escoados e das vazões máximas nas calhas dos rios. Quanto à geometria e composição das trincheiras de infiltração, Lima (2009, p.35-36) as conceitua como

[...] dispositivos lineares que apresentam largura e profundidade reduzidas em contraposição às dimensões longitudinais. São constituídos por valetas preenchidas ou não por material granular graúdo (seixo rolado, brita, etc.) com porosidade em torno de 30 a $40 \%$. No fundo, nos lados e na superfície acima do material de preenchimento são dispostos manta de geotêxtil com o objetivo de impedir a entrada de material fino na estrutura, diminuindo o risco de colmatação (obstrução por material fino) precoce e podendo ainda trabalhar como filtro anticontaminante. Sua alimentação pode ser efetuada diretamente ou através de tubulação perfurada implantada ao longo do seu comprimento. 
A Figura 2.17 apresenta um esquema típico de uma trincheira de infiltração que é abastecida por água através do tubo coletor das calhas e do escoamento superficial no seu entorno. O poço de inspeção é munido de um tubo de extravasamento, ligado à rede de drenagem urbana, que se encontra em cota igual à da saída do tubo coletor das calhas e superior à do tubo de saída para a trincheira.

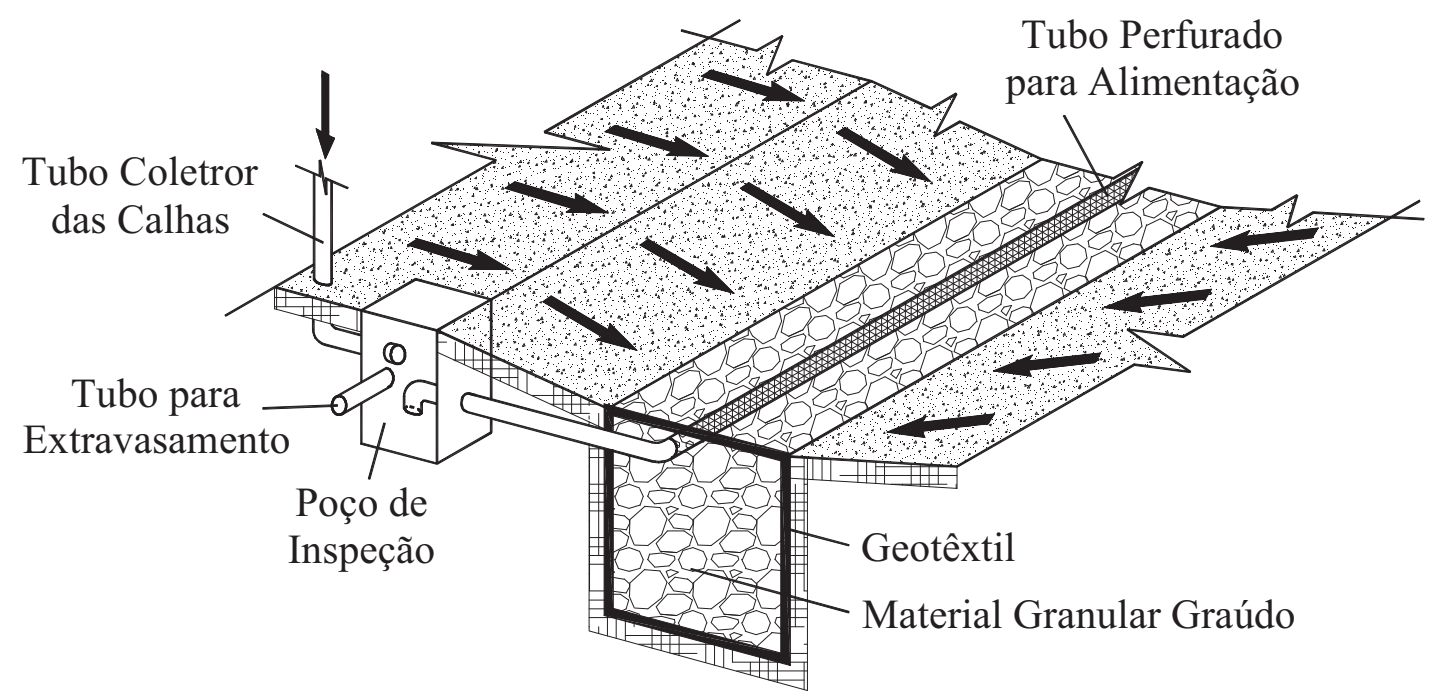

Figura 2.17 - Esquema típico de uma trincheira de infiltração.

Souza (2002) analisou o comportamento de duas trincheiras de infiltração instaladas e monitoradas em uma área do IPH-UFRGS. Os métodos construtivos e materiais utilizados, assim como aos métodos e critérios de utilização e dimensionamento, foram baseados na adaptação, para as condições brasileiras, das técnicas descritas na literatura. Ambas as trincheiras foram dimensionadas pelo "rain-envelope-method", que se baseia na idéia de que o volume do dispositivo (trincheira) deverá ser suficiente para armazenar a máxima diferença entre os volumes acumulados de entrada e de saída (considerando-se a porosidade do material de preenchimento).

Durante o período de monitoramento (33 meses para uma das trincheiras e 6 meses para a outra), as duas trincheiras mostraram-se eficientes, controlando todo o volume escoado, mesmo para eventos de chuva com períodos de retorno superiores aos de projeto. As análises de Souza (2002), o permitiram concluir que a metodologia de projeto empregada ("rainenvelope-method") gera superdimensionamento das estruturas e que as condições iniciais de umidade do solo e as características dos eventos são fatores determinantes para seu funcionamento. 
Assim como Souza (2002), Graciosa (2005) promoveu ensaios de campo em duas trincheiras de infiltração. Uma delas executada em solo arenoso e a outra em solo argiloso, típicos da cidade de São Carlos - SP, com o objetivo de avaliar quantitativamente o comportamento hidráulico das mesmas em resposta a volumes de escoamento controlados. A variação de umidade do experimento foi monitorada com sonda de nêutrons, durante o processo de redistribuição da água no solo. Em paralelo, as duas trincheiras e suas condições, em cada um dos ensaios realizados, foram modelas matematicamente através do software BidiSul - adaptado pela autora e desenvolvido pelo Departamento de Engenharia Rural do Instituto Superior de Agronomia da Universidade Técnica de Lisboa -, que soluciona a Equação de Richards para o fluxo bidimensional com base na função condutividade hidráulica proposta por van Genuchten (1980) (Equação (2.8)).

As capacidades de infiltração das trincheiras experimentais foram um pouco superiores às das trincheiras modeladas. Possivelmente, segundo Graciosa (2005), a ocorrência de tal fato se deveu à simplificação de distribuição unimodal dos diâmetros dos poros, adotada na modelagem, já que experimentalmente, a distribuição observada foi multimodal. Ainda, Graciosa (2005) apresentou um estudo simplificado do impacto do uso de uma trincheira de infiltração em cada um dos lotes de uma microbacia urbana hipotética de $180.000 \mathrm{~m}^{2}$, composta por 12 quarteirões residenciais. Este estudo se baseou no método racional na determinação das vazões e na equação de Philip (1957a) (Equação (2.58)) para o cálculo dos volumes infiltrados. A estimativa de redução no escoamento gerado pela microbacia, devido ao uso de trincheiras nos lotes e analisando-se os dois tipos de solos, foi da ordem de 60 a $65 \%$ para um período de retorno de 2 anos, e de 48 a 53\% para 5 anos.

\subsubsection{Poços de Infiltração}

O uso de poços de infiltração é uma solução de drenagem de águas pluviais na fonte geradora, sendo que parte ou toda a água da chuva captada pelo lote é lançada em um poço de inspeção, e então é conduzida ao poço de infiltração. Somente após a redução da capacidade de absorção do solo que envolve o poço e do enchimento deste, a água passa a ser escoada para o sistema público de drenagem, através de um tubo de extravasamento localizado no poço de inspeção (REIS et al., 2005).

Basicamente, existem dois tipos de poços de infiltração, que são os revestidos e os não revestidos. Durante a construção dos mesmos, apenas a fase de escavação do poço é comum a ambos. O primeiro tipo, segundo Reis et al. (2008) pode ser revestido por tubos de concreto 
perfurados ou tijolos assentados em crivo, envoltos por uma manta geotêxtil fazendo a interface solo/tubo, e o fundo deve ser revestido por uma camada de agregados graúdos, também envolta por geotêxtil, de forma a permitir a infiltração, para o solo, do volume de água pluvial escoado para o seu interior. Os poços não revestidos devem ser cobertos por manta geotêxtil e preenchidos por material granular graúdo (geralmente, matacão e pedra-demão), de modo a conferir estabilidade às paredes da escavação. A Figura 2.18 mostra os dois tipos de poços descritos.

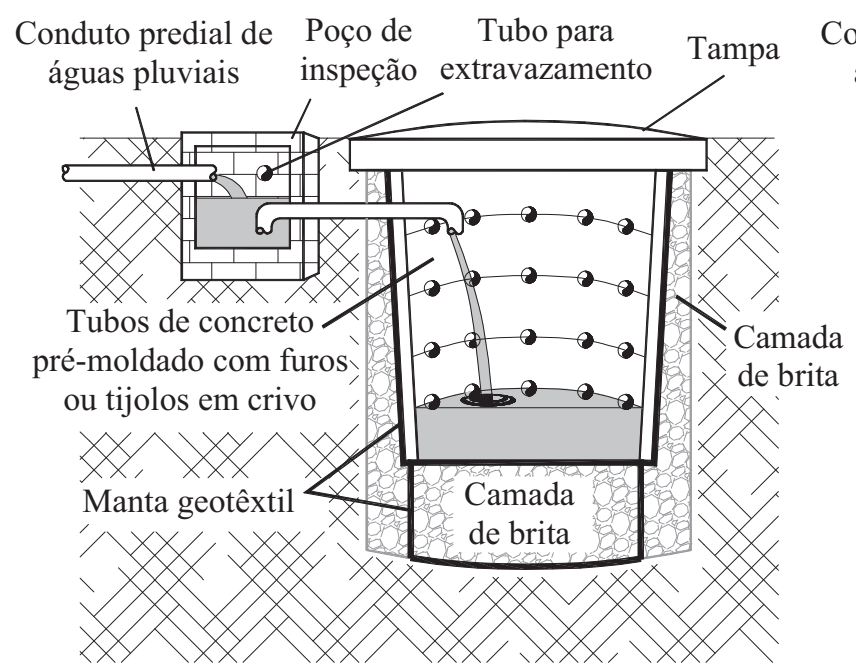

(a)

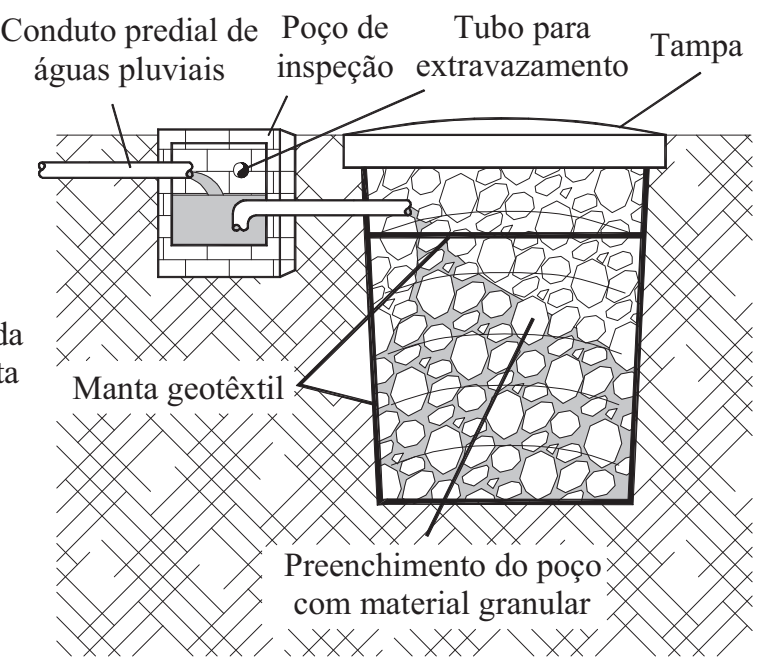

(b)

Figura 2.18 - Esquema dos poços de infiltração. (a) Poço de infiltração revestido (modificado de REIS et al., 2005); (b) Poço de infiltração não revestido (modificado de SOUZA, 2002).

Reis et al. (2008) monitoraram por 10 meses um poço de infiltração semelhante ao da Figura 2.18(a), instalado em uma areia argilosa (solo local) com 1,10 m de diâmetro e 1,30 m de profundidade, que recebia água de uma área de telhados de 107,5 $\mathrm{m}^{2}$. Os autores observaram que, durante a realização dos ensaios de permeabilidade, o poço revestido apresentou um desempenho na capacidade de infiltração de água de chuva de 4 a 19 vezes superior que a de um poço de comparação sem revestimento e escavado a trado, com a mesma profundidade. Ao fim do período de avaliação foi observado que a manta geotêxtil, que revestia a camada de brita do fundo do poço de infiltração, sofreu um processo de colmatação, acarretando uma diminuição de aproximadamente $32 \%$ na sua capacidade de vazão. Apesar deste inconveniente, a capacidade de vazão remanescente na manta geotêxtil ainda continuou superior à capacidade de infiltração do solo na região de instalação do poço de infiltração.

Quanto ao dimensionamento criterioso de um sistema de infiltração de águas pluviais, Reis et al. (2008) salientam que é imprescindível a determinação de parâmetros locais, tais 
como potencial de colapsibilidade do solo, nível do lençol freático, índices pluviométricos regionais, taxa de infiltração, tempo de esgotamento, entre outros. Os autores ressaltam que os poços de infiltração de águas pluviais são soluções que complementam os sistemas de drenagem urbana, e que esses sistemas não têm o compromisso de controle total do escoamento superficial, podendo ocorrer extravasamentos para o sistema público.

Comparado às demais soluções de drenagem na fonte, o poço de infiltração é a solução que mais carece de pesquisas e que possui a vantagem imprescindível de ser uma solução pontual, pois requer uma área bastante pequena e por isso pode ser empregado nos lotes densamente impermeabilizados, dos grandes aglomerados urbanos. 


\section{MATERIAIS E MÉTODOS}

As análises realizadas neste trabalho não contemplam possíveis problemas oriundos da infiltração da água no solo, como o transporte de contaminantes e a ocorrência de recalques de fundações em solos colapsíveis. Ainda, as análises aqui realizadas não avaliam os efeitos de particularidades do processo de infiltração, tais como a infiltração em "fingers", a presença de macroporos e fendas e tampouco leva em consideração a influência das variações de temperatura do solo e da água no processo de infiltração.

\subsection{Geometria dos Poços e Domínios de Referência}

Para a realização das análises paramétricas foram modelados, no SEEP/W (GEOSTUDIO, 2004), poços cilíndricos sem revestimento e sem preenchimento com material granular graúdo, com oito combinações de diâmetros $(d)$ e profundidades $(h)$ distintas, as quais são apresentadas na Tabela 3.1.

Tabela 3.1 - Geometria dos poços de infiltração.

\begin{tabular}{lcccccccc}
\hline \multicolumn{10}{c}{ Poços de Infiltração } \\
\hline Nome & P1 & P2 & P3 & P4 & P5 & P6 & P7 & P8 \\
$d(\mathrm{~m})$ & 0,25 & 0,25 & 0,50 & 0,50 & 1,00 & 1,00 & 2,00 & 2,00 \\
$h(\mathrm{~m})$ & 1,00 & 2,50 & 1,00 & 2,50 & 1,00 & 2,50 & 1,00 & 2,50 \\
\hline
\end{tabular}

Todos os poços foram modelados no software SEEP/W do pacote GeoStudio 2004 com uma análise axissimétrica, assim a simulação tridimensional dos poços foi definida em uma seção bidimensional simétrica em relação ao eixo dos mesmos. Para que as vazões de água infiltrada através da área lateral do poço (paredes e base) fossem computadas automaticamente no SEEP/W, foi atribuída uma espessura de $2 \pi$ aos elementos discretizados.

Cada um dos poços foi definido em um domínio de referência, no qual foram inseridas as seguintes informações: características geométricas dos poços, regiões que subdividem o domínio, elementos que compõem as regiões, características do solo que compõe o domínio e condições de contorno que comandam o regime de fluxo. Os domínios de referência possuem $15 \mathrm{~m}$ de profundidade por $12 \mathrm{~m}$ de largura. A Figura 3.1 apresenta um domínio típico de referência axisimétrico em relação ao eixo vertical que passa pela coordenada $x$ igual à zero. Vale ressaltar que esta é uma figura esquemática e que $h$ e $d / 2$ representam um dado poço inserido neste domínio. 
Todos os poços foram modelados em uma região dos seus respectivos domínios de 5 $\mathrm{m}$ de largura por $5 \mathrm{~m}$ de profundidade, discretizada em malha quadrada com elementos de $12,5 \mathrm{~cm}$ de lado. As demais regiões do domínio foram discretizadas em elementos quadriláteros, com dimensões variáveis, sendo que o maior elemento possui lados de 50×25 $\mathrm{cm}$. Os elementos da última coluna à direita na Figura 3.1 foram definidos como elementos infinitos, de modo a simular a continuidade do meio horizontalmente.

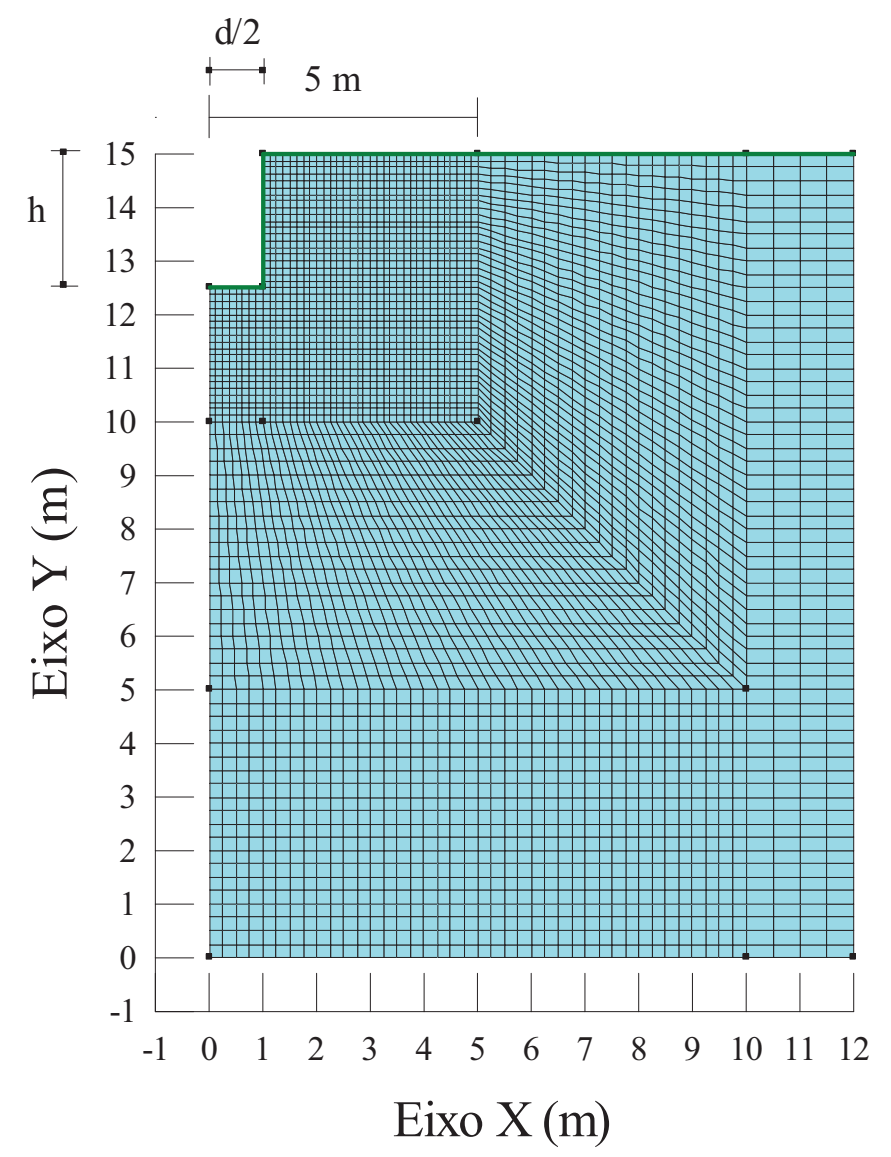

Figura 3.1 - Domínio de referência típico ( $d$ e $h$ variam de acordo com cada poço).

\subsection{Condições de Contorno Iniciais - Fluxo Permanente}

Em todos os domínios o nível freático foi considerado inicialmente a $10 \mathrm{~m}$ de profundidade, em relação à superfície. O perfil inicial de distribuição de pressões na água foi considerado com $-50 \mathrm{kPa}$ na superfície do terreno, tal qual utilizado por Santos (2004) e verificado por Calle (2000) na região de São Carlos-SP, pressão esta que se estende até $5 \mathrm{~m}$ de profundidade (cota de $10 \mathrm{~m}$ no Eixo Y). Abaixo desta profundidade, a pressão reduz-se linearmente até chegar à zero na superfície freática. A Figura 3.2 ilustra a distribuição inicial 
de pressões na água. Abaixo das bases dos poços, a altura do trecho correspondente à pressão de $-50 \mathrm{kPa}$ será de $5 \mathrm{~m}-\mathrm{h}(\mathrm{m})$.

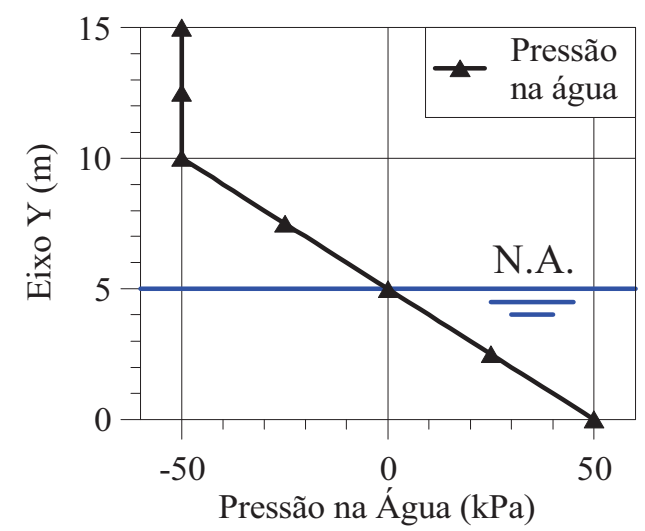

Figura 3.2 - Perfil inicial de distribuição de pressões na água contida no solo, em todas as análises.

\subsection{Características dos Solos que Compõem os Domínios.}

Em todas as análises realizadas neste trabalho, os domínios de referência foram considerados como sendo compostos por um único tipo de solo, homogêneo e isotrópico. As análises foram desenvolvidas basicamente em duas etapas. A primeira delas trata da realização de análises paramétricas da influência das características dos solos nos quais os poços estão inseridos, de modo a avaliar o desempenho dos mesmos quanto à infiltração de água. A outra etapa apresenta uma técnica de dimensionamento de poços de infiltração para fins de drenagem urbana.

\subsubsection{Solos Empregados nas Análises Paramétricas}

As curvas de retenção de água e as funções condutividade hidráulica dos solos empregados nas análises paramétricas são apresentados na Figura 3.3. A Tabela 3.2 apresenta os parâmetros dos solos para o ajuste das curvas de retenção conforme a Equação (2.6) proposta por Fredlund \& Xing (1994) e os coeficientes de condutividade hidráulica saturada dos mesmos. As análises paramétricas são baseadas no solo C (areia argilo siltosa) que foi caracterizado por Calle (2000) e trata-se de um solo típico de vastas áreas do Estado de São Paulo, com limite de liquidez $\left(w_{L}\right)$ de $34 \%$, limite de plasticidade $\left(w_{P}\right)$ de $22 \%$, porosidade $(n)$ de $55 \%$ e grau de saturação $\left(S_{R}\right)$ de $52,1 \%$. No decorrer das análises paramétricas, foram empregadas as funções condutividade hidráulica dos solos A (areia) e B (silte argiloso), sendo que ambos constam no banco de dados do SEEP/W. 


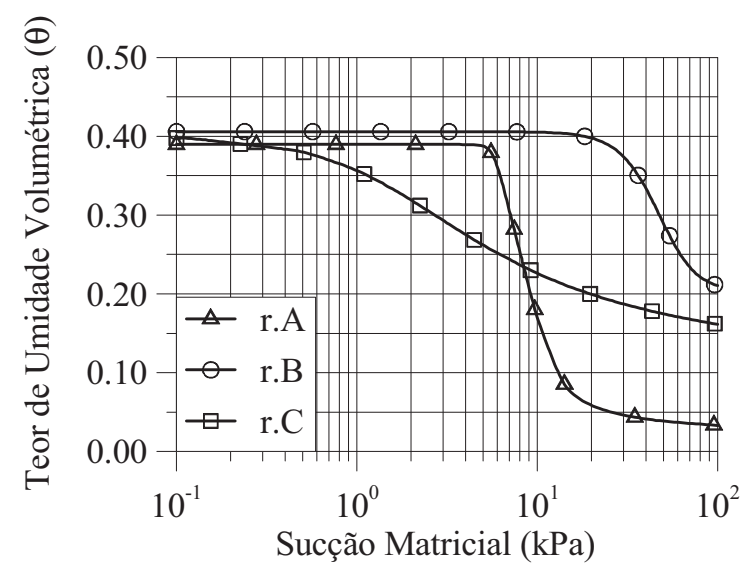

(a)

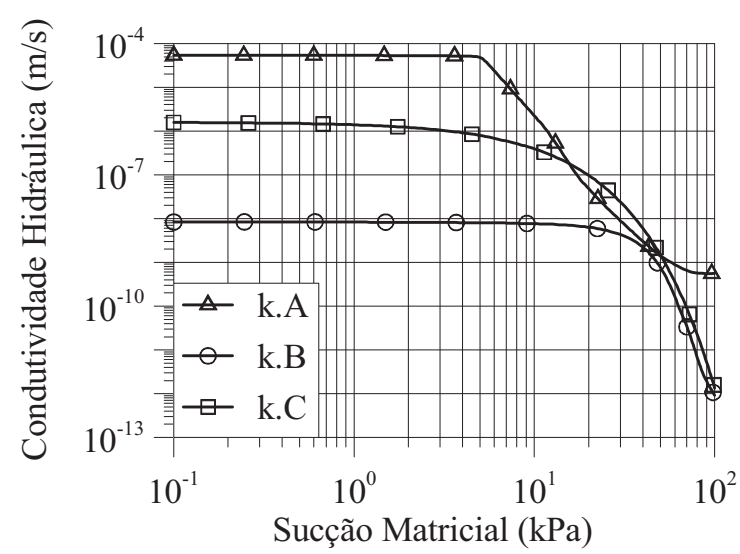

(b)

Figura 3.3 - (a) Curvas de retenção e (b) Funções condutividade hidráulica - Solos A, B e C.

Tabela 3.2 - Parâmetros das curvas de retenção e condutividades hidráulicas saturadas - Solos A, B e C.

\begin{tabular}{ccccccc}
\hline \multicolumn{7}{c}{ Parâmetros - Fredlund \& Xing (1994) } \\
Solos & $\theta_{s}\left(\mathrm{~m}^{3} / \mathrm{m}^{3}\right)$ & $\theta_{r}\left(\mathrm{~m}^{3} / \mathrm{m}^{3}\right)$ & $a(\mathrm{kPa})$ & $n$ & $m$ & $k_{\mathrm{s}}(\mathrm{m} / \mathrm{s})$ \\
\hline A & 0,389 & 0,015 & 7,940 & 10,000 & 0,949 & $5,4 \mathrm{E}-5$ \\
B & 0,406 & 0,200 & 49,943 & 3,630 & 3,030 & $8,4 \mathrm{E}-9$ \\
C & 0,400 & 0,042 & 1,278 & 1,351 & 0,618 & $1,6 \mathrm{E}-6$ \\
\hline
\end{tabular}

Todas as análises realizadas tiveram como base de comparação o solo C, por este ser um solo típico de vasta ocorrência na região de São Carlos-SP. Na caracterização de sua função condutividade hidráulica, Calle (2000) usou a Equação (2.9) proposta por Gardner (1958), com o parâmetro $\alpha$ de $0,14 \mathrm{kPa}^{-1}$ e condutividade hidráulica saturada $\left(k_{s}\right)$ apresentada na Tabela 3.2.

No decorrer das análises paramétricas, para que fosse possível o estudo de parâmetros isolados de um determinado tipo de solo, foram criados solos fictícios a partir do solo C. Para efeito de identificação, esses solos serão apresentados com informações da curva de retenção (sigla r.) e da função condutividade hidráulica (sigla k.) adotadas. Por exemplo, um solo fictício com curva de retenção do solo $\mathrm{C}$ e função condutividade hidráulica do solo $\mathrm{A}$ será denominado solo r.C-k.A.

\subsubsection{Solos Empregados na Técnica de Dimensionamento de Poços de Infiltração}

No desenvolvimento da técnica de dimensionamento de poços de infiltração, além dos solos A, B e C, já citados, foram empregados os seguintes solos: solo D (areia uniforme) retirado do banco de dados do SEEP/W e os solos E e F, ambos areias finas argilosas, caracterizadas por Alfaro Soto (1999). As curvas de retenção de água e as funções 
condutividade hidráulica destes solos são apresentados na Figura 3.4. A Tabela 3.3 apresenta os parâmetros dos solos para o ajuste das curvas de retenção conforme a Equação (2.6) proposta por Fredlund \& Xing (1994) e os coeficientes de condutividade hidráulica saturada dos mesmos.

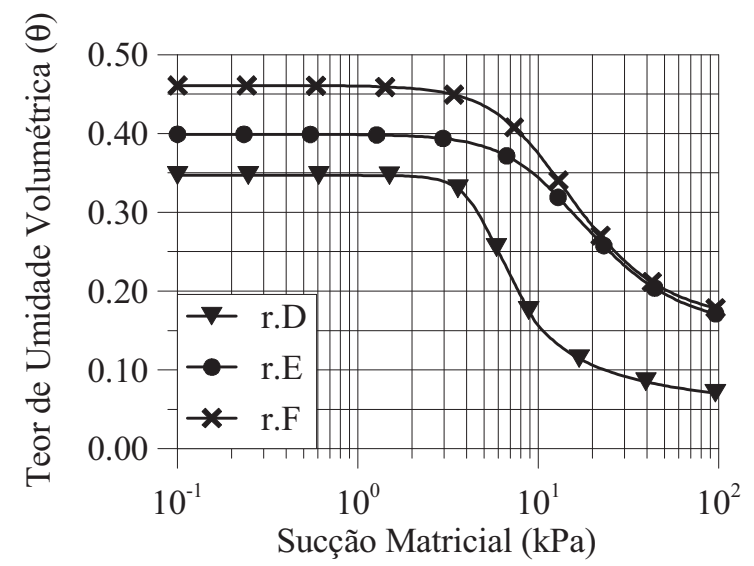

(a)

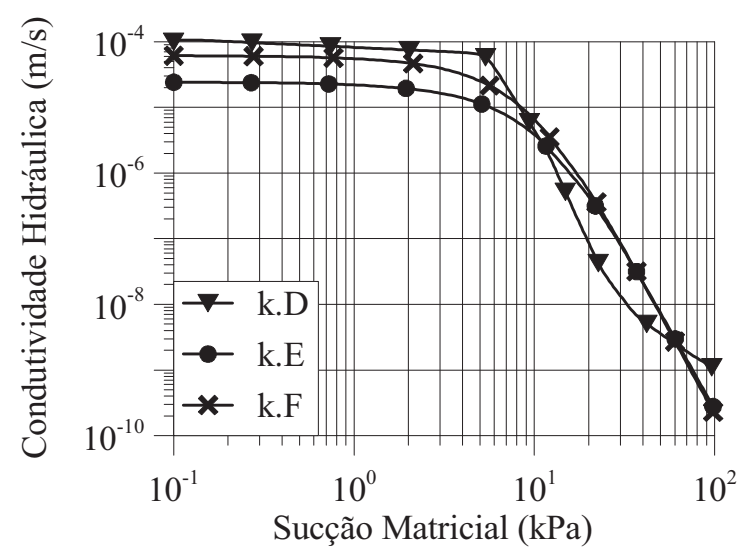

(b)

Figura 3.4 - (a) Curvas de retenção e (b) Funções condutividade hidráulica - Solos D, E e F.

Tabela 3.3 - Parâmetros das curvas de retenção e condutividades hidráulicas saturadas - Solos D, E e F.

\begin{tabular}{ccccccc}
\hline \multicolumn{7}{c}{ Parâmetros - Fredlund \& Xing (1994) } \\
Solos & $\theta_{s}\left(\mathrm{~m}^{3} / \mathrm{m}^{3}\right)$ & $\theta_{r}\left(\mathrm{~m}^{3} / \mathrm{m}^{3}\right)$ & $a(\mathrm{kPa})$ & $n$ & $m$ & $k_{\mathrm{s}}(\mathrm{m} / \mathrm{s})$ \\
\hline $\mathrm{D}$ & 0,347 & 0,015 & 4,854 & 4,839 & 0,670 & $1,0 \mathrm{E}-4$ \\
$\mathrm{E}$ & 0,399 & 0,114 & 12,192 & 2,123 & 1,088 & $2,4 \mathrm{E}-5$ \\
$\mathrm{~F}$ & 0,461 & 0,100 & 9,499 & 2,278 & 0,926 & $6,1 \mathrm{E}-5$ \\
\hline
\end{tabular}

\subsection{Ascensão do Nível de Água no Interior dos Poços}

A taxa de ascensão do nível de água no interior de um poço é função da taxa de precipitação $\left(i_{P}\right)$, da área da região impermeável que se deseja drenar $(A)$, da área da base do poço $\left(A_{b}\right)$, da porosidade $(n)$ do material granular de preenchimento, do coeficiente de condutividade hidráulica saturada do solo $\left(k_{s}\right)$ e da sua sucção matricial. Desta forma, a taxa de ascensão do nível de água em cada configuração de poço que será analisada será diferente, em função das distintas áreas de base e condutividades hidráulicas saturadas dos solos.

De modo a avaliar a variação na taxa de ascensão, foram realizadas análises que permitiram a ascensão do nível de água no poço a uma taxa $i_{A s}$ dada, simplificadamente, pela diferença entre a taxa de abastecimento do poço $i_{A b}$ (aplicada sobre a área da base do mesmo, $A_{b}$ ) e a condutividade hidráulica saturada do solo $k_{s}$ (Equação (3.1)). 


$$
i_{A s}=i_{A b}-k_{s}
$$

Obviamente as taxas de ascensão só foram aplicadas aos poços após o início da geração de lâmina de água nas bases dos mesmos, sendo que neste instante a taxa de infiltração de água no solo $i$, através da área da base do poço, é igual à condutividade hidráulica saturada do solo $k_{s}$. As análises foram levadas até o instante em que os poços tornaram-se completamente cheios por água ( $t_{E}$ - tempo de enchimento) e foram calculados os volumes de água infiltrados $\left(V_{i}\right)$ até este instante.

É importante ressaltar que a taxa de ascensão dada pela Equação (3.1) é uma simplificação da taxa real de ascensão de água em um poço qualquer, pois $i_{A s}$ ainda deve ser abatida da taxa de infiltração de água ao longo das paredes do poço durante a elevação do nível freático no interior do mesmo. Porém, com os recursos disponíveis no SEEP/W, não há como inserir uma condição de contorno que represente a taxa de ascensão de água em um dado poço sem que se faça tal simplificação.

De modo a evitar o uso de distintas taxas de ascensão do nível de água no interior dos poços nas várias análises, admitiu-se que todos os poços são preenchidos por água instantaneamente assim que se inicia o abastecimento dos mesmos. Os efeitos da adoção desta condição são avaliados na subseção 5.1 .

\subsection{Condições de Contorno - Fluxo Transiente}

$\mathrm{Na}$ fase de modelagem do fluxo transiente (infiltração) foi considerado que os poços são preenchidos instantaneamente por água e que o perfil inicial de distribuição de pressões na mesma não se altera em uma seção vertical infinitamente distante do eixo do poço. Assim, as condições de contorno empregadas nesta fase foram de carga hidráulica total $H$ de $15 \mathrm{~m}$ em toda a superfície do poço (poço sempre cheio) e a distribuição de pressões na água tal qual a da Figura 3.2, aplicada na vertical da borda direita da Figura 3.1 adjacente aos elementos infinitos. 


\section{VALIDAÇÃO DO PROGRAMA}

Para efeito de validação do programa SEEP/W (GEOSTUDIO, 2004) e dos métodos empregados na modelagem dos poços, foi reproduzido no SEEP/W um problema proposto, experimentado e modelado por Vauclin et al. (1979) que consiste em um protótipo de recarga de aquífero freático. Nesse experimento, foi preparado um molde de $3 \mathrm{~m}$ de largura, $2 \mathrm{~m}$ de altura e $5 \mathrm{~cm}$ de espessura preenchido por areia fina com massa específica seca de $1,57 \mathrm{~g} / \mathrm{cm}^{3}$, com curva de retenção e função condutividade hidráulica apresentadas na Figura 4.1. O nível freático inicial, em tal molde, estava a uma profundidade de 1,35 m. Durante o ensaio, fez-se infiltrar água a uma taxa de $14,8 \mathrm{~cm} / \mathrm{h}$, em uma faixa de $50 \mathrm{~cm}$ de largura posicionada na parte superior esquerda do molde, enquanto que na lateral direita do mesmo mantinha-se constante o nível freático a 1,35 m de profundidade, a lateral esquerda era impermeável, assim como a base do molde. No decorrer do processo de infiltração as umidades foram medidas por atenuação de raios gama e as cargas hidráulicas por meio de tensiômetros. Ainda, os autores simularam tal experimento numericamente empregando-se a equação da continuidade de Richards (1931).

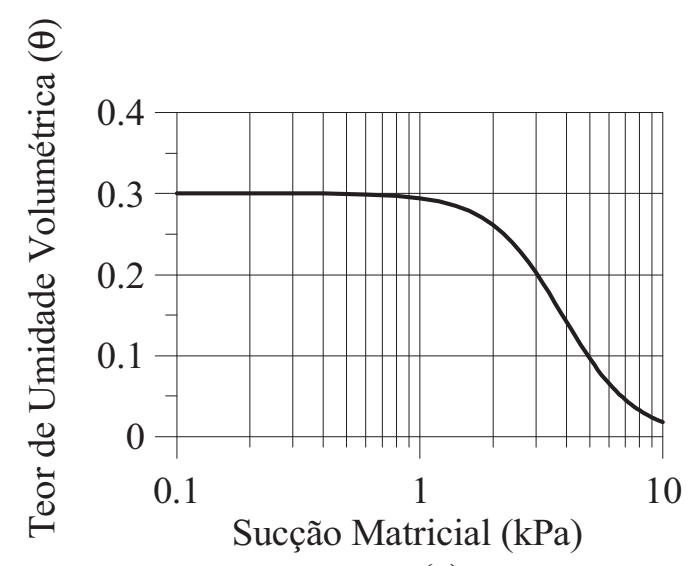

(a)

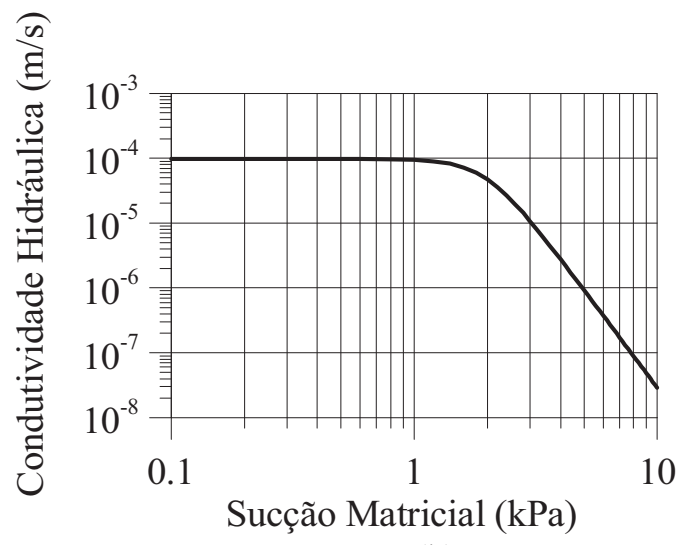

(b)

Figura 4.1 - Propriedades do solo utilizado no experimento de Vauclin et al. (1979). (a) curva de retenção de água e (b) função condutividade hidráulica (modificado de VAUCLIN et al., 1979).

Para a modelação dos resultados experimentais, nesta dissertação o domínio foi discretizado em elementos quadrados de $5 \mathrm{~cm}$ de lado e foi submetido a uma condição estacionária com lençol freático a 1,35 m de profundidade. Em seguida, foram aplicadas as condições de contorno de sorte a permitir a infiltração de água tal qual no experimento.

Dentre os vários resultados obtidos pela modelagem no SEEP/W, a Figura 4.2 apresenta a comparação entre o diagrama de distribuição de cargas totais no perfil de solo, após 8 horas de infiltração, obtido por Vauclin et al. (1979) e o obtido através da modelagem 
no SEEP/W. Percebe-se que não há diferença apreciável entre as Figuras 4.2(a) e (b) em relação à distribuição das cargas totais, situação que se repetiu para vários outros tempos de infiltração analisados, o que confirma a capacidade do programa em realizar análises de infiltração em regime de fluxo transiente, além de comprovar que os métodos empregados na modelagem são suficientemente capazes de reproduzir as condições reais de um determinado fenômeno de infiltração. É importante ressaltar que na Figura 4.2(a) as unidades de medida estão em centímetros enquanto na Figura 4.2(b) as unidades estão em metros, obviamente os valores das cargas totais em cada uma das figuras acompanham as unidades de medidas das mesmas.

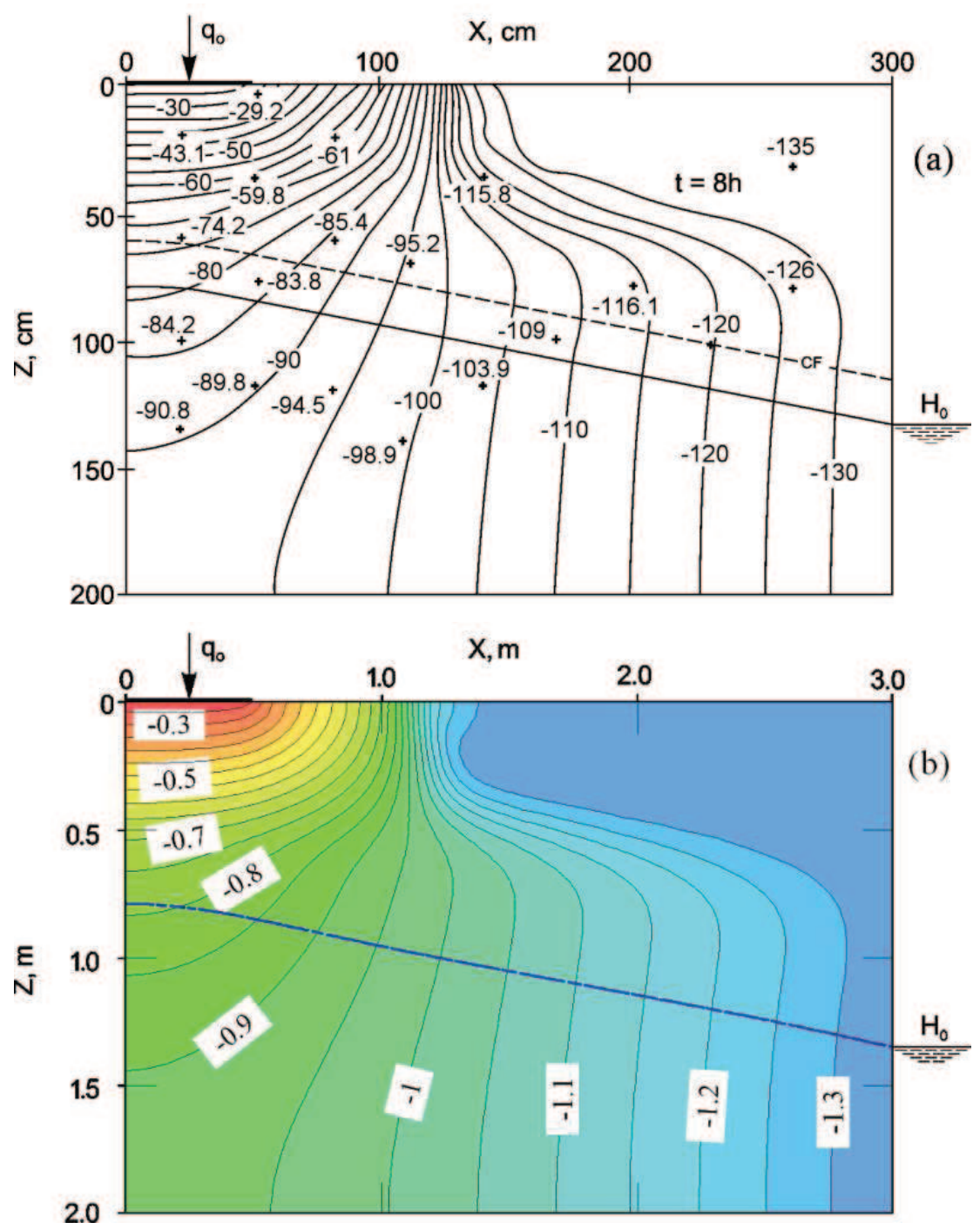

Figura 4.2 - Distribuição de cargas totais após 8 horas de infiltração. (a) Vauclin et al. (1979) (valores assinalados com + são valores experimentais) - cargas totais em centímetros; (b) SEEP/W - cargas totais em metros. 


\section{RESULTADOS E DISCUSSÕES}

\subsection{Avaliação da Condição de Poço Preenchido por Água Instantaneamente}

Como dito na subseção 3.4, a taxa de ascensão de água no interior de um poço depende de vários fatores, sendo que um deles é o diâmetro $(d)$ do mesmo. Evidentemente, uma vez que dois poços sejam submetidos a condições iguais, o de menor diâmetro apresentará taxa de ascensão do nível de água maior do que o outro com maior diâmetro. Isto é explicado, simplificadamente, pelo fato de que quando dois poços são submetidos a uma mesma vazão de abastecimento, o de maior área de base (maior diâmetro) desenvolverá uma lâmina de água menor que a do outro poço que possui área de base menor, já que a água ocupará o mesmo volume em um dado tempo em ambos os poços.

Deste modo, as análises aqui descritas tomaram por base o poço P7 ( $d=2,0 \mathrm{~m}$ e $h=1,0 \mathrm{~m})$, pois, se a condição de poço cheio instantaneamente for satisfatória para P7, ela também o será para qualquer poço de diâmetro menor.

Nestas análises foi empregado o solo C (r.C-k.C) com curva de retenção e função condutividade hidráulica apresentadas na Figura 3.3 e o solo r.C-k.C $\left(10^{-5}\right.$ ) (ver Figura 5.1) que possui curva de retenção e função condutividade hidráulica relativa iguais às do solo $\mathrm{C}$, porém com $k_{s}$ de $1,6 \times 10^{-5} \mathrm{~m} / \mathrm{s}$ (função condutividade hidráulica transladada uma ordem de grandeza a mais em relação à do solo C). Este último trata-se de um solo fictício que difere do solo $\mathrm{C}$ apenas na sua condutividade hidráulica saturada. Com isto, puderam-se avaliar também os efeitos de $k_{s}$ na ascensão do nível de água no interior dos poços.
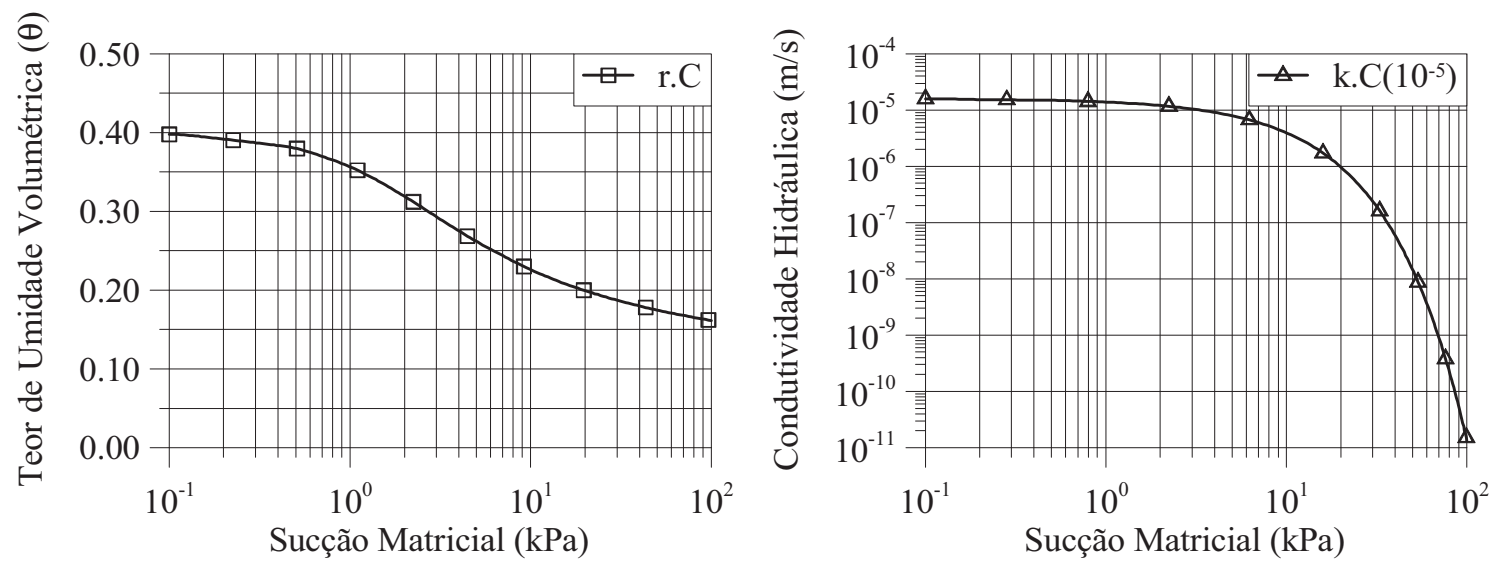

Figura 5.1 - Curva de retenção e função condutividade hidráulica do solo r.C-k.C $\left(10^{-5}\right)$.

Para o poço P7 inserido no solo $\mathrm{C}$ foram realizadas quatro análises com taxas de abastecimento do poço $\left(i_{A b}\right)$ de $300,100,50$ e $20 \mathrm{~mm} / \mathrm{h}$. Também foram realizadas quatro 
análises para o mesmo poço inserido no solo r.C-k.C $\left(10^{-5}\right)$, com taxas de abastecimento de 1500, 500, 300 e $200 \mathrm{~mm} / \mathrm{h}$. Vale ressaltar que todas estas taxas de abastecimento foram aplicadas na área circular da base de P7 que é de 3,14 $\mathrm{m}^{2}$.

As taxas de ascensão de água nos poços $\left(i_{A s}\right)$ foram calculadas como mostrado na Equação (3.1) e só foram aplicadas após o início da geração de lâmina de água na base dos poços. Estas análises foram levadas até o instante em que os poços tornaram-se completamente cheios por água ( $t_{E}$ - tempo de enchimento) e foram calculados os volumes de água infiltrados $\left(V_{i}\right)$ até este instante. A Tabela 5.1 apresenta, para cada uma das análises, os valores de $i_{A s}$ calculados a partir de $i_{A b}$ e $k_{S}$, os tempos $t_{E}$ e os volumes infiltrados $V_{i}$. Ainda, a Tabela 5.1 mostra taxas de precipitações equivalentes a $i_{A b}$ aplicadas a uma área de $100 \mathrm{~m}^{2}$ $\left(i_{P 100}\right)$.

Tabela 5.1 - Taxa de ascensão do nível de água, tempos de enchimento e volumes de água infiltrados nos poços.

\begin{tabular}{|c|c|c|c|c|c|c|c|}
\hline Solo & Análise & $\begin{array}{c}i_{A b} \\
(\mathrm{~mm} / \mathrm{h}) \\
(1)\end{array}$ & $\begin{array}{c}k_{s} \\
(\mathrm{~mm} / \mathrm{h}) \\
(2)\end{array}$ & $\begin{array}{c}i_{P 100} \\
(\mathrm{~mm} / \mathrm{h})\end{array}$ & $\begin{array}{c}i_{A s} \\
(\mathrm{~mm} / \mathrm{h}) \\
(1)-(2)\end{array}$ & $\begin{array}{c}t_{E} \\
\text { (h) }\end{array}$ & $\begin{array}{c}V_{i} \\
\left(\mathrm{~m}^{3}\right)\end{array}$ \\
\hline \multirow{4}{*}{$\mathrm{C}$} & (a) & 300 & 5,76 & 9,42 & 294,24 & 3,14 & 0,76 \\
\hline & (b) & 100 & 5,76 & 3,14 & 94,24 & 10,66 & 1,71 \\
\hline & (c) & 50 & 5,76 & 1,57 & 44,24 & 22,73 & 3,05 \\
\hline & (d) & 20 & 5,76 & 0,63 & 14,24 & 72,84 & 7,72 \\
\hline \multirow{4}{*}{ r.C-k.C $\left(10^{-5}\right)$} & (e) & 1500 & 57,60 & 47,12 & 1442,40 & 0,70 & 1,26 \\
\hline & (f) & 500 & 57,60 & 15,71 & 442,40 & 2,27 & 3,01 \\
\hline & (g) & 300 & 57,60 & 9,42 & 242,40 & 4,19 & 4,98 \\
\hline & (h) & 200 & 57,60 & 6,28 & 142,40 & 7,26 & 7,68 \\
\hline
\end{tabular}

As Figuras 5.2(a) e (b) apresentam, para os dois solos analisados, os gráficos de $V_{i}$ e de $t_{E}$, ambos em função de $i_{A b}$. Os gráficos na Figura 5.2(a) apresentam comportamentos condizentes com os seguintes limites:

$$
\begin{gathered}
\lim _{i_{A b} \rightarrow \infty} V_{i}\left(i_{A b}\right)=0 ; \quad \text { poço cheio instantaneamente } \\
\lim _{i_{A b} \rightarrow k_{s}^{+}} V_{i}\left(i_{A b}\right)=\infty ; \quad \text { poço sem formação de lâmina de água }
\end{gathered}
$$

Em outras palavras, um poço submetido a uma taxa de abastecimento infinitamente grande apresentará volume infiltrado nulo até o instante em que o mesmo torna-se completamente cheio. Por outro lado, um poço submetido a uma taxa de abastecimento igual à $k_{s}$ jamais se tornará cheio (supondo-se que o abastecimento não dure o bastante para que o nível freático do solo atinja a superfície do terreno), pois não haverá formação de nível de 
água no interior do mesmo, fazendo com que o volume de água infiltrado até o enchimento do poço tenda ao infinito.

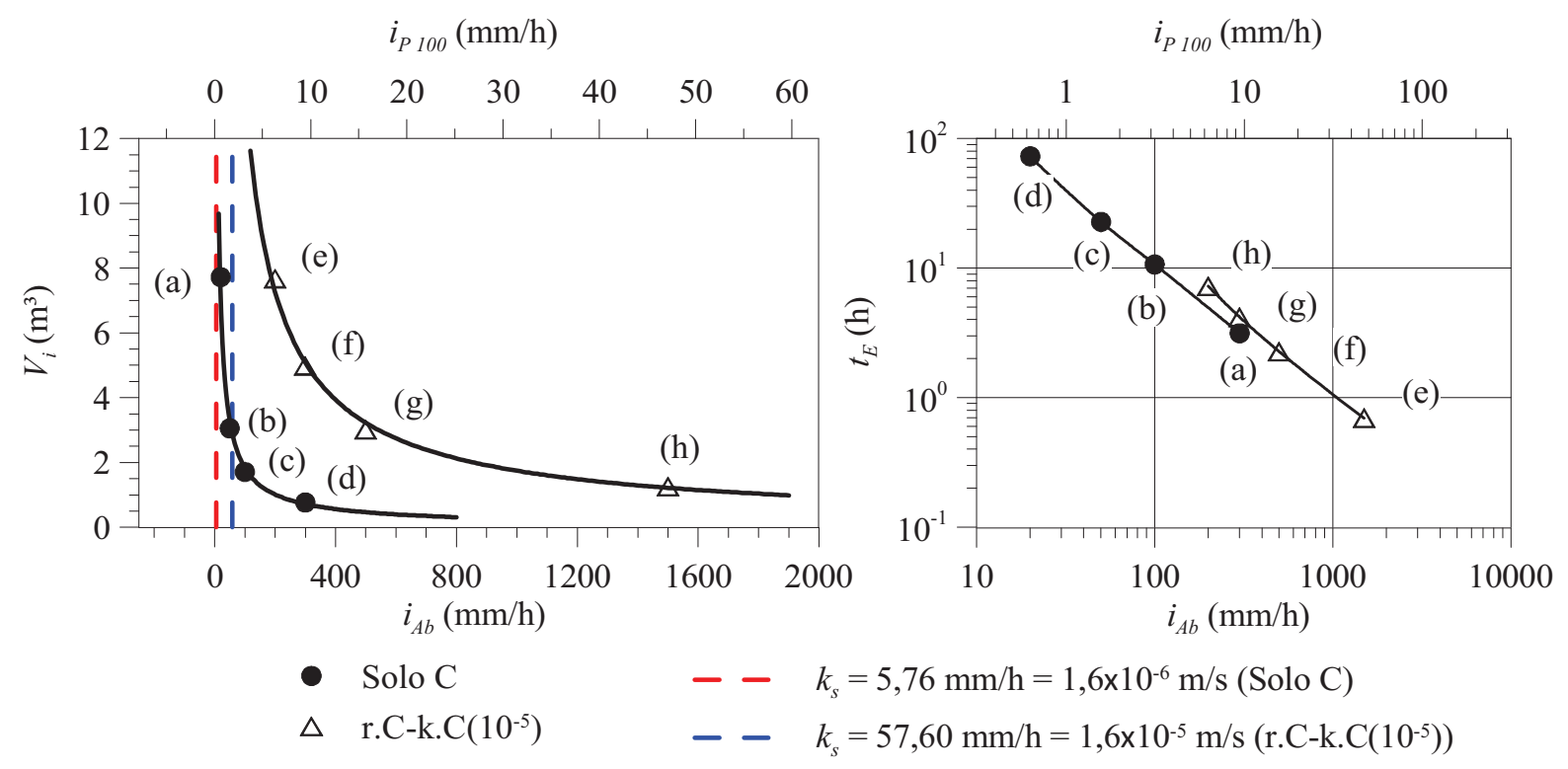

(a)

(b)

Figura 5.2 - (a) Volumes de água infiltrados em função da taxa de abastecimento dos poços; (b) Tempo de enchimento dos poços em função da taxa de abastecimento.

Analisando-se ainda a Figura 5.2(a), percebe-se que taxas de abastecimento $i_{A b}$ superiores a uma taxa de precipitação equivalente $i_{P} 100$ de $20 \mathrm{~mm} / \mathrm{h}$ permitem aos poços $\mathrm{P} 7$, instalados no solo C, a infiltração de volumes de água de no máximo $0,5 \mathrm{~m}^{3}$, até o instante em que os poços tornam-se completamente cheios. Por outro lado, tal taxa de abastecimento para os poços P7 instalados no solo r.C-k.C $\left(10^{-5}\right)$ permitem uma infiltração máxima de $2,5 \mathrm{~m}^{3}$ de água, até o instante de enchimento dos mesmos. A Figura 5.2(b) mostra que o tempo de enchimento dos poços analisados jamais excederá $2 \mathrm{~h}$, quando da aplicação de taxas $i_{A b}$ superiores a taxa equivalente $i_{P} 100$ de $20 \mathrm{~mm} / \mathrm{h}$.

Com o exposto pode-se constatar que mesmo chuvas de intensidades não tão elevadas (como a de $20 \mathrm{~mm} / \mathrm{h}$ ), quando aplicadas sobre áreas impermeáveis relativamente pequenas (como a de $100 \mathrm{~m}^{2}$ ), permitem uma rápida ascensão do nível de água em um poço que tenha a função de drenar tal área, mesmo que este possua dimensões consideráveis como o P7 e instalado em um solo bastante permeável como o r.C-k.C $\left(10^{-5}\right)$. Em outras palavras, a condição de poço cheio instantaneamente é uma simplificação tão mais próxima da realidade quanto maiores forem as taxas de precipitações e as áreas impermeáveis que se desejem drenar (ambas situações são inconvenientes à drenagem urbana); e quanto menores forem os diâmetros dos poços empregados na drenagem. 
Outra observação importante é o fato de que os poços sem revestimento, que são o objeto de estudo deste trabalho, comumente estarão preenchidos com material granular graúdo para que seja mantida a estabilidade de suas paredes. Como geralmente o material de preenchimento possui porosidade entre 30 e 40\%, o tempo de enchimento dos poços preenchidos com material granular será entre 2,33 e 1,50 vezes mais rápido do que em poços idênticos sem material granular de preenchimento (supondo-se que tal material não ofereça resistência ao fluxo de água). Deste modo, os poços com material granular de preenchimento se aproximam ainda mais da condição de poço preenchido por água instantaneamente do que aqueles aqui modelados.

Logo, a condição de poço preenchido por água instantaneamente representa de forma fidedigna as piores situações (mais inconvenientes à drenagem urbana) e é a favor da segurança nas situações mais convenientes, o que possibilita o emprego de tal condição de forma satisfatória.

\subsection{Análise Paramétrica das Funções Condutividade Hidráulica dos Solos}

As situações estudadas englobam basicamente três casos. O primeiro analisa a influência da condutividade hidráulica saturada $k_{s}$ no processo de infiltração de água em poços, o segundo estuda a influência do parâmetro $\alpha$ da função condutividade hidráulica (Equação (2.9)) proposta por Gardner (1958) para o ajuste da função condutividade hidráulica e o último analisa a influência do formato de distintas funções condutividade hidráulica no processo de infiltração.

Em seguida apresentam-se cada uma das situações detalhadamente e seus respectivos resultados. É importante ressaltar que todas as análises realizadas foram baseadas no solo $\mathrm{C}$ (r.C-k.C) e que o comportamento deste em relação à infiltração de água através de poços serviu de padrão de comparação em relação aos demais casos analisados. Ainda, todos os casos modelados foram levados até um tempo máximo de dois dias de infiltração (48 horas).

\subsubsection{Influência da Condutividade Hidráulica Saturada}

Para avaliar a influência da condutividade hidráulica saturada $k_{s}$ no processo de infiltração de água através de poços, a partir do solo $\mathrm{C}$ já apresentado, foi alterada a ordem de grandeza deste parâmetro sem que a função condutividade hidráulica relativa 
(Equação (2.10)) fosse alterada. Em outras palavras, neste item foram criados dois solos fictícios, ambos com curvas de retenção iguais à do solo C, (r.C, ver Figura 5.3(a)) e funções condutividade hidráulica transladadas uma ordem de grandeza a mais e outra a menos que a da função condutividade hidráulica do solo C. Os solos fictícios foram denominados de solo r.C-k.C $\left(10^{-5}\right)$ e o outro de solo r.C-k.C $\left(10^{-7}\right)$. A curva de retenção do solo C (r.C) e as funções condutividade hidráulica dos solos criados, assim como a do solo C são apresentadas na Figura 5.3.

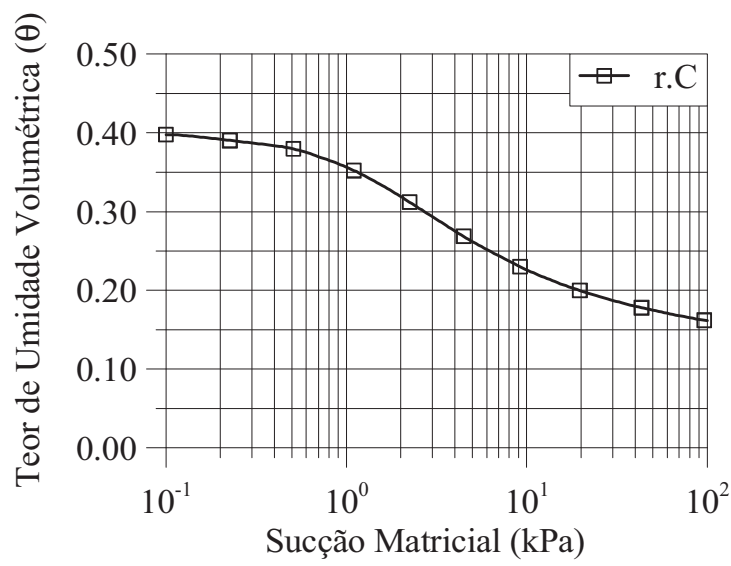

(a)

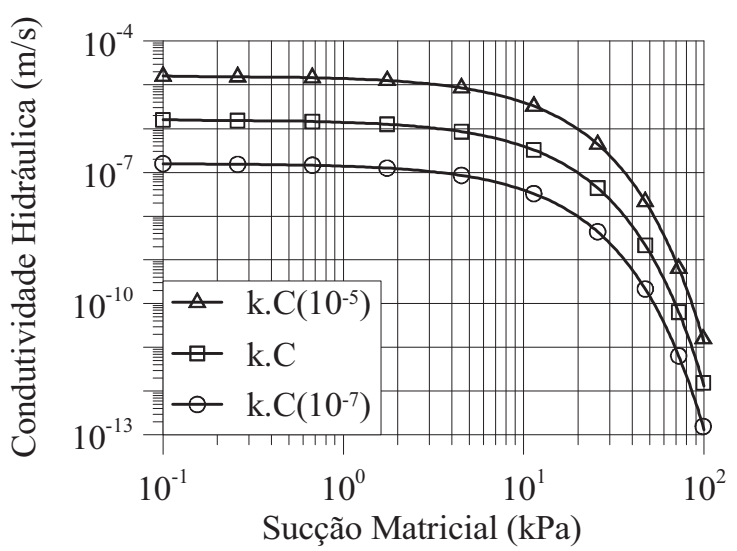

(b)

Figura 5.3 - (a) Curva de retenção r.C; (b) Funções condutividade hidráulica k.C $\left(10^{-5}\right)$, k.C e k.C(10-7).

Para efeito de visualização da influência da condutividade hidráulica saturada no processo de infiltração de água em poços, a Figura 5.4 apresenta a variação das vazões infiltradas $\left(Q\left(\mathrm{~m}^{3} / \mathrm{h}\right)\right)$ através da área lateral (paredes e base) dos poços ao longo do tempo $(t(\mathrm{~h}))$.

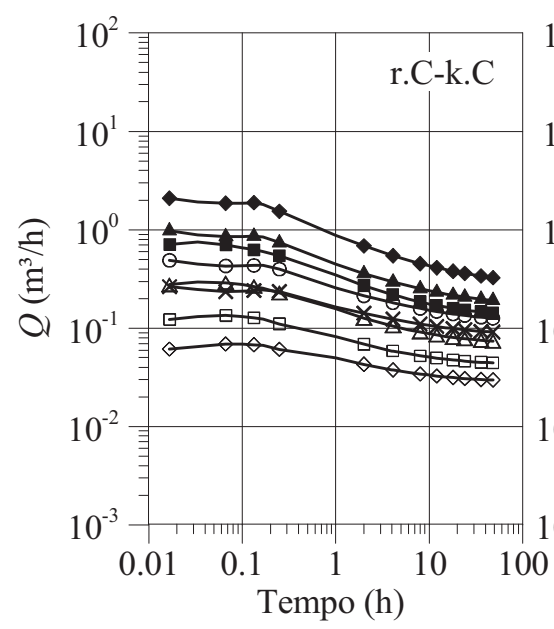

(a)

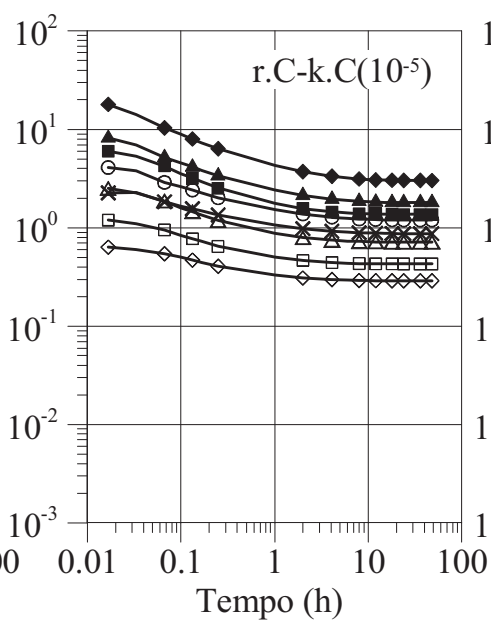

(b)

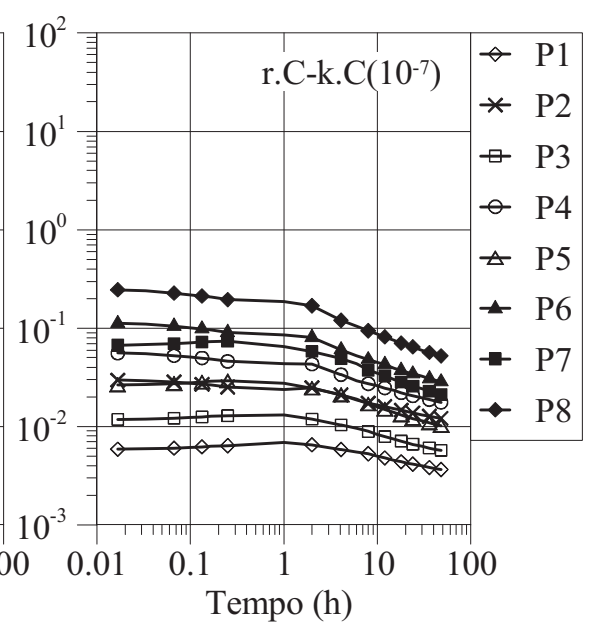

(c)

Figura 5.4 - Variação das vazões infiltradas através da área lateral do poço (paredes e base) ao longo do tempo. (a) Solo C; (b) Solo r.C-k.C $\left(10^{-5}\right)$; (c) Solo r.C-k.C $\left(10^{-7}\right)$. 
Percebe-se na Figura 5.4 que as vazões em poços de infiltração de iguais dimensões, inseridos em solos que se distinguem apenas pelas suas condutividades hidráulicas saturadas, variam na mesma proporção que $k_{s}$. $\mathrm{O}$ que pode ser justificado observando-se a Equação (2.18) que é o caso geral da Equação de Darcy, nesta é evidente que a função condutividade hidráulica do solo é diretamente proporcional à densidade de fluxo, que por sua vez é diretamente proporcional à vazão da água no solo. Logo se $k(\psi)$ varia uma ordem de grandeza de uma análise pra a outra, o mesmo ocorrerá com as vazões. Por exemplo, tomando-se um poço qualquer na Figura 5.4(a) (Solo C) a sua curva de $Q$ ao longo de $t$ varia, praticamente, paralelamente uma ordem de grandeza em relação aos poços com iguais dimensões instalados nos outros dois solos (solos r.C-k.C $\left(10^{-5}\right)$ e r.C-k.C $\left.\left(10^{-7}\right)\right)$.

Fazendo-se a integração numérica pela regra dos trapézios das curvas de $Q$ ao longo de $t$ chega-se aos volumes infiltrados acumuladas $(V)$ ao longo do tempo. A Figura 5.5 apresenta os volumes de água infiltrados nos poços ao longo do tempo.

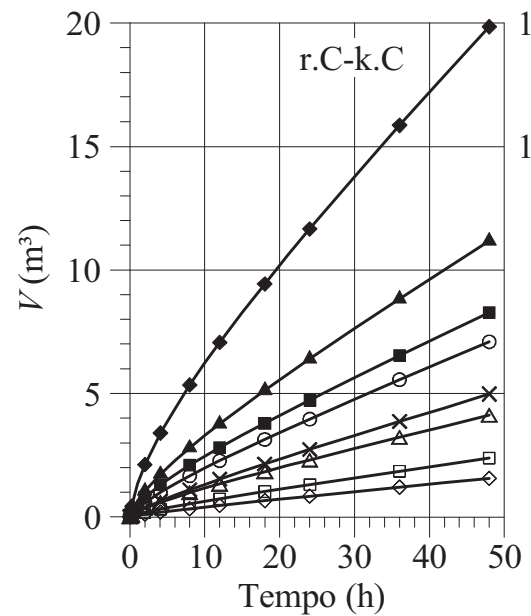

(a)

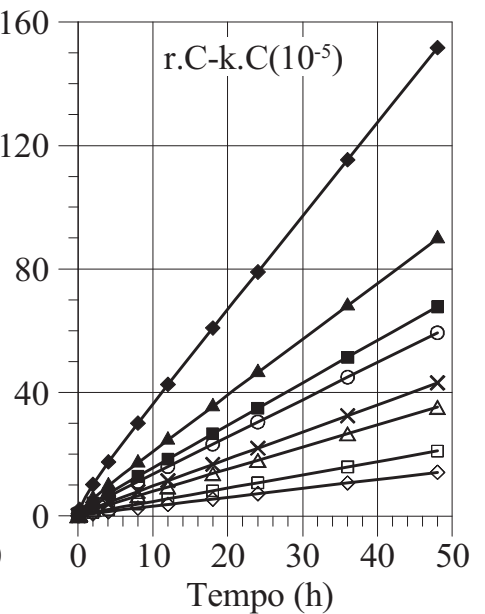

(b)

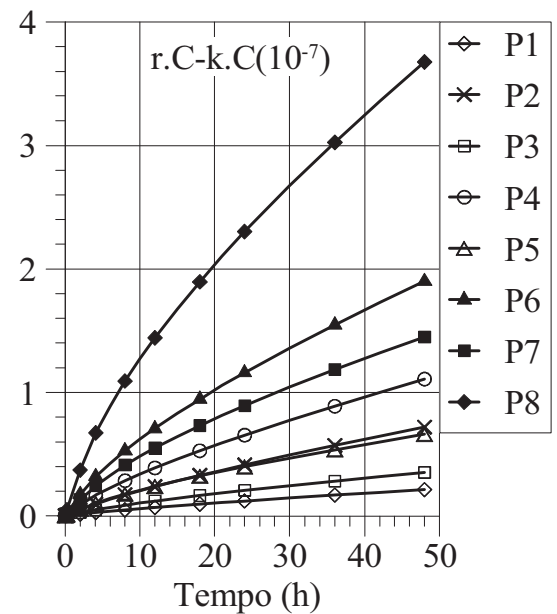

(c)

Figura 5.5 - Volumes infiltrados acumulados ao longo do tempo. (a) Solo C; (b) Solo r.C-k.C(10 ${ }^{-5}$ ); (c) Solo r.C-k.C $\left(10^{-7}\right)$.

Os eixos dos volumes infiltrados nas Figuras 5.5(a), (b) e (c) estão em escalas diferentes. Para efeitos práticos, esta figura apresenta de forma ainda mais clara a influência de $k_{s}$ no processo de infiltração em poços. Os volumes de água infiltrados num poço no solo C são cerca de $13 \%$ dos volumes infiltrados em um poço idêntico instalado no solo r.C-k.C $\left(10^{-5}\right)$, que possui $k_{s}$ uma ordem de grandeza maior que a do solo C. Por outro lado, os volumes de água infiltrados num poço no solo r.C-k.C $\left(10^{-7}\right)$ são cerca de $18 \%$ dos volumes infiltrados em um poço idêntico instalado no solo C. 


\subsubsection{Influência do Parâmetro $\alpha$ de Gardner (1958)}

Para avaliar a influência do parâmetro $\alpha$ da Equação (2.9) proposta por Gardner (1958) na infiltração de água em poços, foram criados dois solos fictícios, ambos com curvas de retenção e condutividades hidráulicas saturadas $\left(k_{s}\right)$ iguais às do solo C. Um dos solos possui uma função condutividade hidráulica com parâmetro $\alpha$ de 0,10 e o outro possui um $\alpha$ de 0,20. Estes dois solos fíctícios foram denominados de solo r.C-k.C(0,10) e de r.Ck.C $(0,20)$. A Figura 5.6 apresenta as funções condutividade destes solos, assim como a curva de retenção do solo $\mathrm{C}$ e sua função condutividade hidráulica.

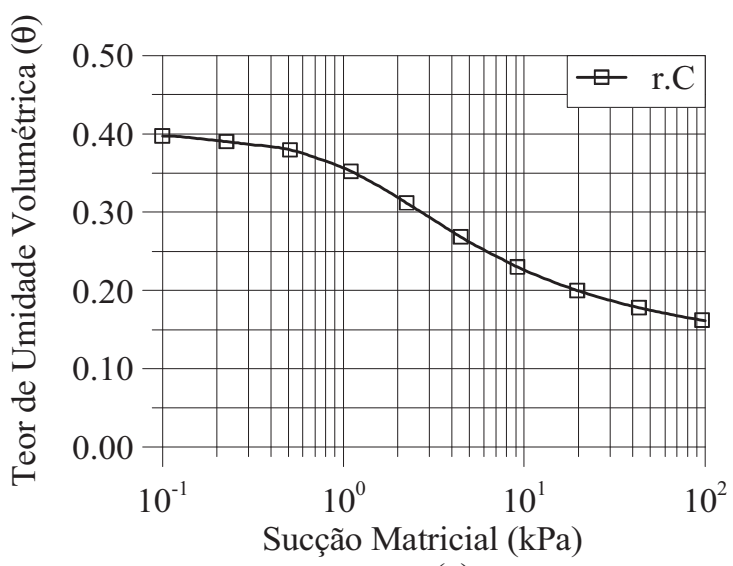

(a)

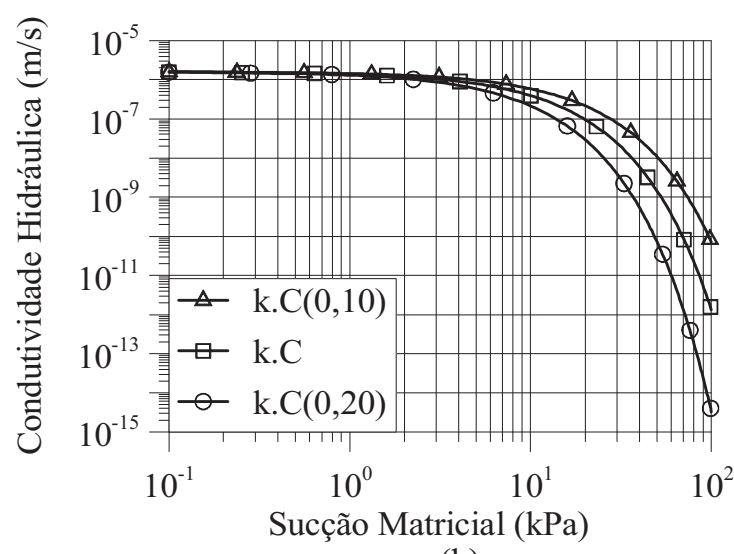

(b)

Figura 5.6 - (a) Curva de retenção r.C; (b) Funções condutividade hidráulica k.C(0,10), k.C e k.C $(0,20)$.

A Figura 5.7 apresenta a variação das vazões de água infiltrada ao longo do tempo, quando se varia o parâmetro $\alpha$ da função condutividade hidráulica. Percebe-se nesta figura que a variação de $\alpha$ da Equação (2.9) pouco influencia o processo de infiltração. Entretanto, esta figura mostra, como esperado, uma tendência de as vazões infiltradas serem inversamente proporcionais aos valores de $\alpha$. Pode-se notar que um poço no solo r.C-k.C $(0,10)$ possibilita maiores vazões que as de um poço idêntico no solo C (r.C-k.C) e este, por sua vez, possibilita maiores vazões que um mesmo poço no solo r.C-k.C $(0,20)$.

Este comportamento é explicado observando-se as funções condutividade hidráulica da Figura 5.6. Para uma mesma sucção matricial, as funções que possuem menores valores de $\alpha$ apresentam maiores condutividades hidráulicas. Entretanto, estas são diretamente proporcionais às vazões calculadas pela lei de Darcy - que rege o fluxo de água no solo -, logo quanto menor for o parâmetro $\alpha$ da função condutividade hidráulica de um determinado solo, maiores serão as vazões de infiltração no mesmo. 


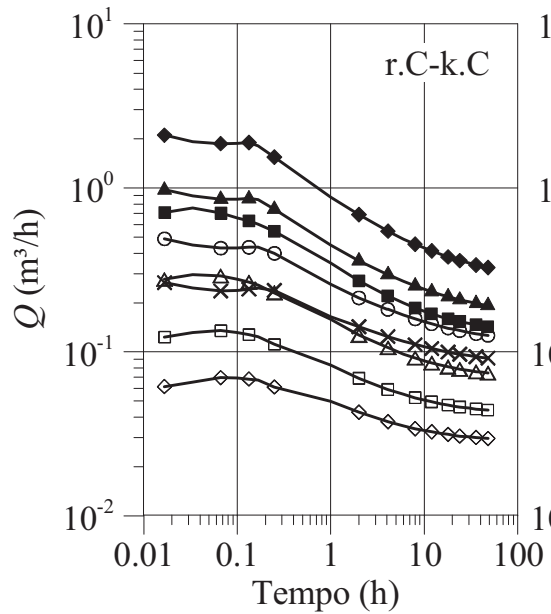

(a)

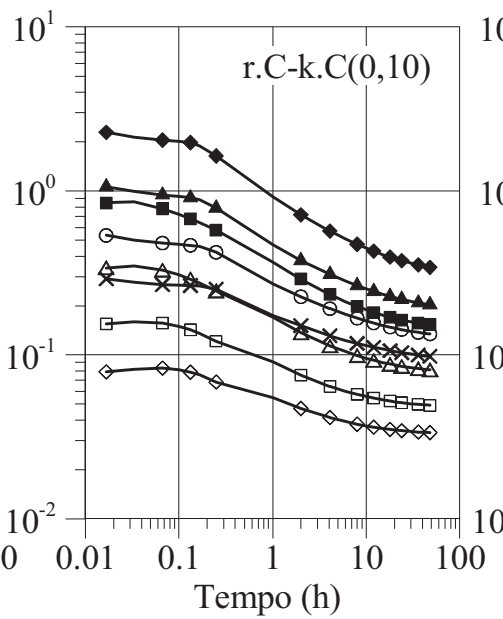

(b)

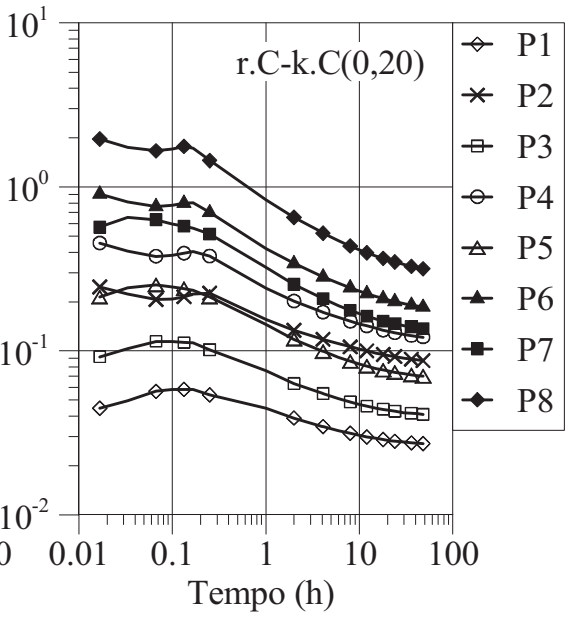

(c)

Figura 5.7 - Variação das vazões infiltradas através da área lateral do poço (paredes e base) ao longo do tempo. (a) Solo C; (b) Solo r.C-k.C(0,10); (c) Solo r.C-k.C(0,20).

A pouca influência do parâmetro $\alpha$ no processo de infiltração, nas análises aqui realizadas, fica mais evidente ao se observar a Figura 5.8 que relaciona os volumes de água infiltrada ao longo do tempo. Comparando-se os gráficos (a), (b) e (c) desta figura, nota-se que as vazões infiltradas em um mesmo poço até um dado instante de tempo, praticamente não se alteram de um solo para outro.

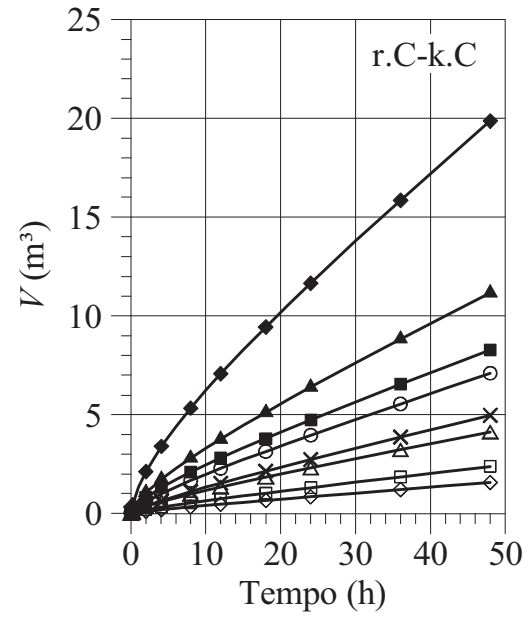

(a)

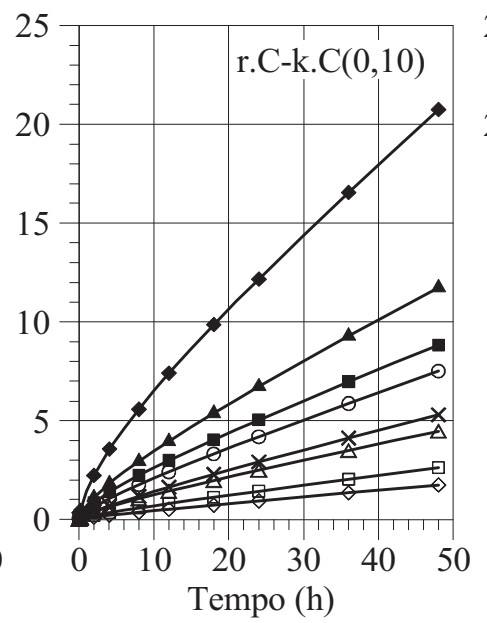

(b)

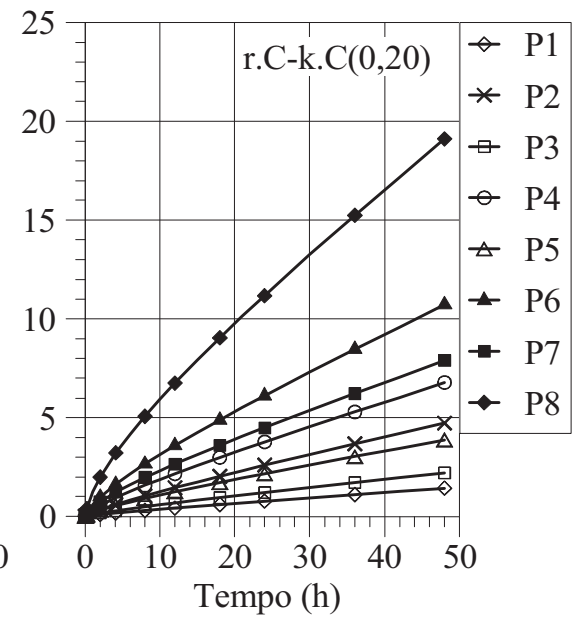

(c)

Figura 5.8 - Volumes infiltrados acumulados ao longo do tempo. (a) Solo C; (b) Solo r.C-k.C(0,10); (c) Solo r.C-k.C $(0,20)$.

\subsubsection{Influência do Formato da Função Condutividade Hidráulica}

$\mathrm{Na}$ avaliação da influência do formato da função condutividade hidráulica, foram criados dois solos fictícios, ambos com curvas de retenção iguais à do solo C (r.C). Estes solos possuem funções condutividade hidráulica relativa iguais às dos solos A e B, porém 
transladadas para um condutividade hidráulica saturada $k_{s}$ igual à do solo $\mathrm{C}$. Estes dois solos criados foram denominados de solo r.C-k.A $\left(10^{-6}\right)$ e solo r.C-k.B $\left(10^{-6}\right)$. A Figura 5.9 apresenta as funções condutividade destes solos e a do solo $\mathrm{C}$, assim como a curva de retenção deste.

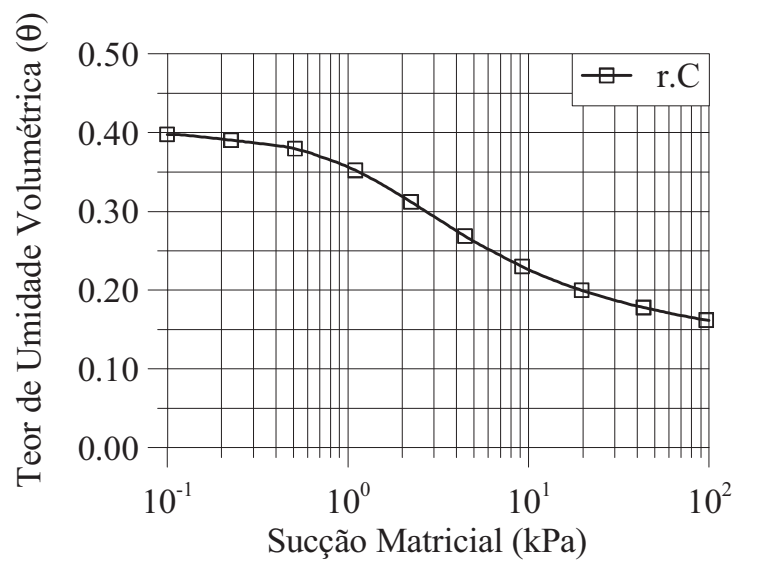

(a)

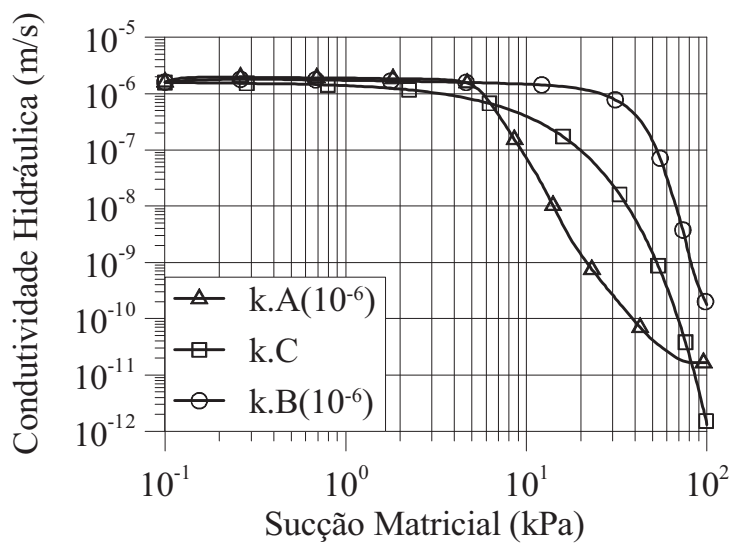

(b)

Figura 5.9 - (a) Curva de retenção r.C; (b) Funções condutividade hidráulica k.A $\left(10^{-6}\right)$, k.C e k.B $\left(10^{-6}\right)$.

A Figura 5.10 apresenta a variação das vazões de água infiltrada ao longo do tempo para os 8 poços estudados. Esta figura constata que um poço instalado no solo r.C-k.B $\left(10^{-6}\right)$ terá vazões de infiltração maiores do que as vazões de poços idênticos instalados nos outros dois solos. Este comportamento é explicado observando-se a Figura 5.9. Nesta, percebe-se que funções com valores de $k_{s}$ mantidos em grandes intervalos de sucção, como na função $\mathrm{k} \cdot \mathrm{B}\left(10^{-6}\right)$, tendem a ser mais permeáveis para uma mesma sucção matricial do que funções com $k_{s}$ mantidos em pequenos intervalos de sucção.

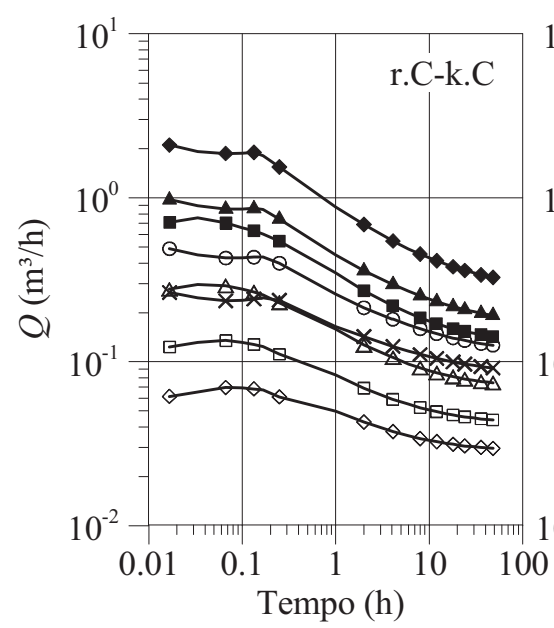

(a)

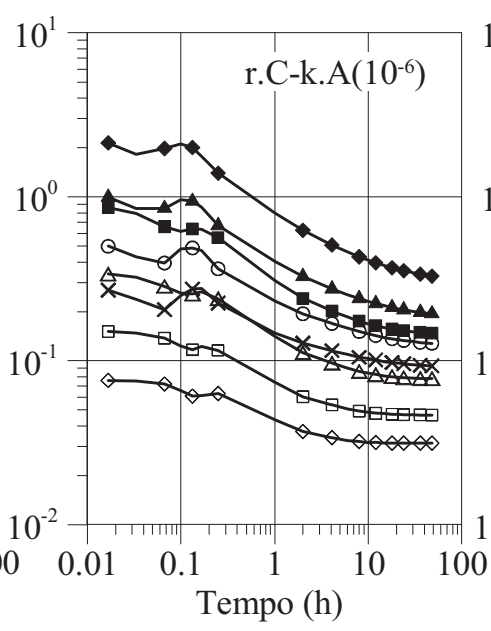

(b)

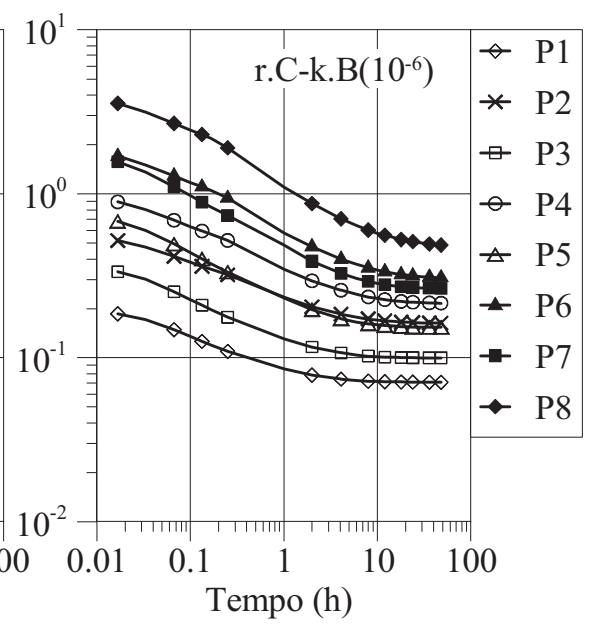

(c)

Figura 5.10 - Variação das vazões infiltradas através da área lateral do poço (paredes e base) ao longo do tempo. (a) Solo C; (b) Solo r.C-k.A $\left(10^{-6}\right)$; (c) Solo r.C-k.B $\left(10^{-6}\right)$.

Esta constatação é ainda mais evidente na Figura 5.11, nesta percebe-se que os volumes infiltrados em um dado poço no solo r.C-k.A $\left(10^{-6}\right)$ serão menores que os infiltrados 
num poço idêntico no solo $\mathrm{C}$ e que os volumes infiltrados neste serão menores que os infiltrados no mesmo poço instalado no solo r.C-k.B $\left(10^{-6}\right)$.

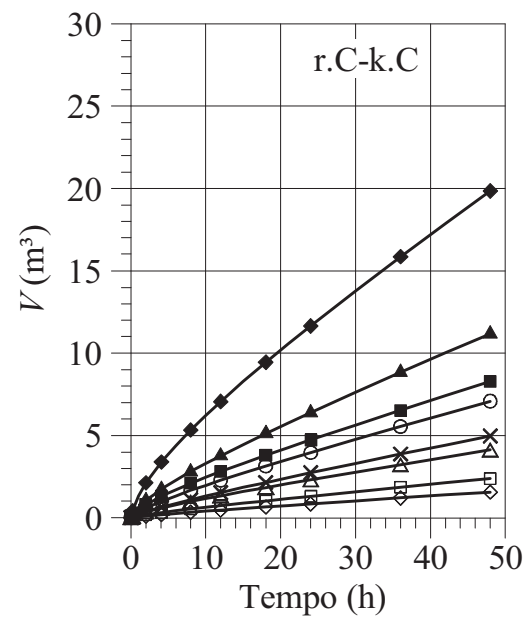

(a)

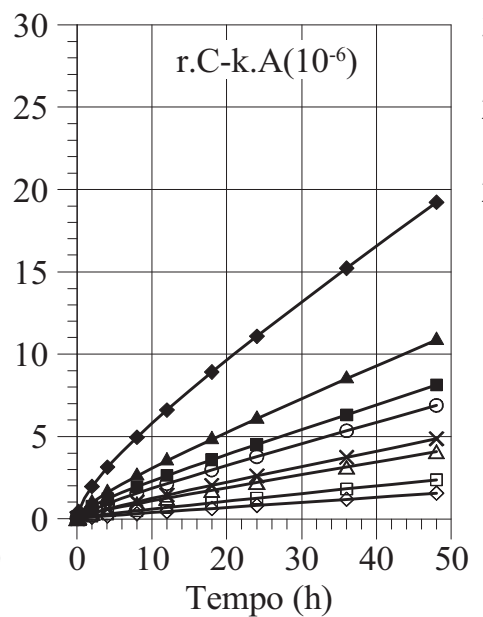

(b)

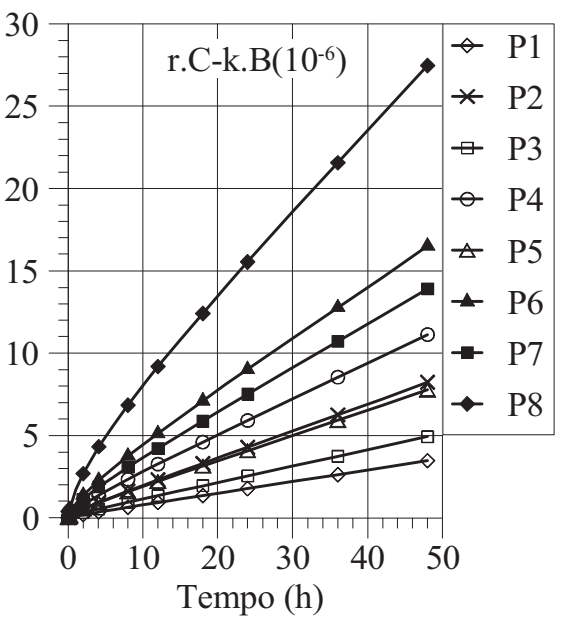

(c)

Figura 5.11 - Volumes infiltrados acumulados ao longo do tempo. (a) Solo C; (b) Solo r.C-k.A(10-6); (c) Solo r.C-k.B $\left(10^{-6}\right)$.

\subsection{Análise Paramétrica das Curvas de Retenção dos Solos}

As situações estudadas englobam cinco casos. O primeiro analisa a influência do teor de umidade volumétrica na condição de saturação $\theta_{s}$ no processo de infiltração de água em poços, o segundo estuda a influência do formato de distintas curvas de retenção e os outros três casos analisam a influência dos parâmetros $a, n$ e $m$ da Equação (2.6), proposta por Fredlund \& Xing (1994) para o ajuste das curvas de retenção dos solos.

Assim como na análise paramétrica das funções condutividade hidráulica dos solos, aqui todas as análises também foram baseadas no solo C (r.C-k.C) e o comportamento deste em relação à infiltração de água através de poços serviu de padrão de comparação em relação aos demais casos analisados. Ainda, todos os casos modelados foram levados até um tempo máximo de dois dias de infiltração (48 horas).

\subsubsection{Influência do Teor de Umidade Volumétrica na Condição Saturada}

Para avaliar a influência do teor de umidade volumétrica na condição saturada $\theta_{s}$ no processo de infiltração de água através de poços, foi alterado o valor de $\theta_{s}$ do solo $\mathrm{C}$ sem que o teor de umidade volumétrica normalizada (Equação (2.7)) fosse alterado. Em outras palavras, neste item foram criados dois solos fictícios com funções condutividade hidráulica 
iguais à do solo C, (k.C, ver Figura 5.12(b)) e curvas de retenção transladadas em 25\%, para mais e para menos do valor de $\theta_{s}$ de 0,40 do solo C. Assim os solos criados possuem $\theta_{s}$ de 0,50 e de 0,30 . Os solos fictícios foram denominados de solo r.C(0,50)-k.C e o outro de solo r.C(0,30)-k.C. A função condutividade hidráulica do solo C (k.C) e as curvas de retenção dos solos criados, assim como a do solo C são apresentadas na Figura 5.12.

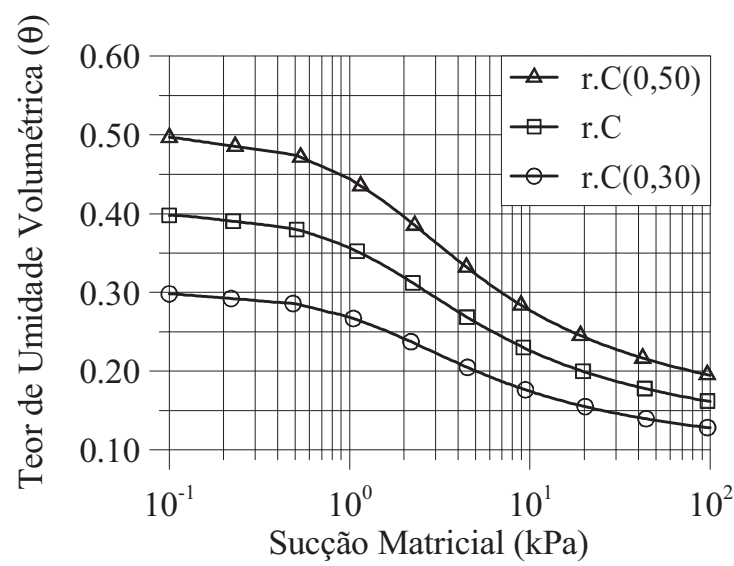

(a)

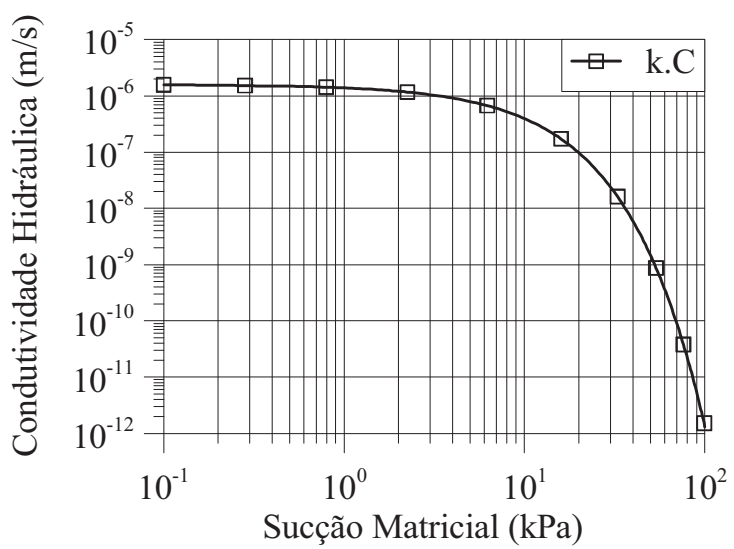

(b)

Figura 5.12 - (a) Curvas de retenção r.C(0,50), r.C e r.C(0,30); (b) Função condutividade hidráulica k.C.

A Figura 5.13 apresenta a variação das vazões de água infiltrada ao longo do tempo, quando se varia $\theta_{s}$. Percebe-se nesta figura que a variação de $\theta_{s}$ pouco influencia o processo de infiltração, uma vez que não há diferença significativa entre as vazões infiltradas ao longo do tempo em cada um dos poços nas três situações estudadas.

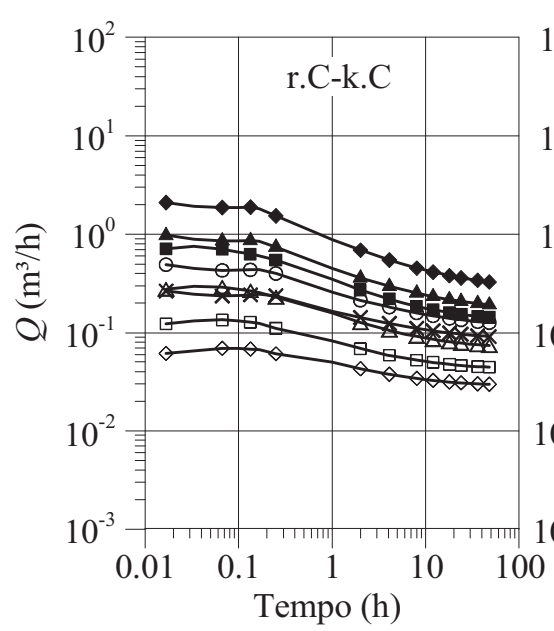

(a)

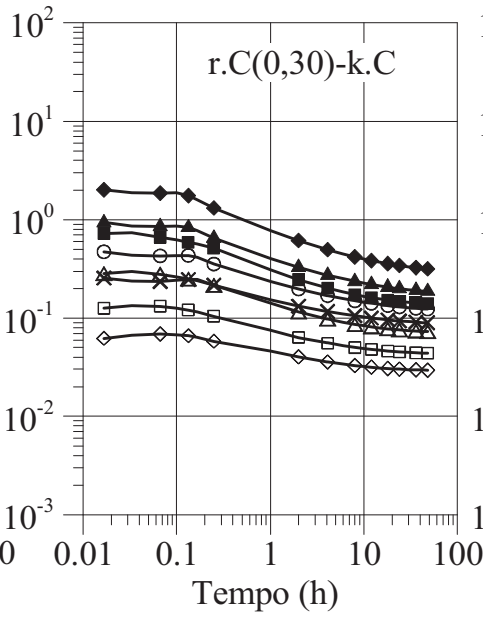

(b)

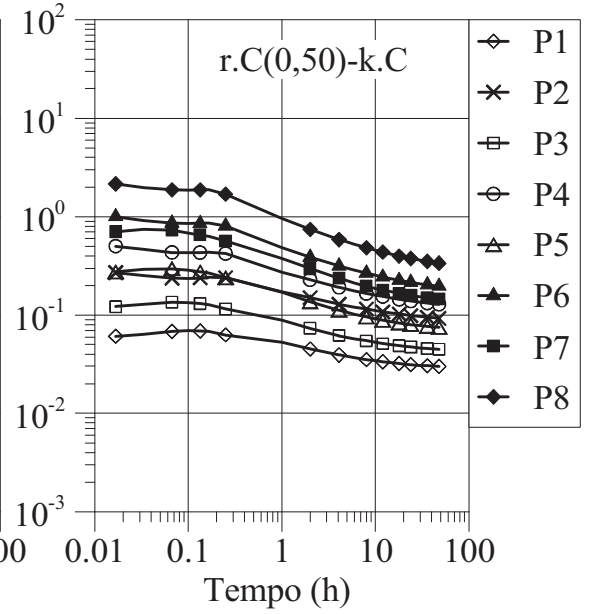

(c)

Figura 5.13 - Variação das vazões infiltradas através da área lateral do poço (paredes e base) ao longo do tempo. (a) Solo C; (b) Solo r.C(0,30)-k.C; (c) Solo r.C(0,50)-k.C.

Observando-se a Figura 5.14, que mostra os volumes de água infiltrados nos poços ao longo do tempo, pode-se notar que um poço no solo r.C(0,50)-k.C possibilita maiores volumes infiltrados que os de um poço idêntico no solo $\mathrm{C}$ e este, por sua vez, possibilita 
maiores volumes que os de um mesmo poço no solo r.C(0,30)-k.C. Esta figura mostra, como esperado, uma tendência de os volumes infiltradas serem diretamente proporcionais aos valores de $\theta_{s}$, já que para uma mesma sucção matricial os solos com maiores teores de umidade volumétrica devem apresentar maiores volumes de água armazenados em um dado volume de solo.

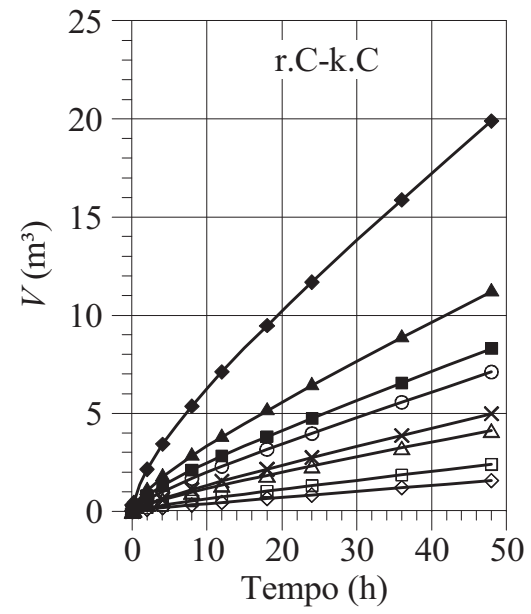

(a)

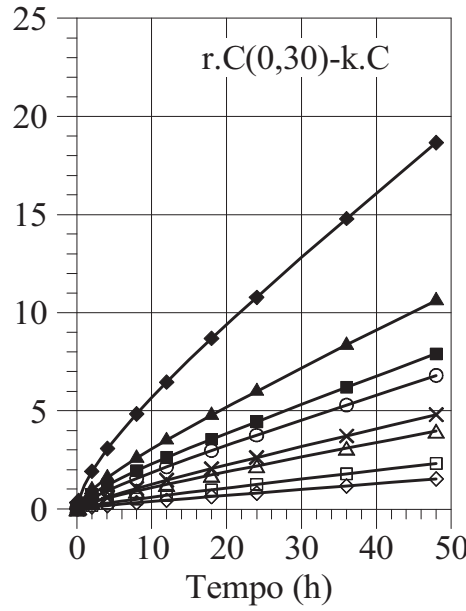

(b)

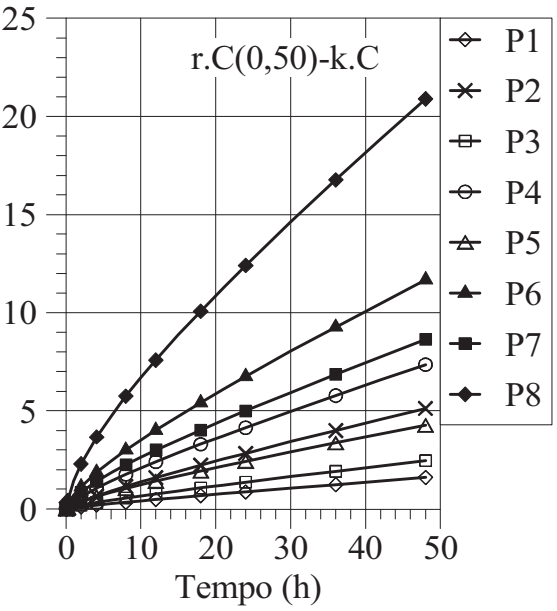

(c)

Figura 5.14 - Volumes infiltrados acumulados ao longo do tempo. (a) Solo C; (b) Solo r.C(0,30)-k.C; (c) Solo r.C $(0,50)-k . C$.

\subsubsection{Influência do Formato da Curva de Retenção}

$\mathrm{Na}$ avaliação da influência do formato da curva de retenção no processo de infiltração de água em poços, foram criados dois solos fictícios, ambos com funções condutividade hidráulica iguais à do solo C (k.C). Estes solos possuem teores de umidades volumétricas normalizadas iguais às dos solos $\mathrm{A}$ e $\mathrm{B}$, porém transladados para um $\theta_{s}$ igual ao do solo $\mathrm{C}$. Os dois solos criados foram denominados de solo r.A(0,40)-k.C e solo r.B(0,40)-k.C. A Figura 5.15 apresenta as curvas de retenção destes solos e a do solo $\mathrm{C}$, assim como a função condutividade hidráulica deste.

A Figura 5.16 apresenta a variação das vazões de água infiltrada ao longo do tempo, quando se varia o formato das curvas de retenção. Nesta figura, fica claro que apenas a variação do formato da curva de retenção pouco influência na variação de vazões nos poços ao longo do tempo. 


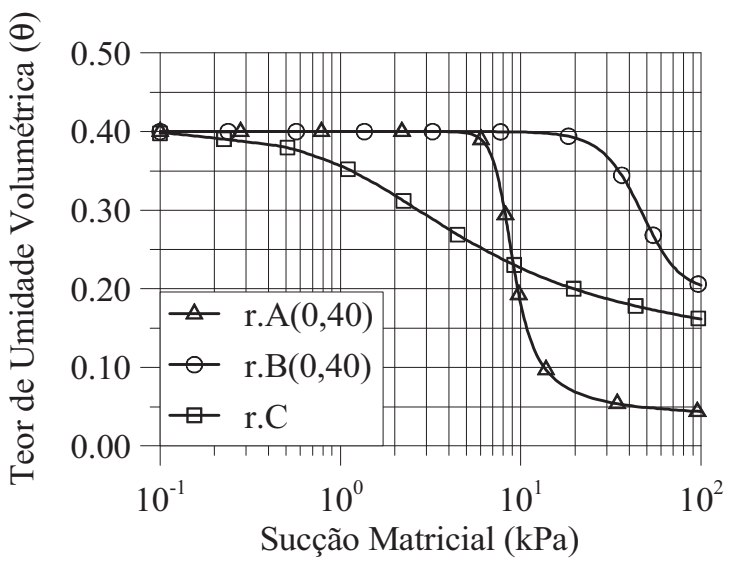

(a)

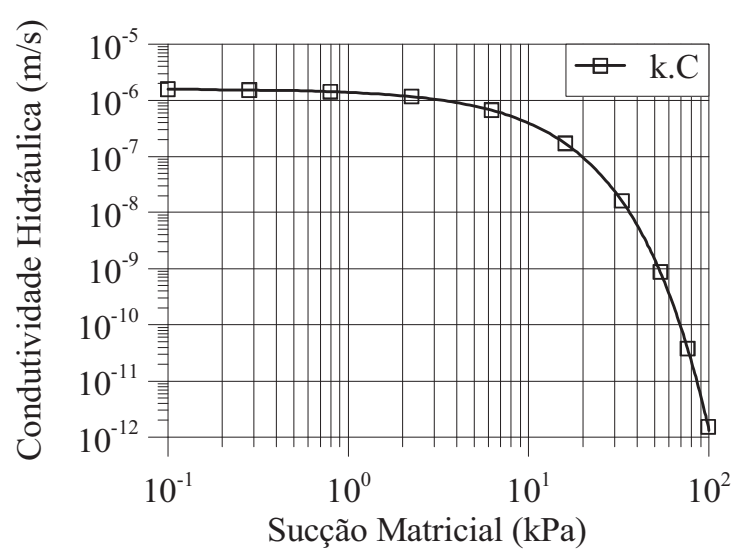

(b)

Figura 5.15 - (a) Curvas de retenção r.A(0,40), r.B(0,40) e r.C; (b) Função condutividade hidráulica k.C.

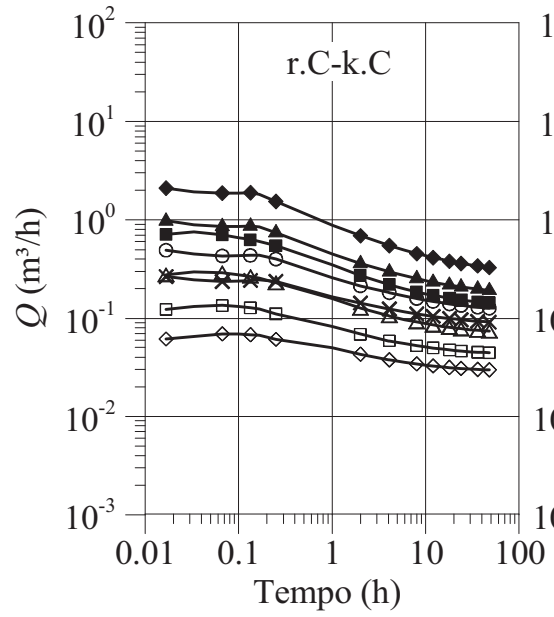

(a)

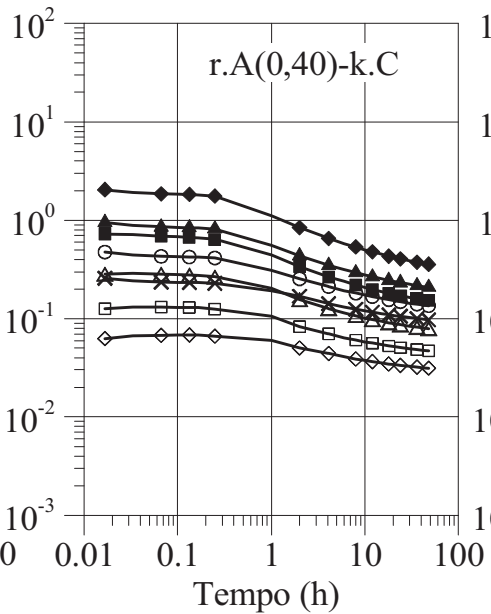

(b)

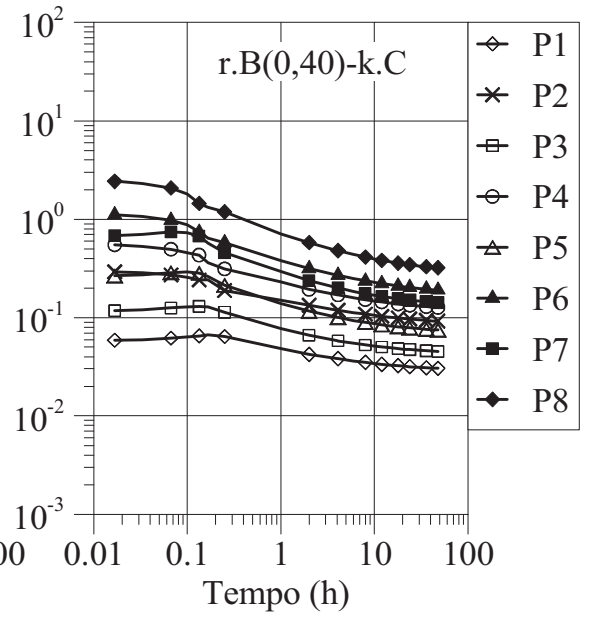

(c)

Figura 5.16 - Variação das vazões infiltradas através da área lateral do poço (paredes e base) ao longo do tempo. (a) Solo C; (b) Solo r.A(0,40)-k.C; (c) Solo r.B(0,40)-k.C.

Entretanto, na Figura 5.17 que mostra os volumes de água infiltrada acumulados ao longo do tempo, é evidente que estes são maiores para os poços instalados no solo r.A( $(0,40)$ k.C do que para os instalados no solo $\mathrm{C}$, que por sua vez apresentam volumes maiores que os dos poços instalados no solo r.B(0,40)-k.C. A explicação de tal comportamento dos volumes infiltrados nos três solos não parece clara devido a diversidade nos formatos das curvas de retenção. Assim, fez-se necessária uma análise mais detalhada dos parâmetros da curva de retenção e de suas influências no processo de infiltração de água em poços. 


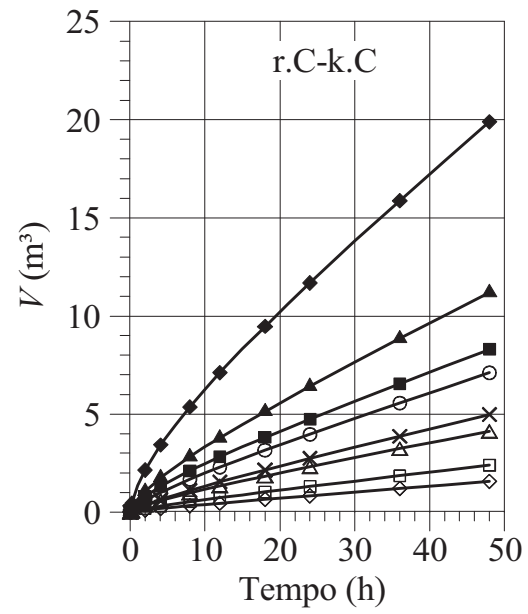

(a)

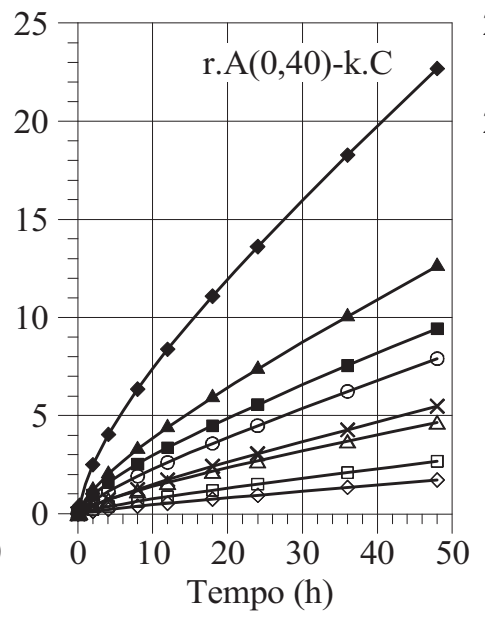

(b)

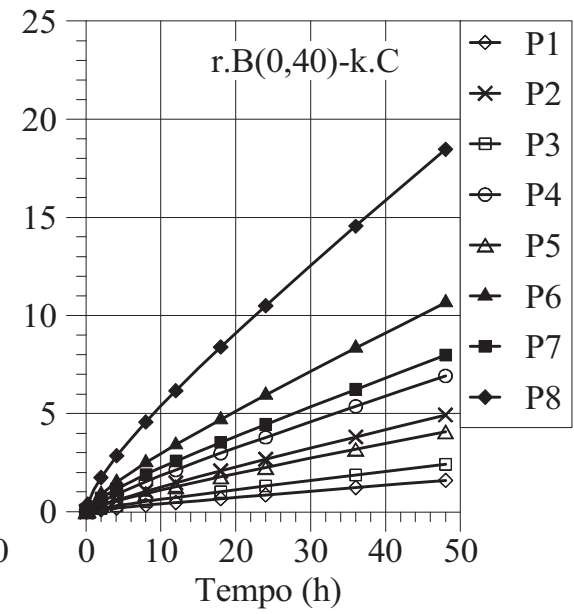

(c)

Figura 5.17 - Volumes infiltrados acumulados ao longo do tempo. (a) Solo C; (b) Solo r.A(0,40)-k.C; (c) Solo r.B(0,40)-k.C.

\subsubsection{Influência do Parâmetro $a$ da Curva de Retenção de Fredlund \& Xing (1994)}

Para a avaliação da influência do parâmetro $a$, da curva de retenção de Fredlund \& Xing (1994) (Equação (2.6)), no processo de infiltração de água em poços foram criados dois solos fictícios com parâmetros $a$ de 40 e $10 \mathrm{kPa}$, os mesmos divergem do solo $\mathrm{C}$ apenas no valor deste parâmetro, que neste solo é de 1,278 $\mathrm{kPa}$. Os solos criados foram denominados de solo r.C(a40)-k.C e solo r.C(a10)-k.C. A Figura 5.18 apresenta as curvas de retenção destes solos e a do solo C, assim como a função condutividade hidráulica deste.

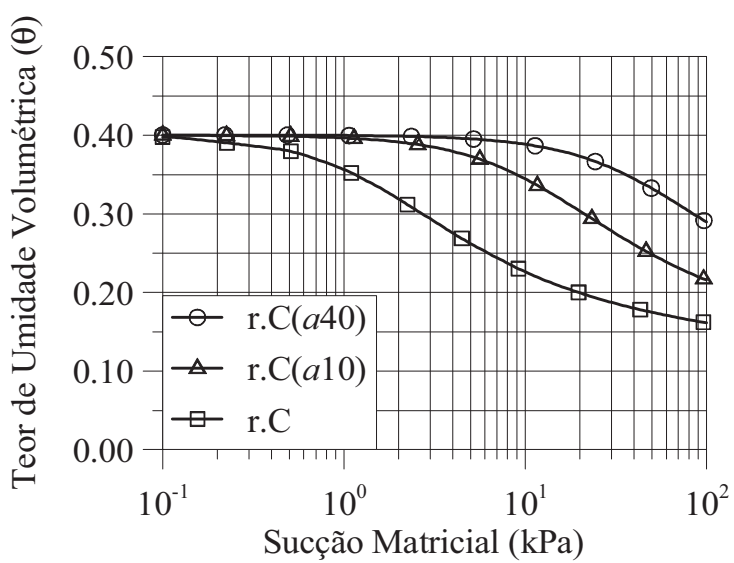

(a)

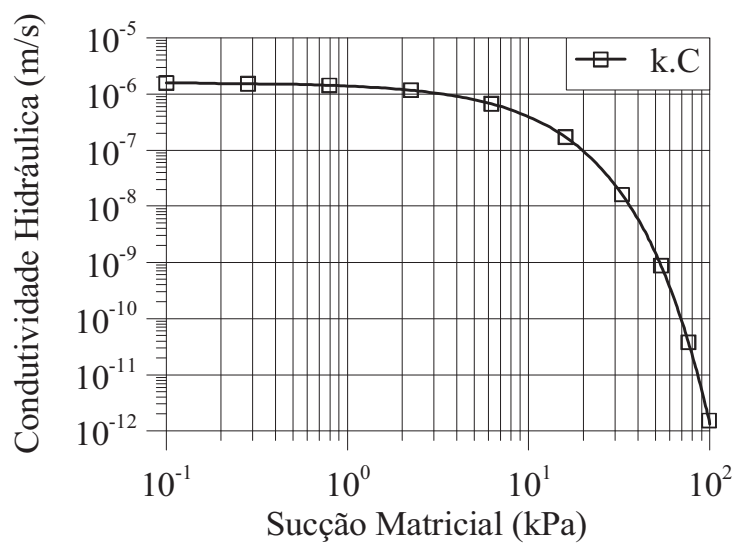

(b)

Figura 5.18 - (a) Curvas de retenção r.C(a40), r.C(a10) e r.C; (b) Função condutividade hidráulica k.C.

Quando $n$ e $m$ são fixos, o parâmetro $a$ (com unidade de $\mathrm{kPa}$ ) está intimamente relacionado com o valor da pressão de entrada de ar. Em geral, o valor de $a$ é superior ao valor da pressão de entrada de ar. No entanto, para pequenos valores de $m$, o valor da pressão 
de entrada de ar pode ser usado como sendo o parâmetro $a$ (FREDLUND \& XING, 1994). Assim, nas análises desta subseção o valor de $a$ será considerado como o valor da pressão de entrada de ar, pois os valores de $n$ e $m$ foram fixados e este último é pequeno e vale 0,618 para todos os solos aqui descritos.

Na Figura 5.19 percebe-se que há uma sutil diferença na variação das vazões ao longo do tempo para um mesmo poço instalado em solos que se distinguem apenas pelos valores de $a$, porém a magnitude desta diferença é mais evidente na Figura 5.20 que relaciona os volumes de água infiltrada ao longo do tempo em cada um dos poços instalados nos três tipos de solos aqui estudados.

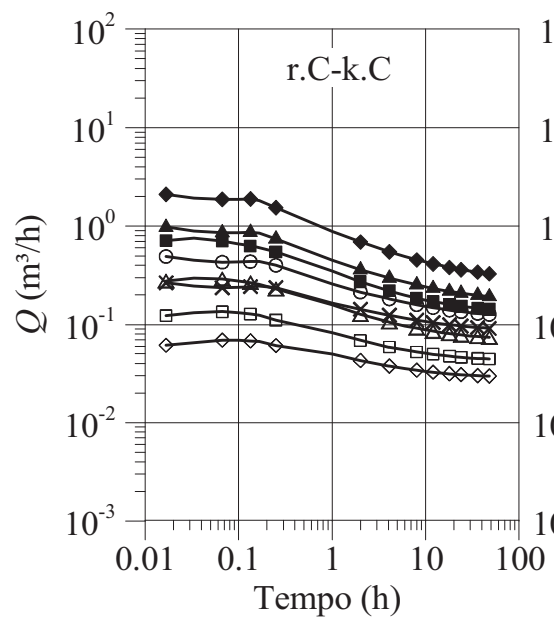

(a)

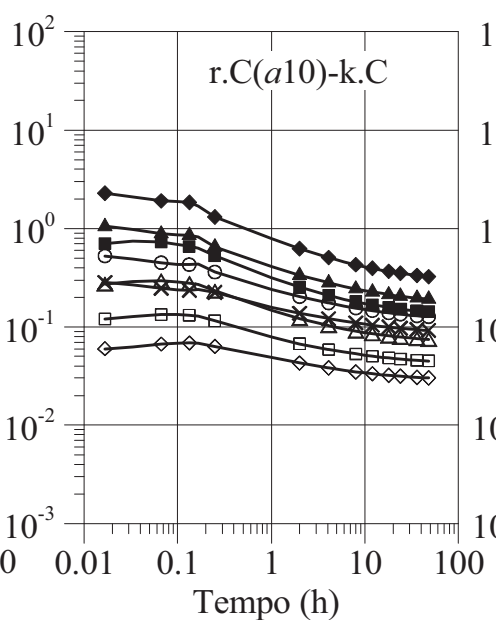

(b)

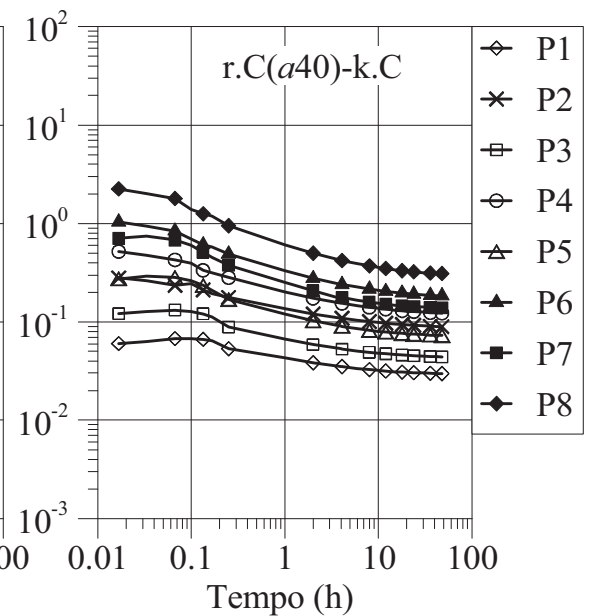

(c)

Figura 5.19 - Variação das vazões infiltradas através da área lateral do poço (paredes e base) ao longo do tempo. (a) Solo C; (b) Solo r.C(a10)-k.C; (c) Solo r.C(a40)-k.C.

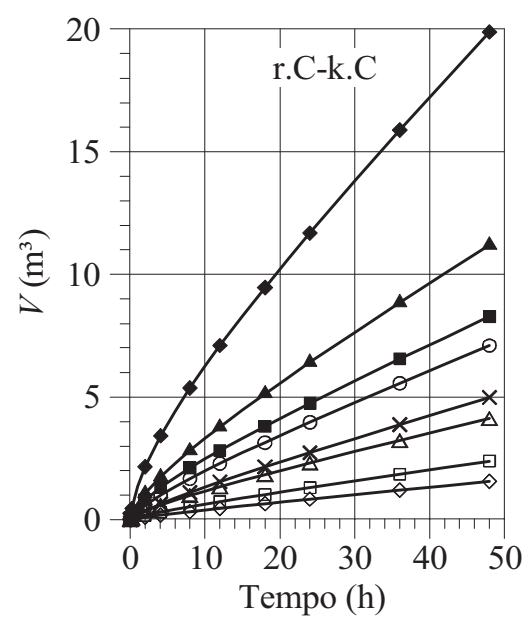

(a)

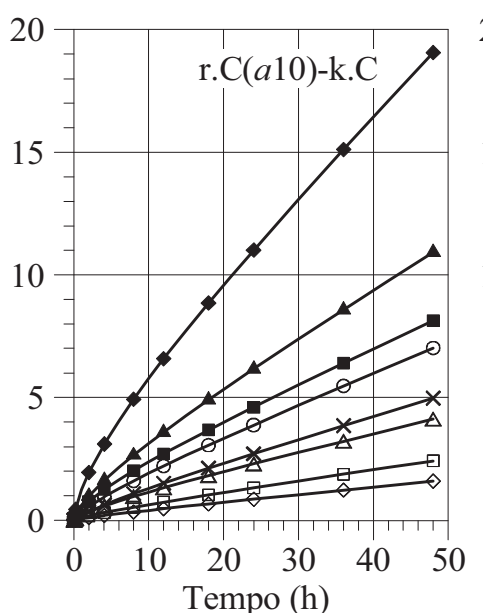

(b)

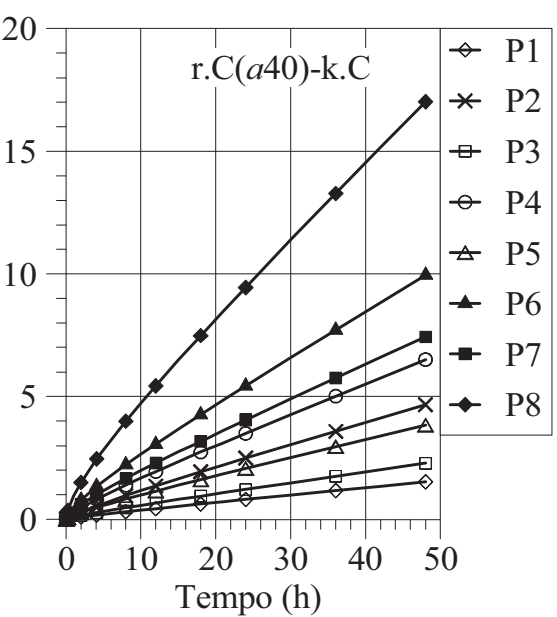

(c)

Figura 5.20 - Volumes infiltrados acumulados ao longo do tempo. (a) Solo C; (b) Solo r.C(a10)-k.C; (c) Solo r.C(a40)-k.C. 
Avaliando-se a Figura 5.20 nota-se que quanto maiores forem as pressões de entrada de ar dos solos (aqui relacionadas ao parâmetro $a$, da curva de retenção de Fredlund \& Xing (1994)), menores serão os volumes de água infiltrada nos poços.

Tal constatação pode ser explicada observando-se a Figura 5.18(a), nesta pode-se notar que, por exemplo, o teor de umidade volumétrica do solo r.C(a40)-k.C variou de 0,33 para $0,40 \mathrm{~m}^{3} / \mathrm{m}^{3}\left(\Delta \theta=0,07 \mathrm{~m}^{3} / \mathrm{m}^{3}\right)$ para este solo nas proximidades dos poços saísse da condição inicial de sucção matricial de $50 \mathrm{kPa}$ para a condição de saturação. Do mesmo modo, no solo r.C(a10)-k.C a variação do teor de umidade foi de 0,25 para $0,40 \mathrm{~m}^{3} / \mathrm{m}^{3}(\Delta \theta=$ $\left.0,15 \mathrm{~m}^{3} / \mathrm{m}^{3}\right)$ e para o solo $\mathrm{C}$ foi de 0,17 para $0,40 \mathrm{~m}^{3} / \mathrm{m}^{3}\left(\Delta \theta=0,23 \mathrm{~m}^{3} / \mathrm{m}^{3}\right)$.

Logo, se os solos com menores valores de $a$ apresentam maiores variações no teor de umidade volumétrica, para que os mesmos tornem-se saturados nas proximidades dos poços, eles também devem acumular um volume de água maior.

\subsubsection{Influência do Parâmetro $n$ da Curva de Retenção de Fredlund \& Xing (1994)}

Foram criados dois solos fictícios com parâmetros $n$ de 3 e 10, para que fosse realizada a avaliação da influência do parâmetro $n$, da curva de retenção de Fredlund \& Xing (1994) (Equação (2.6)), no processo de infiltração de água em poços. Os dois solos divergem do solo C apenas no valor parâmetro $n$, que neste solo é de 1,351. Os solos criados foram denominados de solo r.C(n3)-k.C e solo r.C(n10)-k.C. A Figura 5.21 apresenta as curvas de retenção destes solos e a do solo $\mathrm{C}$, assim como a função condutividade hidráulica deste.

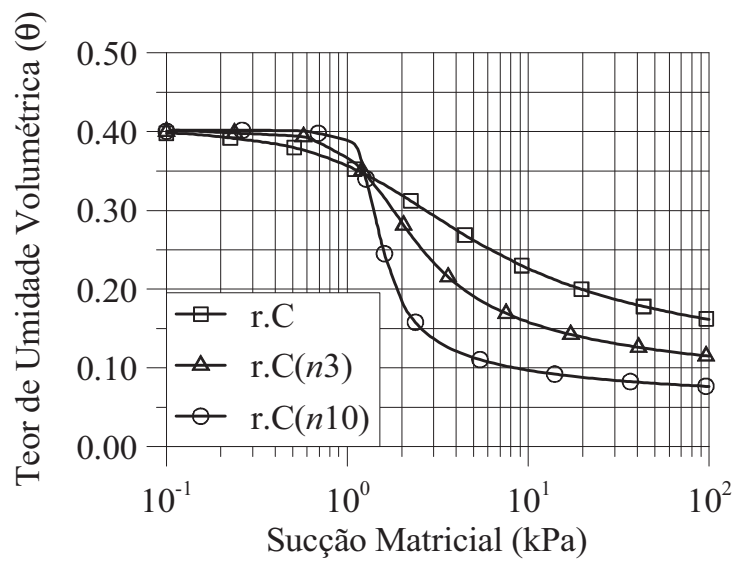

(a)

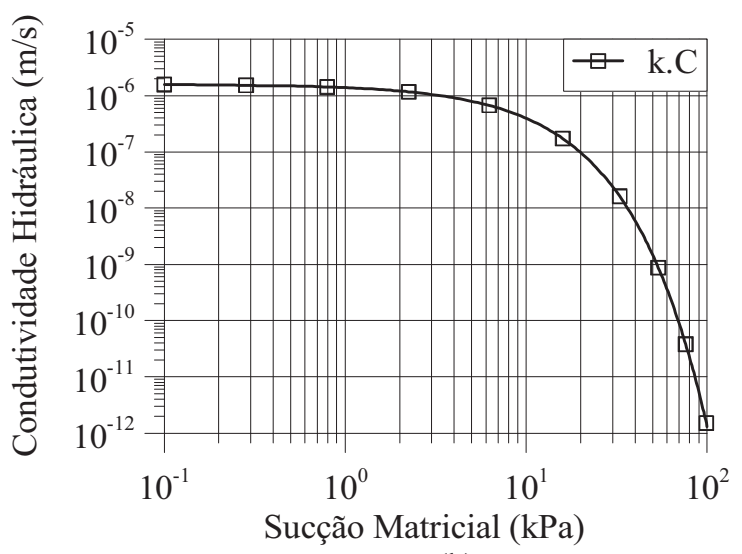

(b)

Figura 5.21 - (a) Curvas de retenção r.C , r.C(n3) e r.C(n10); (b) Função condutividade hidráulica k.C.

Analisando-se a Figura 5.22 que mostra a variação das vazões nos poços ao longo do tempo e a Figura 5.23 que apresenta os volumes infiltrados nos poços ao longo do tempo, 
percebe-se que o parâmetro $n$ tem influência mínima no processo de infiltração de água em poços.

Ainda, nota-se que quanto maiores forem os valores de $n$ maiores serão os volumes de água infiltrada, o que novamente pode ser explicado pela variação de $\theta$ necessária para que se leve o solo nas proximidades dos poços da condição inicial de $50 \mathrm{kPa}$ de sucção matricial para a condição de saturação. A Figura 5.21(a), explicita que os solos com curvas de retenção com maiores valores de $n$ devem apresentar uma maior variação de $\theta$ para que seja alcançada a condição de saturação, o que implica um maior acúmulo de água nos mesmos.

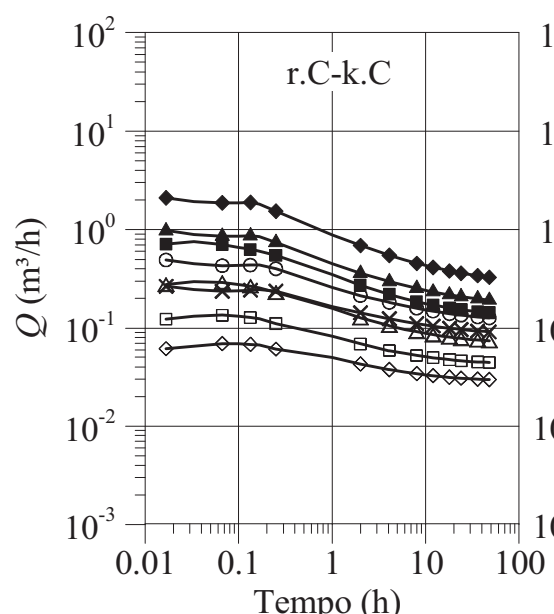

(a)

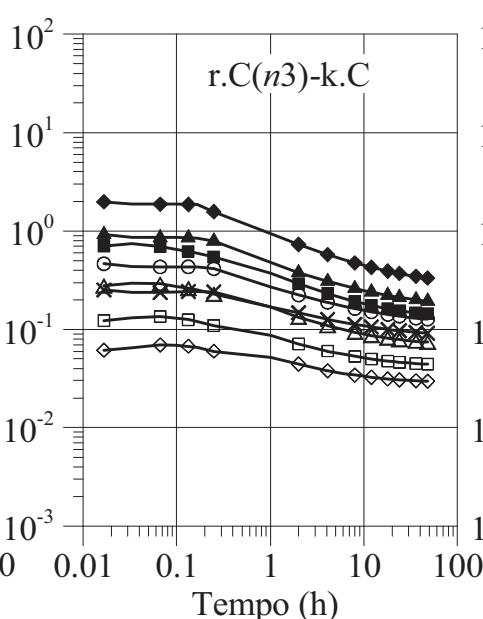

(b)

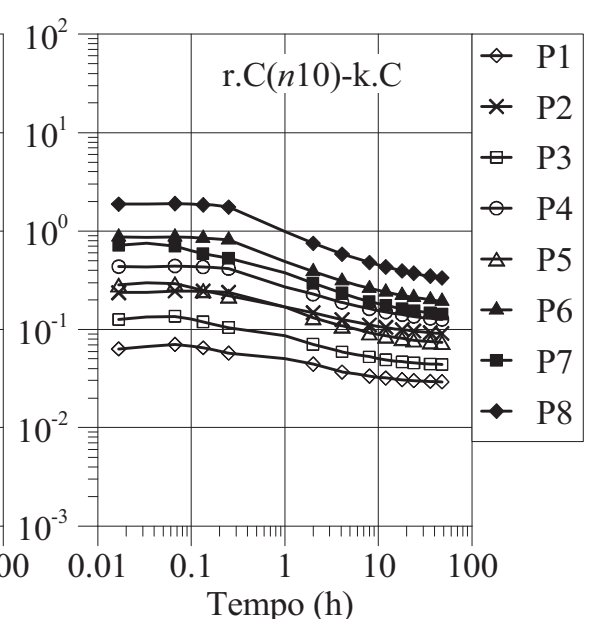

(c)

Figura 5.22 - Variação das vazões infiltradas através da área lateral do poço (paredes e base) ao longo do tempo. (a) Solo C; (b) Solo r.C(n3)-k.C; (c) Solo r.C(n10)-k.C.

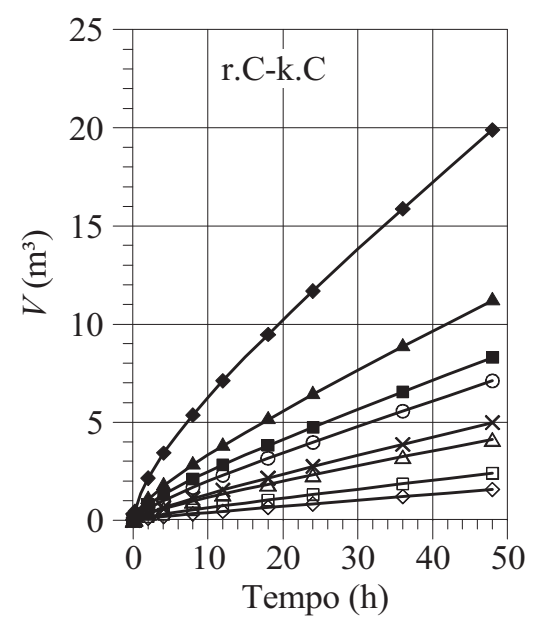

(a)

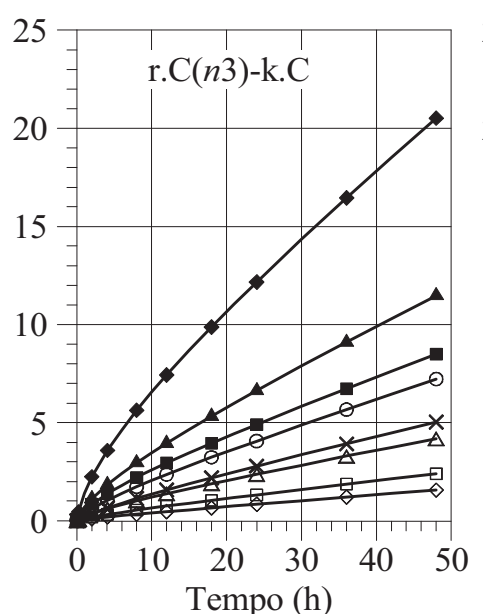

(b)

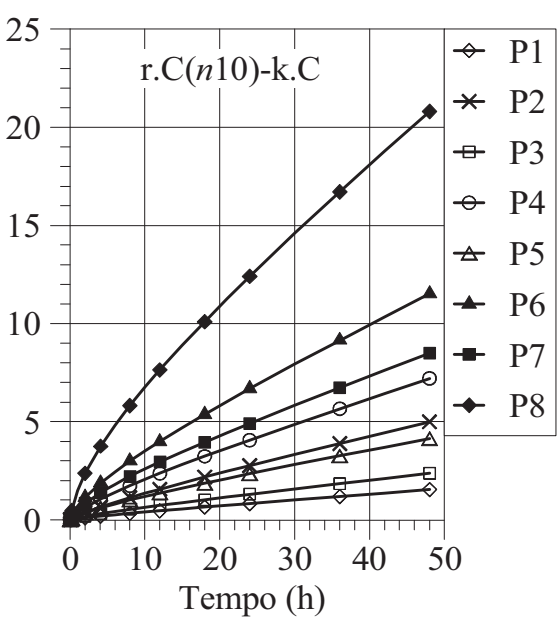

(c)

Figura 5.23 - Volumes infiltrados acumulados ao longo do tempo. (a) Solo C; (b) Solo r.C(n3)-k.C; (c) Solo r.C(n10)-k.C. 
5.3.5 Influência do Parâmetro $m$ da Curva de Retenção de Fredlund \& Xing (1994)

Para a avaliação da influência do parâmetro $m$, da curva de retenção de Fredlund \& Xing (1994) (Equação (2.6)), no processo de infiltração de água em poços foram criados dois solos fictícios com funções condutividade hidráulica iguais à do solo $\mathrm{C}$ e com curvas de retenção distintas da do solo $\mathrm{C}$ apenas no parâmetro $m$, que neste vale 0,618 enquanto que nos dois solos criados valem 0,10 e 0,30 . Os solos criados foram denominados de solo r.C $(m 0,10)-k . C$ e solo r.C $(m 0,30)-k . C$. As curvas de retenção destes solos e a do solo $\mathrm{C}$, assim como a função condutividade hidráulica deste são apresentadas na Figura 5.24.

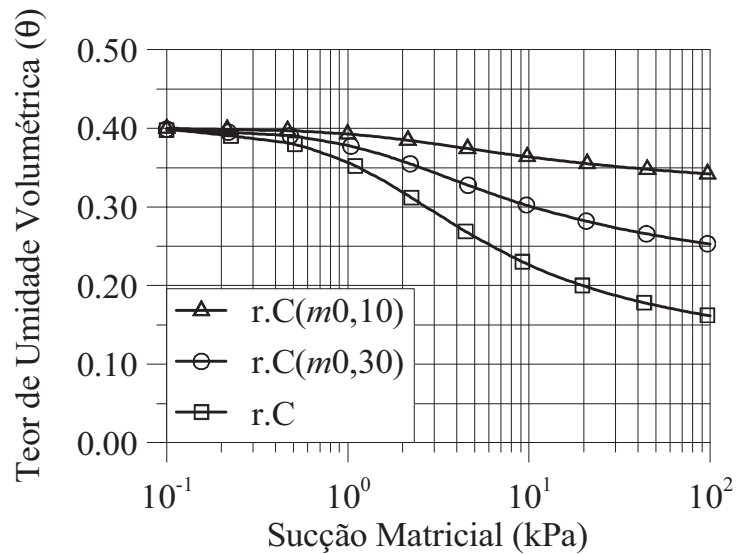

(a)

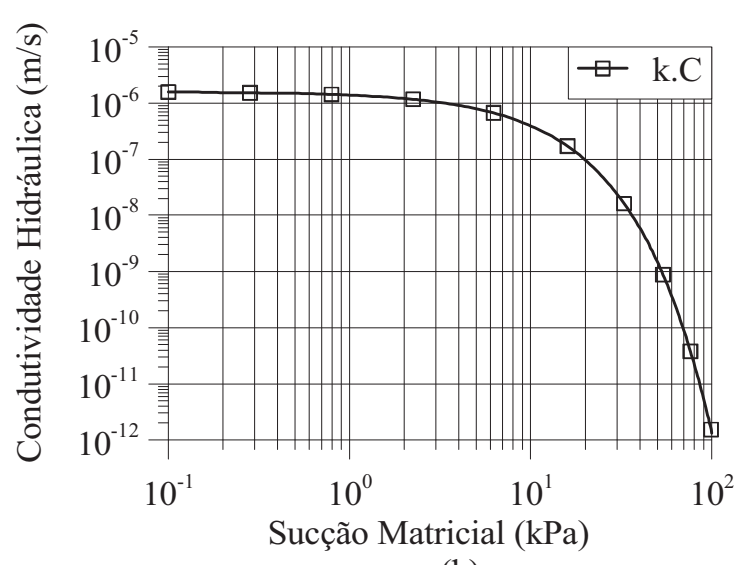

(b)

Figura 5.24 - (a) Curvas de retenção r.C $(m 0.10)$, r.C $(m 0.30)$ e r.C; (b) Função condutividade hidráulica k.C.

Analisando-se as Figura 5.25 e Figura 5.26 que mostram a variação das vazões nos poços e os volumes infiltrados nos mesmos ao longo do tempo, respectivamente, percebe-se que o parâmetro $m$ tem pouca influência no processo de infiltração de água em poços.

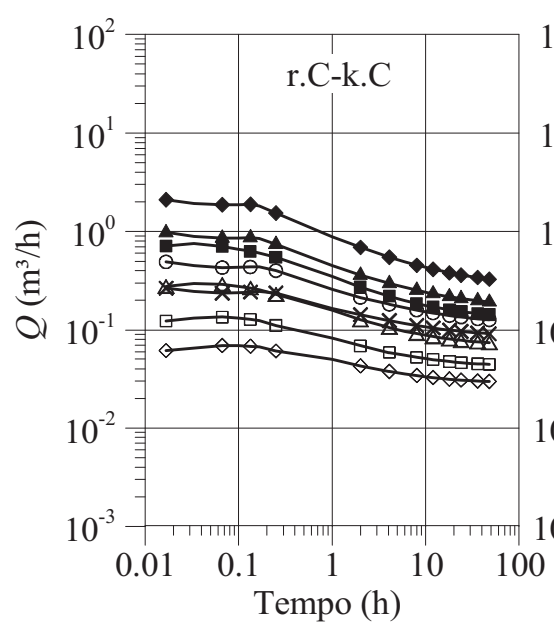

(a)

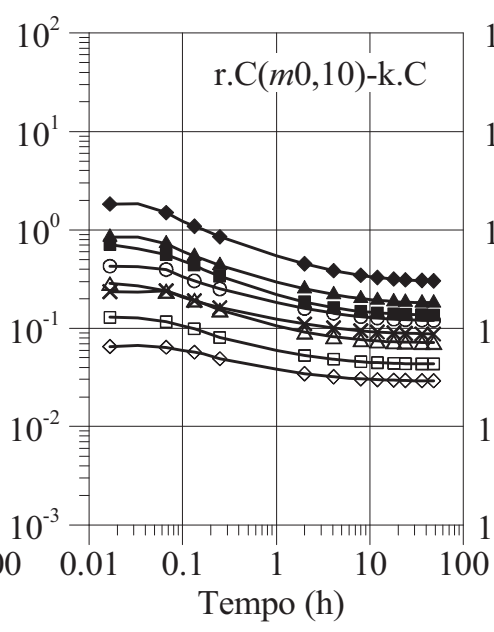

(b)

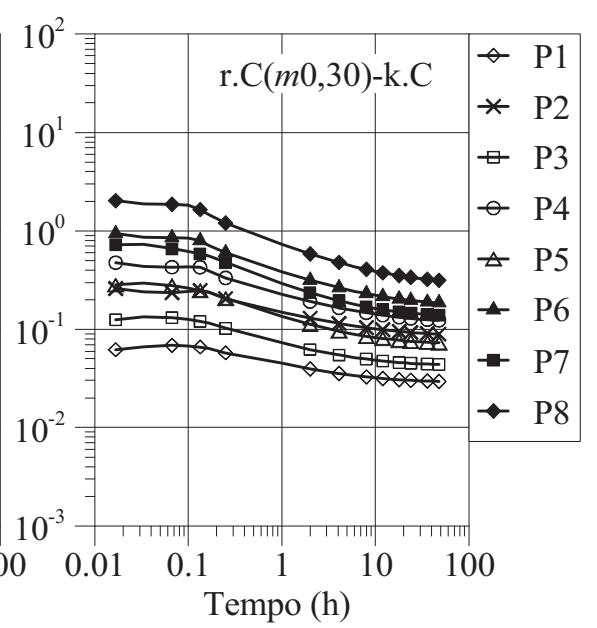

(c)

Figura 5.25 - Variação das vazões infiltradas através da área lateral do poço (paredes e base) ao longo do tempo. (a) Solo C; (b) Solo r.C(m0,10)-k.C; (c) Solo r.C(m0,30)-k.C. 
Na Figura 5.26 nota-se que os volumes de água infiltrada nos poços são tanto maiores quanto maiores forem os valor de $m$. Isto se explica observando-se a Figura 5.24(a), nesta pode-se constatar que curvas de retenção com maiores valores de $m$ devem apresentar maiores variações de $\theta$ para que se leve o solo nas proximidades dos poços da condição inicial de sucção matricial de $50 \mathrm{kPa}$ para a condição de saturação. Tal constatação, elucida a ocorrência de maiores volumes de água infiltrada em poços instalados nos solos com maiores valores de $m$.

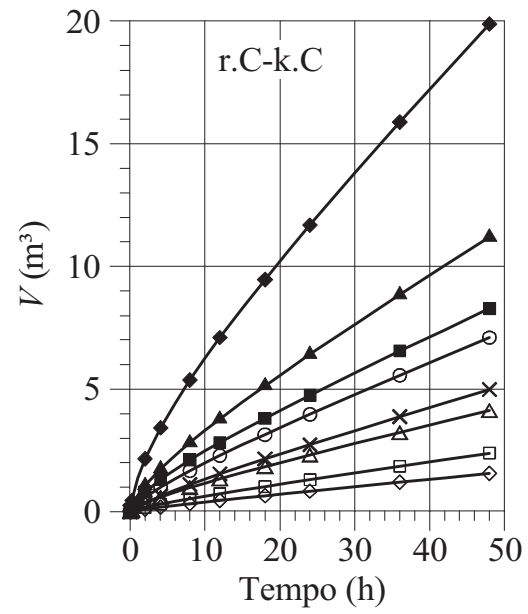

(a)

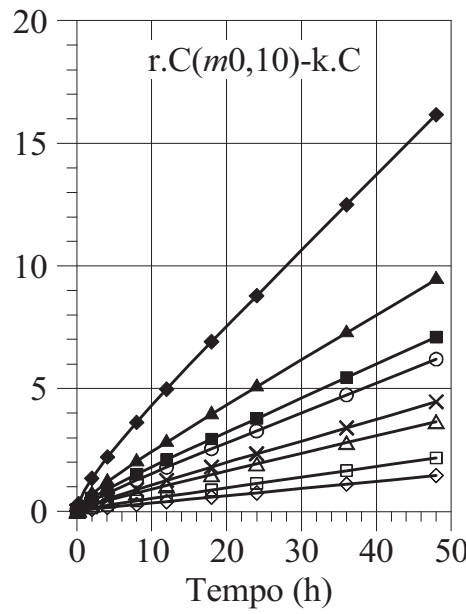

(b)

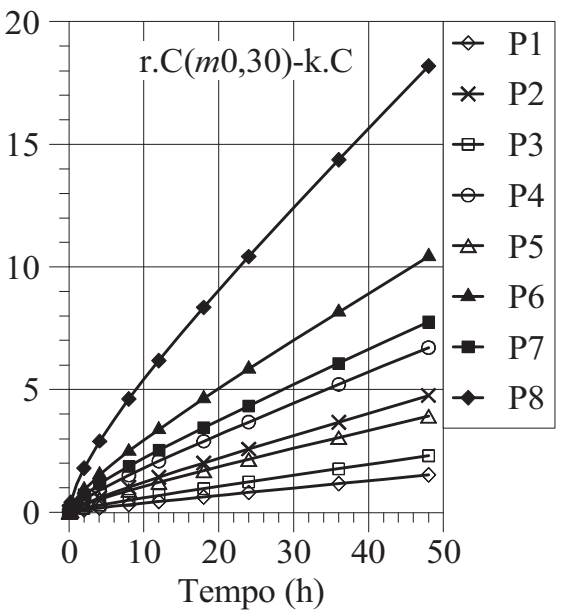

(c)

Figura 5.26 - Volumes infiltrados acumulados ao longo do tempo. (a) Solo C; (b) Solo r.C(m0,10)-k.C; (c) Solo r.C $(m 0,30)-k . C$.

\subsection{Dimensionamento de Poços de Infiltração}

Os resultados obtidos mostram que $k_{s}$ é o parâmetro de maior relevância no processo de infiltração de água em poços. Tal constatação permite estabelecer um método prático de projeto de poços que necessite de poucos parâmetros e que exclua a interferência dos parâmetros que possuem pequena influência no processo de infiltração em poços. Para este fim foram modelados oito poços de infiltração (P1 a P8) em seis solos distintos, sendo eles: solos A, B, C, D, E e F, com curvas de retenção e funções condutividade hidráulica já apresentadas nas Figura 3.3 e Figura 3.4. A Figura 5.27 mostra a variação das vazões ao longo do tempo nos poços instalados nos solos A, B, C, D, E e F.

Para o dimensionamento de um poço de infiltração faz-se necessário conhecer a área impermeável que se deseja drenar, a taxa e a duração de uma precipitação de projeto, relacionada a um tempo de retorno. Com isto pode-se calcular o volume de água que se deseja drenar em um determinado intervalo de tempo. Assim, para efeitos práticos de 
dimensionamento, as informações de volumes de água infiltrada ao longo do tempo em um determinado poço instalado, em um dado solo, são mais úteis do que as informações relacionadas às vazões instantâneas ao longo do tempo neste mesmo poço.

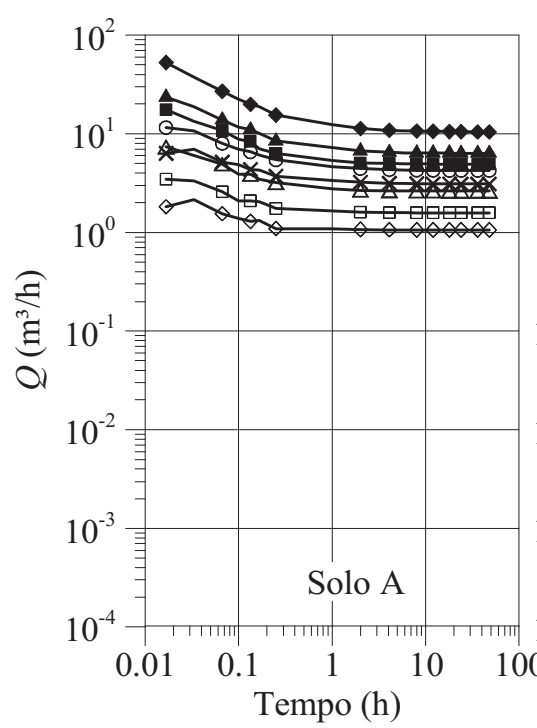

(a)

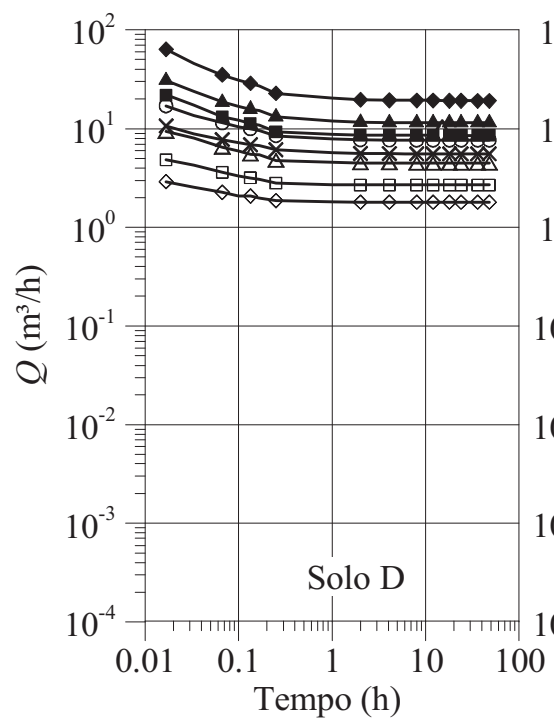

(d)

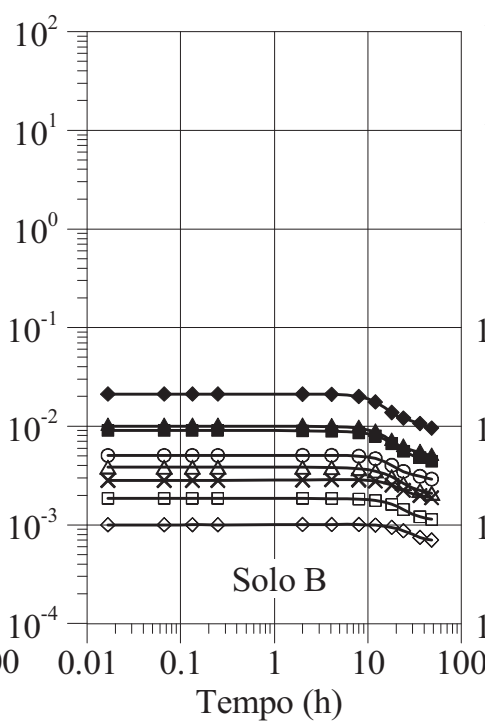

(b)

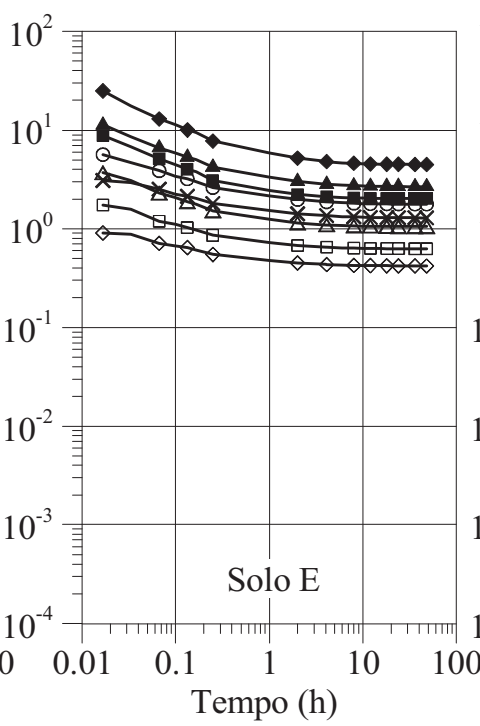

(e)

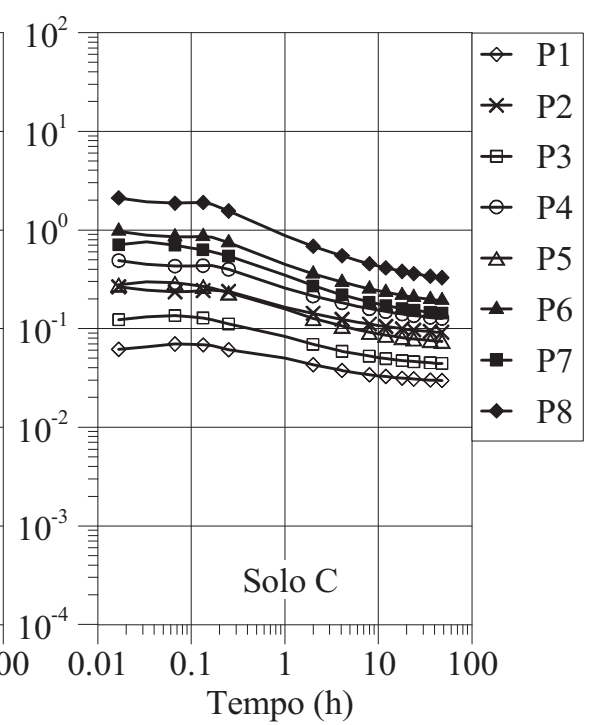

(c)

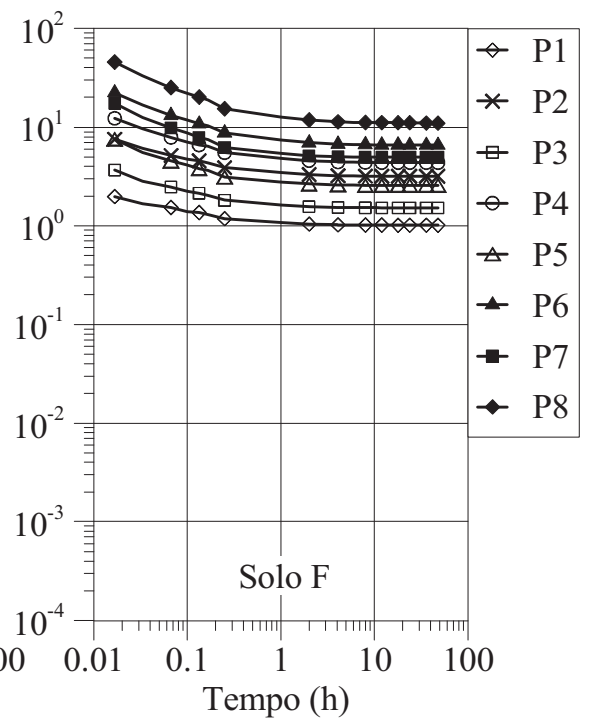

(f)

Figura 5.27 - Variação das vazões ao longo do tempo nos poços instalados no solo A, B, C, D, E e F.

Deste modo, buscou-se agrupar as curvas de $Q(t)$ (Figura 5.27) através das curvas de um parâmetro $\lambda$ (Equação (5.3)) versus o tempo. Este trabalho não pretende dar um significado físico para este parâmetro, apenas buscou-se agrupar as famílias de curvas de vazões ao longo do tempo.

$$
\lambda=\frac{Q}{A_{T} \cdot t}
$$

em que $A_{T}\left(\mathrm{~m}^{2}\right)$ é a área total do poço (computando-se paredes e base), $Q\left(\mathrm{~m}^{3} / \mathrm{h}\right)$ é a vazão no poço e $t(\mathrm{~h})$ é o tempo de infiltração. 
A Figura 5.28 apresenta os ábacos de $\lambda(t)$ para os oito poços instalados nos seis solos analisados. Percebe-se que esta parametrização agrupa as curvas dos oito poços de modo que as mesmas possam ser representadas por curvas médias de $\lambda(t)$ que são apresentadas na Figura 5.29.

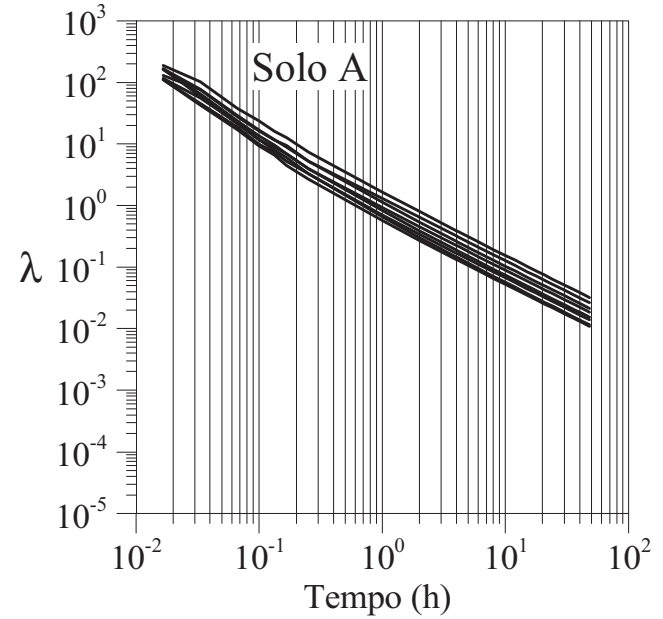

(a)

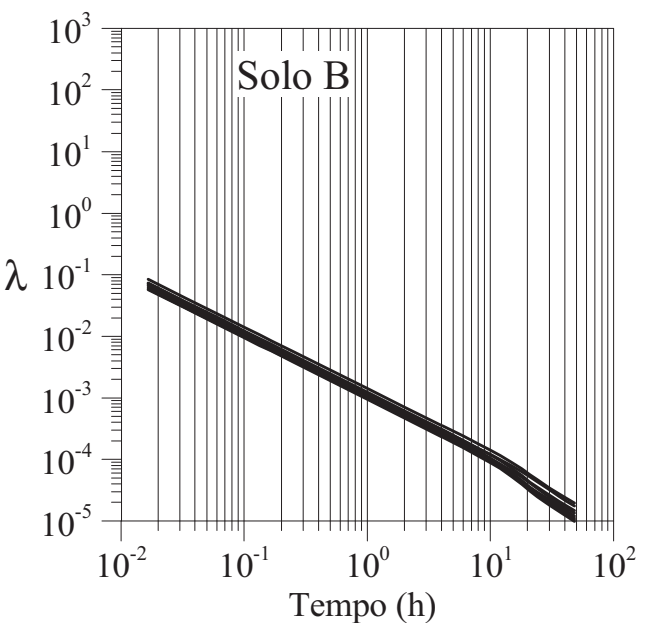

(b)

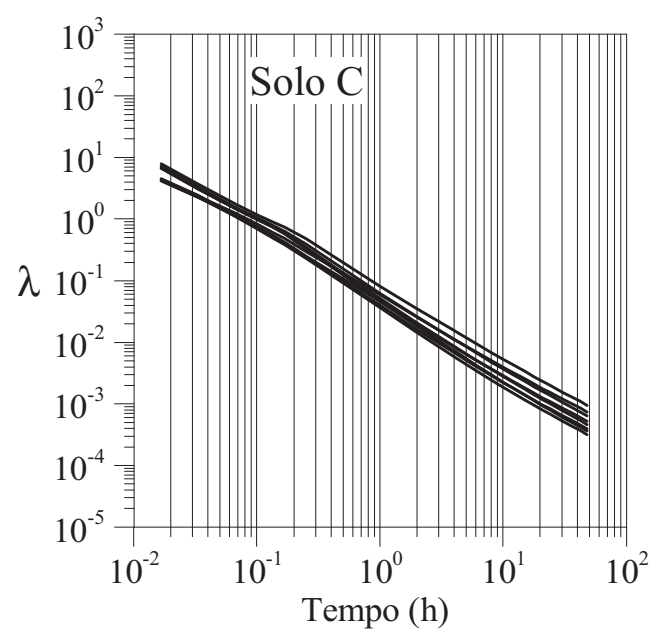

(c)

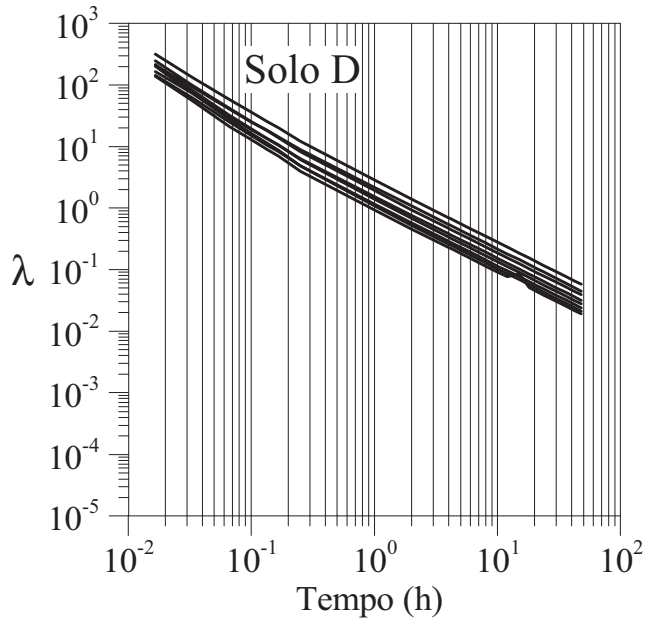

(d)

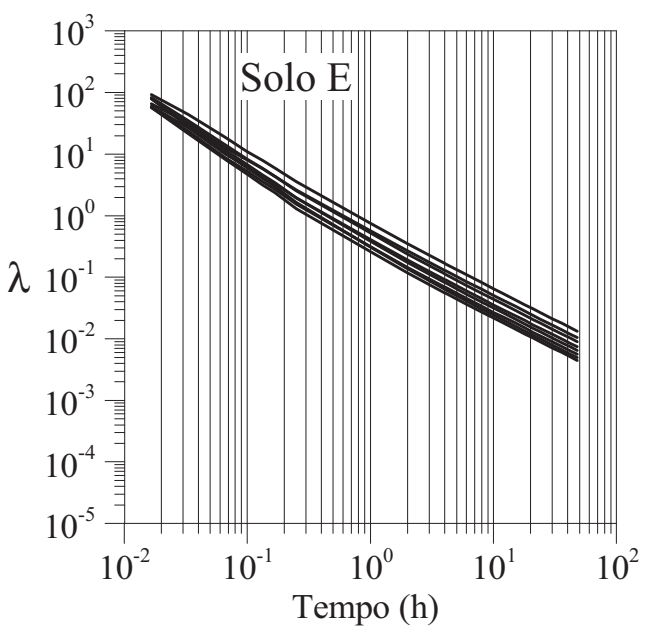

(e)

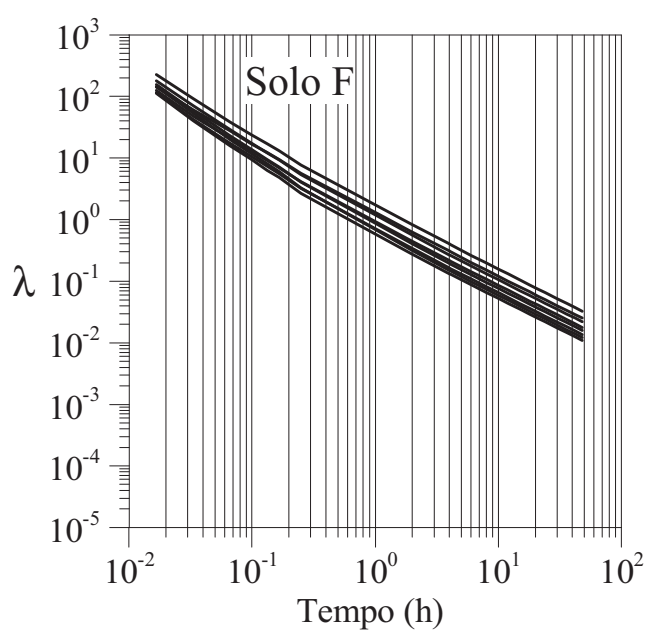

(f)

Figura 5.28 - Ábacos que relacionam os parâmetros $\lambda$ com o tempo para os solos A, B, C, D, E e F. 


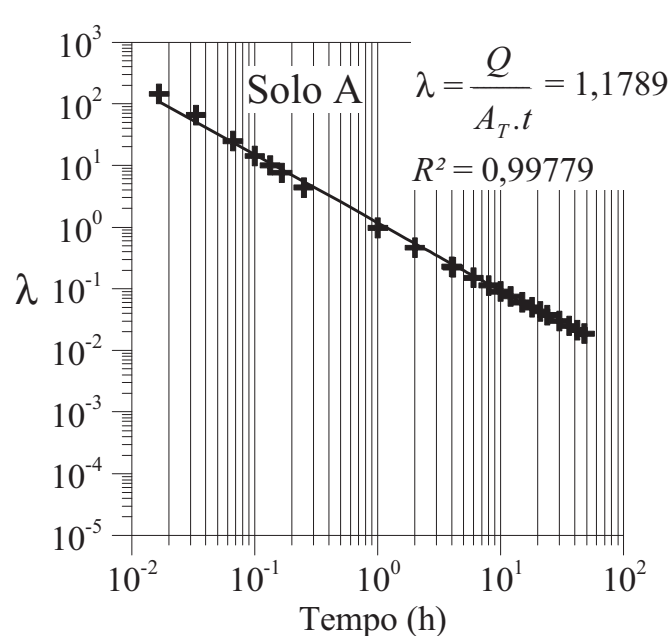

(a)

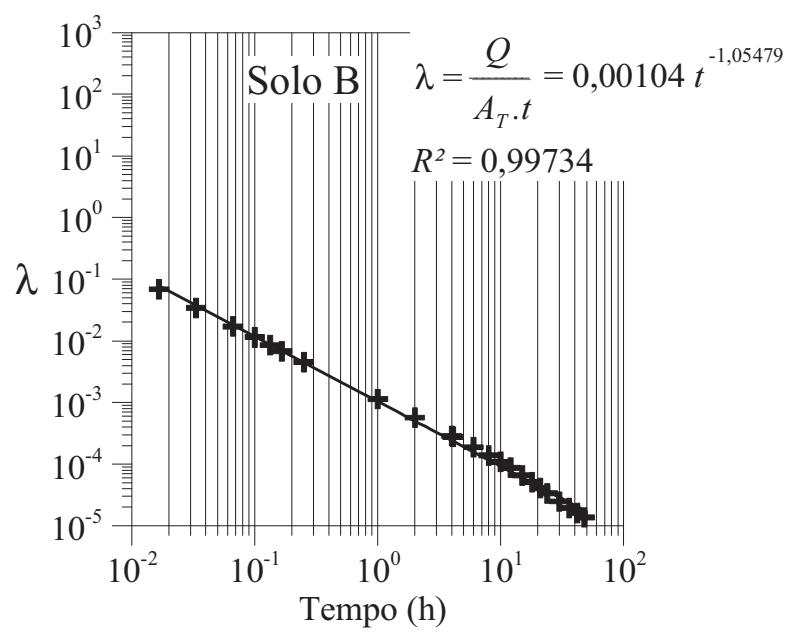

(b)

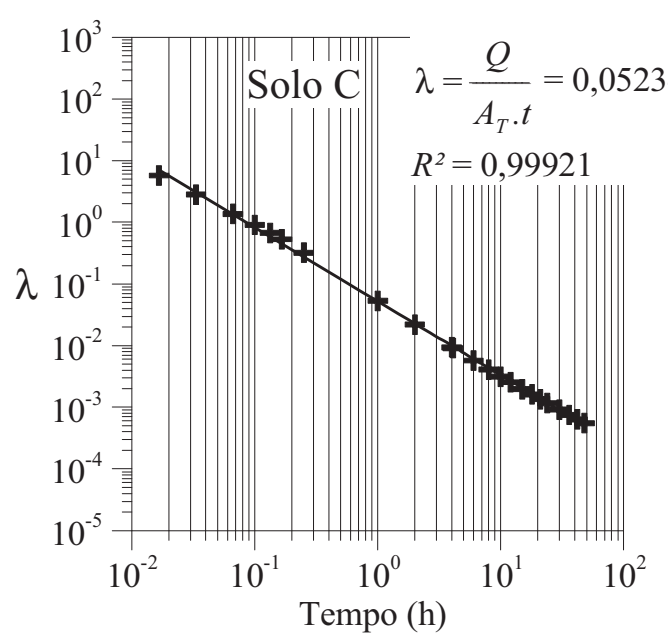

(c)

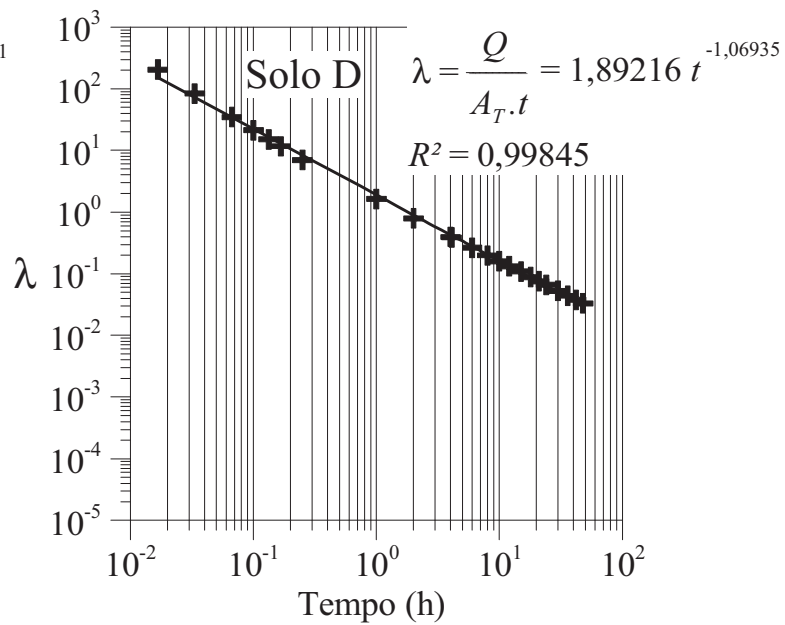

(d)

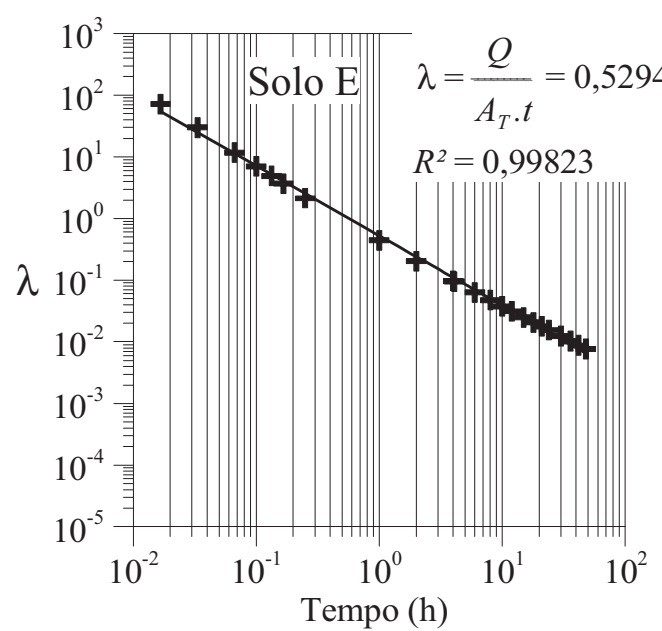

(e)

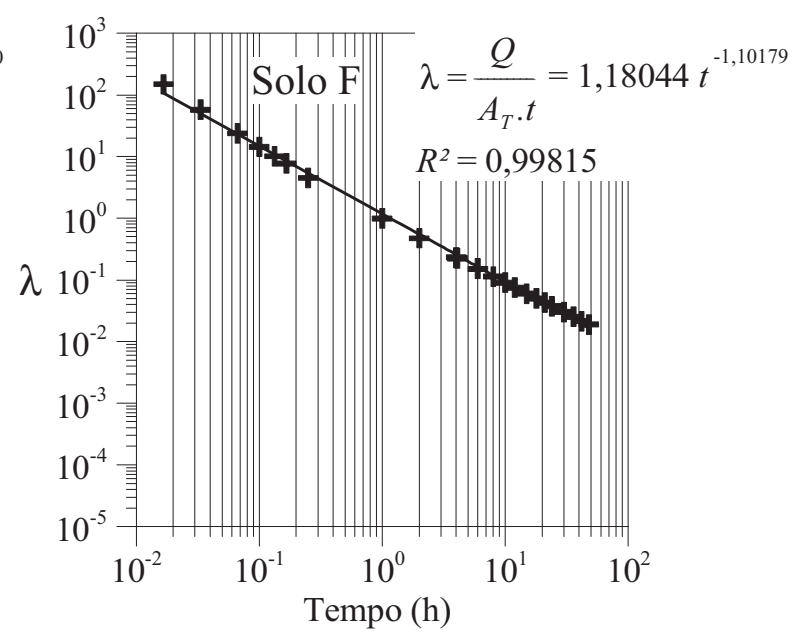

(f)

Figura 5.29 - Ábacos e equações de ajuste que relacionam as curvas médias dos parâmetros $\lambda$ com o tempo para os solos A, B, C, D, E e F.

As equações de ajuste das curvas médias são funções potência e podem ser representadas genericamente pela Equação (5.4). 


$$
\lambda=\frac{Q}{A_{T} \cdot t}=b \cdot t^{-c}
$$

em que $b(\mathrm{~m} / \mathrm{h})$ e $c$ são parâmetros de ajuste.

Os termos $b$ e $c$ desta equação, assim como o coeficiente de condutividade hidráulica saturada dos seis solos analisados são apresentados na Tabela 5.2. Nesta, os dados foram organizados a partir da ordem crescente dos valores de $k_{s}$.

Tabela 5.2 - Parâmetros $b$ e $c$ das curvas médias de $\lambda(t)$.

\begin{tabular}{cccccc}
\hline Solo & $k_{s}(\mathrm{~m} / \mathrm{s})$ & $k_{s}(\mathrm{~m} / \mathrm{h})$ & $b(\mathrm{~m} / \mathrm{h})$ & $c$ & $R^{2}$ \\
\hline B & $8,4 \mathrm{E}-09$ & $3,0 \mathrm{E}-05$ & 0,00104 & 1,05479 & 0,99734 \\
C & $1,6 \mathrm{E}-06$ & $5,8 \mathrm{E}-03$ & 0,05234 & 1,19760 & 0,99921 \\
E & $2,4 \mathrm{E}-05$ & $8,6 \mathrm{E}-02$ & 0,52943 & 1,13198 & 0,99823 \\
A & $5,4 \mathrm{E}-05$ & $1,9 \mathrm{E}-01$ & 1,17893 & 1,10471 & 0,99779 \\
F & $6,1 \mathrm{E}-05$ & $2,2 \mathrm{E}-01$ & 1,18044 & 1,10179 & 0,99815 \\
D & $1,0 \mathrm{E}-04$ & $3,6 \mathrm{E}-01$ & 1,89216 & 1,06935 & 0,99845 \\
\hline
\end{tabular}

Da Equação (5.4), pode-se obter a equação que permite a determinação da vazão em um poço em um dado instante $(t)$, conhecendo-se a área total $\left(A_{T}\right)$ do mesmo e os parâmetros $b$ e $c$ que são associados ao tipo de solo no qual o poço está inserido:

$$
Q=A_{T} \cdot b \cdot t^{1-c}
$$

Integrando-se os dois lados da igualdade na Equação (5.5) em relação ao tempo, chega-se à equação que permite a determinação dos volumes infiltrados acumulados em um poço, que é função do tempo:

$$
\begin{gathered}
V(t)=\int Q d t=A_{T} \cdot b \cdot \int t^{1-c} d t \\
V(t)=A_{T} \cdot b \cdot \frac{t^{2-c}}{2-c}
\end{gathered}
$$

Para que a Equação (5.7) possa ser empregada no dimensionamento de poços de infiltração basta que se conheça a área total do poço $\left(A_{T}\left(\mathrm{~m}^{2}\right)\right)$ que se deseja dimensionar (computando-se paredes e base) e os parâmetros $b$ e $c$.

Da Tabela 5.2 percebe-se que o parâmetro $c$ apresenta pequena oscilação mesmo para solos extremamente distintos. Deste modo pode-se adotar $c$ como constante e igual a 1,11 que é a média dos valores deste parâmetro na Tabela 5.2. Por outro lado, grafando-se os parâmetros $b$ da Tabela 5.2 em função de $k_{s}(\mathrm{~m} / \mathrm{h})$ chega-se à Figura 5.30, que apresenta um comportamento linear, podendo-se ajustar a seguinte equação:

$$
b=5,45 \cdot k_{s}
$$




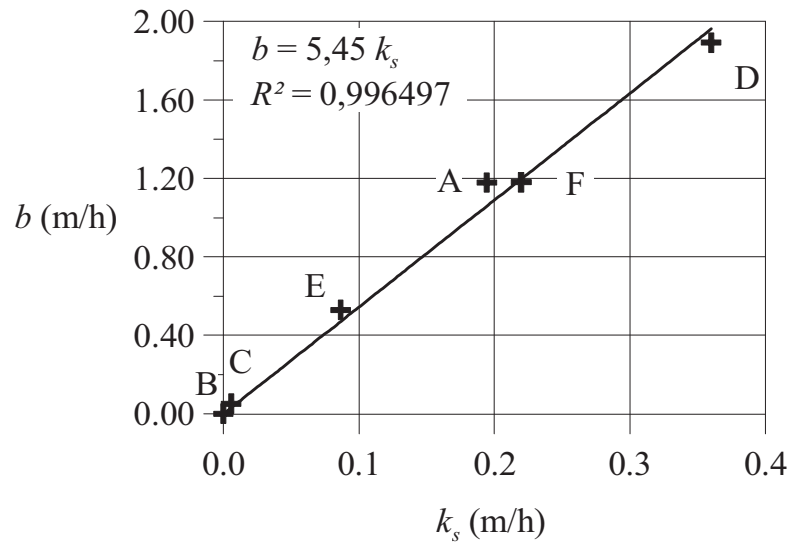

Figura 5.30 - Parâmetro $b$ em função de $k_{s}$.

Substituindo-se os parâmetros $b=5,45 k_{s}$ (com $k_{s}$ em m/h) e $c=1,11$ na Equação (5.7), obtêm-se a equação geral de estimativa do volume de água infiltrada em um dado tempo, para um poço com área total (paredes e base) conhecida:

$$
V(t)=6,12 \cdot k_{s} \cdot A_{T} \cdot t^{0,89}
$$

Para a validação da Equação (5.9), devido à dificuldade em encontrar na literatura experimentos em poços de infiltração, comparou-se o resultado do primeiro experimento realizado por Lima (2009) em uma trincheira de infiltração de pequenas dimensões, com comprimento de 2,5 m, por 1,0 $\mathrm{m}$ de altura e 1,0 $\mathrm{m}$ de largura. A escolha desta trincheira se deveu ao fato da mesma se assemelhar a um poço de infiltração, devido à sua pequena dimensão longitudinal (comprimento de 2,5 m). O solo caracterizado por Lima (2009), no qual foi instalada a trincheira de infiltração, trata-se de uma areia média a fina argilosa típica do Campus 1 da Escola de Engenharia de São Carlos, com coeficiente de condutividade hidráulica saturada $\left(k_{s}\right)$ de $32,616 \times 10^{-3} \mathrm{~m} / \mathrm{h}\left(9,06 \times 10^{-6} \mathrm{~m} / \mathrm{s}\right)$.

Substituindo-se na Equação (5.9) a área total $\left(A_{T}\right)$ da trincheira de $9,5 \mathrm{~m}^{2}$, a condutividade hidráulica saturada $\left(k_{s}\right)$ do solo de $32,616 \times 10^{-3} \mathrm{~m} / \mathrm{h}$ e o tempo $(t)$ de abastecimento da trincheira de $0,367 \mathrm{~h}$ ( 22 minutos), chega-se a um volume estimado de 0,78 $\mathrm{m}^{3}$ de água infiltrada ao final de $0,367 \mathrm{~h}$.

A Figura 5.31 apresenta a variação do volume de água infiltrada na trincheira durante a fase de abastecimento e recessão do primeiro experimento realizado por Lima (2009). Notase claramente nesta figura que o volume de água infiltrada foi de aproximadamente $0,80 \mathrm{~m}^{3}$ ao final do tempo de abastecimento da trincheira $(t=0,367 \mathrm{~h})$, o que concorda perfeitamente com o volume de $0,78 \mathrm{~m}^{3}$ de água obtido através da Equação (5.9). Com o exposto, pode-se afirmar que a Equação (5.9) permite uma boa estimativa do volume de água infiltrado até o final de um determinado intervalo de tempo de abastecimento de um poço ou de uma 
trincheira de infiltração de pequenas dimensões. Entretanto, é imprescindível que os volumes de água infiltrada estimados a partir da Equação (5.9) sejam validados com outros ensaios realizados em campo em poços de infiltração.

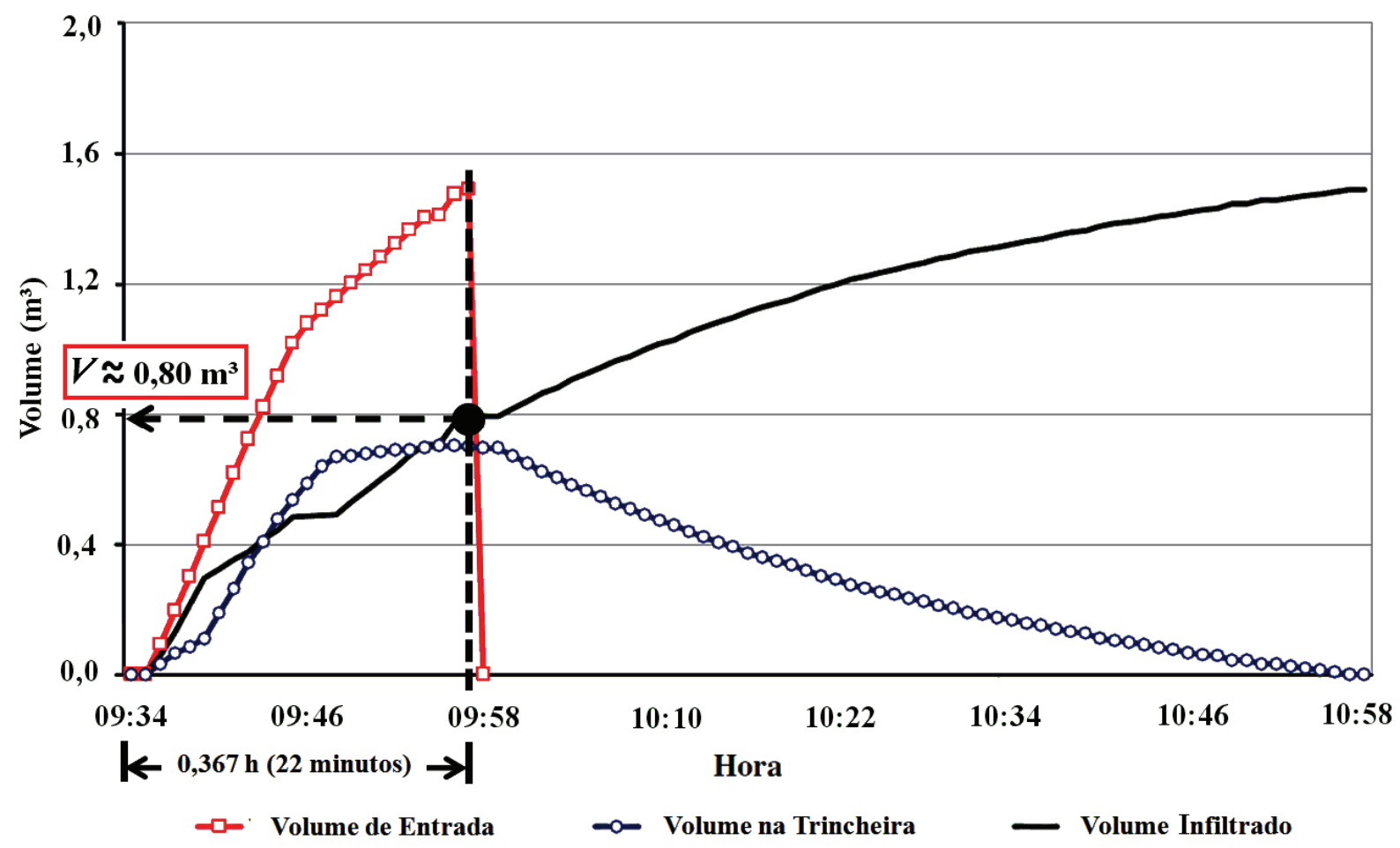

Figura 5.31 - Variação do volume de água infiltrada na trincheira durante a fase de abastecimento e recessão do primeiro experimento realizado por Lima (2009) (modificado de Lima (2009)).

Entretanto, o volume de água $V\left(\mathrm{~m}^{3}\right)$ que se deseja drenar através de um poço de infiltração é igual ao volume total que se deseja fazer infiltrar $\left(V_{T}\left(\mathrm{~m}^{3}\right)\right)$ dividido pela quantidade $j$ de poços que serão necessários. Assim, o volume $V$ de água infiltrada em um poço ao fim de um tempo $t$ de duração de uma precipitação é dado pela seguinte expressão:

$$
V=\frac{V_{T}}{j}=\frac{1}{j} \cdot\left(\frac{r \cdot V_{C}-j \cdot n \cdot V_{P}}{100}\right)
$$

em que: $V_{C}$, é o volume total de água precipitada em uma dada área, ao fím de um evento de chuva $\left(\mathrm{m}^{3}\right)$;

$r$, é a porcentagem de $V_{C}$ que se pretende infiltrar (\%);

$n$, é a porosidade do material de preenchimento do poço (para poços sem material de preenchimento $n$ vale $100 \%)(\%)$;

$V_{P}$, é o volume interno do poço de infiltração $\left(\mathrm{m}^{3}\right)$.

A parcela $j \cdot n \cdot V_{P}$ da equação (5.10) leva em conta o volume de água retido nos vazios do material de preenchimento de todos os poços. Neste caso, calcula-se o volume $V$, que deve 
ser drenado ao fim do tempo $t$ de duração da chuva, abatendo-se o volume $j \cdot n \cdot V_{P}$, já que este pode ser infiltrado quando a chuva cessar.

Sabendo-se que $V_{C}$ e $V_{P}$ valem:

$$
\begin{gathered}
V_{C}=i \cdot t \cdot A \\
V_{P}=0,25 \cdot \pi \cdot d^{2} \cdot h
\end{gathered}
$$

em que: $i$, é uma taxa de precipitação de projeto $(\mathrm{m} / \mathrm{h})$;

$t$, é o tempo de duração da precipitação de projeto (h);

$A$, é a área impermeável, que se pretende drenar $\left(\mathrm{m}^{2}\right)$

Substituindo-se as Equações (5.11) e (5.12) em (5.10) chega-se a seguinte expressão:

$$
V=\frac{r \cdot i \cdot t \cdot A-0,25 \cdot j \cdot n \cdot \pi \cdot d^{2} \cdot h}{100 \cdot j}
$$

Sabendo-se que para poços cilindricos, $A_{T}$ na Equação (5.9) vale:

$$
A_{T}=0,25 \cdot \pi \cdot d^{2}+\pi \cdot d \cdot h
$$

pode-se substituir (5.14) em (5.9). Igualando-se as expressões (5.9) e (5.13) e isolando-se $h$, obtém-se a equação de dimensionamento de poços de infiltração. A profundidade do poço é calculada para um diâmetro e um quantidade $j$ de poços adotados, assim pode-se testar vários valores de $j$ e de $d$ na Equação (5.15) de modo que se escolha a melhor combinação de $j, d$ e $h$ para os poços de infiltração. As unidades de medida de todos os dados de entrada devem ser em metros para unidades de comprimento e em horas para unidades de tempo. Logo, deve-se entrar com $r$ e $n$ em porcentagem (\%), $i$ e $k_{s}$ em metros por hora $(\mathrm{m} / \mathrm{h}), A$ em metros quadrados $\left(\mathrm{m}^{2}\right), d$ em metros $(\mathrm{m}), t$ em horas $(\mathrm{h})$.

$$
h=\frac{r \cdot i \cdot t \cdot A-153 \cdot k_{s} \cdot j \cdot \pi \cdot d^{2} \cdot t^{0,89}}{j \cdot \pi \cdot\left(0,25 \cdot n \cdot d^{2}+612 \cdot k_{s} \cdot d \cdot t^{0,89}\right)}
$$

Como exemplo de utilização da Equação (5.15), foram dimensionados poços de infiltração, instalados no solo C da cidade de São Carlos-SP com $k_{s}$ de $5,76 \times 10^{-3} \mathrm{~m} / \mathrm{h}$ $\left(k_{s}=1,60 \times 10^{-6} \mathrm{~m} / \mathrm{s}\right)$, que drenem uma área impermeável $(A)$ de $100 \mathrm{~m}^{2}$, sujeita a uma taxa de precipitação de $i$ de $20 \times 10^{-3} \mathrm{~m} / \mathrm{h}(20 \mathrm{~mm} / \mathrm{h})$ durante 12 minutos $(t=0,2 \mathrm{~h})$. Adimite-se que estes poços não possuem material de preenchimento $(n=100 \%)$ e que todo o volume precipitado na área seja drenado através dos mesmos $(r=100 \%)$, sem que ocorra a geração de escoamento superficial.

Assim, todos os dados obtidos podem ser inseridos na Equação (5.15), calculando-se as profundidades dos poços $(h)$ para alguns valores de $i$ e $d$ adotados. 
A Tabela 5.3 apresenta o dimensionamento de alguns poços de infiltração. Caso se deseje drenar toda a área de $100 \mathrm{~m}^{2}$ sem geração de escoamento superficial com um único poço $(j=1)$, este deverá ter as dimensões do poço $\mathrm{Pa}$ ou as do poço $\mathrm{Pb}$. Ainda, caso se deseje drenar toda a área com dois poços $(j=2)$, estes podem ter dimensões iguais as do poço Pc ou as do poço $\mathrm{Pd}$. O critério de escolha da quantidade, das dimensões dos poços e do posicionamento dos mesmos no terreno fica ao critério de cada projetista. Entretanto, quando uma solução de drenagem necessitar de vários poços, estes devem ser posicionados suficientemente afastados, para que se garanta que alguns poços não interfiram no comportamento dos outros.

Tabela 5.3 - Exemplo de dimensionamento de poços de infiltração.

\begin{tabular}{|c|c|c|c|c|c|c|c|c|c|c|c|c|}
\hline & & & & & & & & & & & & \\
\hline & & & & & & & & & & Para cad & a poço & \\
\hline Poço & $j$ & $\begin{array}{c}r \\
(\%)\end{array}$ & $\begin{array}{c}i \\
(\mathrm{~m} / \mathrm{h})\end{array}$ & $\begin{array}{c}t \\
(\mathrm{~h})\end{array}$ & $\begin{array}{c}A \\
\left(\mathrm{~m}^{2}\right)\end{array}$ & $\begin{array}{c}V_{C} \\
\left(\mathrm{~m}^{3}\right) \\
\end{array}$ & $\begin{array}{c}n \\
(\%)\end{array}$ & $\begin{array}{c}k_{s} \\
(\mathrm{~m} / \mathrm{h})\end{array}$ & $\begin{array}{c}V_{P} \\
\left(\mathrm{~m}^{3}\right)\end{array}$ & $\begin{array}{c}V \\
\left(\mathrm{~m}^{3}\right)\end{array}$ & $\begin{array}{c}d \\
(\mathrm{~m})\end{array}$ & $\begin{array}{c}h \\
(\mathrm{~m})\end{array}$ \\
\hline $\mathrm{Pa}$ & 1 & 100 & $2,0 \mathrm{E}-02$ & 0,2 & 100 & 0,400 & 100 & $5,76 \mathrm{E}-03$ & 0,375 & 0,025 & 0,56 & 1,50 \\
\hline $\mathrm{Pb}$ & 1 & 100 & $2,0 \mathrm{E}-02$ & 0,2 & 100 & 0,400 & 100 & $5,76 \mathrm{E}-03$ & 0,378 & 0,022 & 0,70 & 1,00 \\
\hline $\mathrm{Pc}$ & 2 & 100 & $2,0 \mathrm{E}-02$ & 0,2 & 100 & 0,400 & 100 & $5,76 \mathrm{E}-03$ & 0,183 & 0,017 & 0,39 & 1,50 \\
\hline $\mathrm{Pd}$ & 2 & 100 & $2,0 \mathrm{E}-02$ & 0,2 & 100 & 0,400 & 100 & $5,76 \mathrm{E}-03$ & 0,186 & 0,014 & 0,49 & 1,00 \\
\hline
\end{tabular}




\section{CONCLUSÃO}

Nesta pesquisa foram efetuadas análises paramétricas acerca da influência das funções condutividade hidráulica e das curvas de retenção dos solos no processo de infiltração de água em poços cilíndricos instalados em solos inicialmente não saturados. Para a realização das análises paramétricas, foi empregado o programa SEEP/W do pacote GeoStudio 2004, que utiliza a técnica dos elementos finitos na solução numérica da Equação de Richards que rege o fluxo de água em meio não saturado. Com isto, desenvolveu-se uma técnica de dimensionamento de poços de infiltração para fins de drenagem urbana, que tem por base a estimativa do volume de água infiltrada em um dado poço, ao fim de um tempo de precipitação.

Inicialmente foi realizada uma avaliação da condição adotada de poço preenchido por água instantaneamente. Nesta, pôde-se constatar que esta simplificação representa de forma fidedigna as situações mais inconvenientes à drenagem urbana, como nos casos em que as taxas de precipitações e as áreas impermeáveis são elevadas e os poços de drenagem disponíveis têm pequenos diâmetros. Verificou-se ainda que nas outras situações, diferentes das anteriores, a simplificação adotada é a favor da segurança, pois a infiltração real é maior que a modelada. Estas observações permitiram o emprego da condição de poço preenchido por água instantaneamente de forma satisfatória.

Com as análises paramétricas da influência da função condutividade hidráulica do solo, concluiu-se que o parâmetro que mais interfere no comportamento da infiltração de água em poços é a condutividade hidráulica saturada $k_{s}$. A redução de $k_{s}$ de uma ordem de grandeza fez com que os volumes de água infiltrada no solo com menor $k_{s}$ fossem de até $13 \%$ dos volumes infiltrados nos poços instalados em solo com maior $k_{s}$. Para os mesmos valores de $k_{s}$, as interferências do parâmetro $\alpha$ da equação de Gardner (1958) e do formato da função condutividade hidráulica, no processo de infiltração em poços, mostraram-se pouco relevantes. As pequenas influências destes na infiltração de água em poços se devem aos fatos de que em solos com iguais valores de $k_{s}$, aqueles que apresentam funções condutividade hidráulica com baixos valores de $\alpha$ ou funções condutividade hidráulica com valores de $k_{s}$ mantidos em grandes intervalos de sucção, tendem a ser mais permeáveis para uma mesma sucção matricial.

As análises paramétricas da influência da curva de retenção do solo mostraram que os parâmetros da mesma pouco influenciam no processo de infiltração de água em poços. Partindo-se de uma condição de sucção matricial inicial igual para os solos analisados, a 
pequena influência do teor de umidade volumétrica saturada $\theta_{\mathrm{s}}$ e dos parâmetros $a, n$ e $m$ do ajuste da curva de retenção proposto por Fredlund \& Xing (1994) no processo de infiltração de água em poços se deve ao fato de que os solos que possuem maiores valores de $\theta_{\mathrm{s}}$, menores valores do parâmetro $a$ - que é associado à pressão de entrada de ar - e maiores valores de $n$ e $m$ apresentam maiores variações no teor de umidade volumétrica para que os mesmos tornem-se saturados nas proximidades dos poços, logo estes solos devem acumular mais água.

Ao fim das análises paramétricas foi desenvolvida uma técnica de dimensionamento de poços de infiltração que possibilita a estimativa do volume de água infiltrada em um dado poço em função do tempo de precipitação, do coeficiente de condutividade hidráulica saturada do solo e da área total do poço (paredes e base). Por fim, comparou-se o volume estimado de água infiltrada obtido através da técnica de dimensionamento proposta com o volume medido em um ensaio de infiltração realizado por Lima (2009) em uma trincheira de pequenas dimensões e pôde-se constatar que o a técnica de dimensionamento desenvolvida é consistente com o ensaio de infiltração realizado em campo. Entretanto, é imprescindível que em trabalhos futuros os volumes de água infiltrada estimados, a partir da técnica desenvolvida neste trabalho, sejam validados com outros ensaios realizados em campo em poços de infiltração. 


\section{REFERÊNCIAS}

ALFARO SOTO, M.A. (1999). Estudo da Condutividade Hidráulica em Solos Não Saturados. Dissertação de Mestrado - Escola de Engenharia de São Carlos Universidade de São Paulo, São Carlos, SP, 1999. 121 pp

ARAÚJO, P.R.; TUCCI, C.E.M.; GOLDENFUM, J.A. (2000). Avaliação da Eficiência dos Pavimentos Permeáveis na Redução de Escoamento Superficial. RBRH - Revista Brasileira de Recursos Hídricos, v.5, n.3, p.21-29.

ARAVENA, J.E.; DUSSAILLANT, A. (2009). Storm-Water Infiltration and Focused Recharge Modeling with Finite-Volume Two-Dimensional Richards Equation: Application to an Experimental Rain Garden. Journal of Hydraulic EngineeringAsce, v.135, n.12, p.1073-1080.

ASLESON, B.C. et al. (2009). Performance Assessment of Rain Gardens ${ }^{1}$. Journal of the American Water Resources Association, v.45, n.4, p.1019-1031.

BODMAN, G.B.; COLMAN, E.A. (1944). Moisture and Energy Conditions During Downward Entry of Water into Soils. Soil Science Society of America Proceedings, v.8, p.116-122.

BRANDÃO, V.S. et al. (2009). Infilttração da Água no Solo. Viçosa, MG: Editora UFV Universidade Federal de Viçosa. 120 pp

BRATTEBO, B.O.; BOOTH, D.B. (2003). Long-Term Stormwater Quantity and Quality Performance of Permeable Pavement Systems. Water Research, v.37, n.18, p.43694376.

CALLE, J.A.C. (2000). Análise de Ruptura de Talude em Solo Não Saturado. Dissertação de Mestrado - Escola de Engenharia de São Carlos - Universidade de São Paulo, São Carlos, SP, 2000. 156 pp

CHAHINIAN, N. et al. (2005). Comparison of Infiltration Models to Simulate Flood Events at the Field Scale. Journal of Hydrology, v.306, n.1-4, p.191-214.

DUSSAILLANT, A.R.; WU, C.H.; POTTER, K.W. (2004). Richards Equation Model of a Rain Garden. Journal of Hydrologic Engineering, v.9, n.3, p.219-225. 
FREDLUND, D.G.; RAHARDJO, H. (1993). Soil Mechanics for Unsaturated Soils. New York: John Wiley \& Sons, Inc. 507 pp

FREDLUND, D.G.; XING, A.Q. (1994). Equations for the Soil-Water Characteristic Curve. Canadian Geotechnical Journal, v.31, n.4, p.521-532.

FREDLUND, D.G.; XING, A.Q.; HUANG, S.Y. (1994). Predicting the Permeability Function for Unsaturated Soils Using the Soil-Water Characteristic Curve. Canadian Geotechnical Journal, v.31, n.4, p.533-546.

FREEZE, R.A.; CHERRY, J.A. (1979). Groundwater. New Jersey: Prentice-Hall, Englewood Cliffs. 604 pp

GARDNER, W.R. (1958). Some steady-state solutions of the unsaturated moisture flow equation with application to evaporation from a water table. Soil Science, v.85, n.4, p.228-232.

GEOSTUDIO (2004). Seepage Modeling with SEEP/W. An Engineering Methodology, Calgary, Canada, 2004. 398 pp

GRACIOSA, M.C.P. (2005). Trincheiras de Infiltração como Tecnologia Alternativa em Drenagem Urbana: Modelagem Experimental e Numérica. Dissertação de Mestrado - Escola de Engenharia de São Carlos - Universidade de São Paulo, São Carlos, SP, 2005. 232 pp

GREEN, W.H.; AMPT, G.A. (1911). Studies on Soil Physics. Part I - The flow of air and water through soils. Journal of Agricultural Science, v.4, p.1-24.

HILlEL, D. (1980). Applications of Soil Physics. San Diego, California: Academic Press, Inc. $385 \mathrm{pp}$

HORTON, R.E. (1933). The Role of Infiltration in the Hydrologic Cycle. TransactionsAmerican Geophysical Union, v.14, p.446-460. (1940). An Approach Toward a Physical Interpretation of Infiltration-Capacity. Soil Science Society of America Proceedings, v.5, p.399-417. 
LEONG, E.C.; RAHARDJO, H. (1997a). Review of Soil-Water Characteristic Curve Equations. Journal of Geotechnical and Geoenvironmental Engineering, v.123, n.12, p.1106-1117.

(1997b). Permeability Functions for Unsaturated Soils. Journal of Geotechnical and Geoenvironmental Engineering, v.123, n.12, p.1118-1126.

LIBARDI, P.L. (1995). Dinâmica da Água no Solo. Piracicaba, SP: Departamento de Ciências Exatas da Escola Superior de Agricultura Luiz Queiroz (ESALQ) Universidade de São Paulo. 497 pp

LIMA, V.C.G.R. (2009). Análise Experimental e Numérica de Trincheiras de Infiltração em Meio Não Saturado. Dissertação de Mestrado - Escola de Engenharia de São Carlos - Universidade de São Paulo, São Carlos, SP, 2009. 176 pp

MIGUEL, M.G.; VILAR, O.M. (2009). Study of the Water Retention Properties of a Tropical Soil. Canadian Geotechnical Journal, v.46, n.9, p.1084-1092.

PHILIP, J.R. (1955). Numerical Solution of Equations of the Diffusion Type with Diffusivity Concentration-Dependent. Transactions of the Faraday Society, v.51, n.7, p.885892.

. (1957a). The Theory of Infiltration: 4. Sorptivity and Algebraic Infiltration Equations. Soil Science, v.84, n.3, p.257-264.

. (1957b). Numerical Solution of Equations of the Diffusion Type with Diffusivity Concentration-Dependent. II. Australian Journal Physics, v.10, p.29-42.

REICHARDT, K. (1985). Processos de Transferência no Sistema Solo-Planta-Atmosfera. Campinas, SP: Fundação Cargill. 445 pp

. (1996). Dinâmica da Matéria e da Energia em Ecossistemas. Piracicaba, SP: Departamento de Ciências Exatas da Escola Superior de Agricultura Luiz Queiroz (ESALQ) - Universidade de São Paulo. 513 pp

REIS, R.P.A.; OLIVEIRA, L.H.; SALES, M.M. (2005). Proposição de Parâmetros de Dimensionamento e Avaliação de Poço de Infiltração de Água Pluvial. In: M. $23^{\circ}$ Congresso Brasileiro de Engenharia Sanitária e Ambiental - Campo Grande. ABES - 
Associaçao Brasileira de Engenharia Sanitaria e Ambiental. Saneamento Ambiental Brasileiro: Utopia ou Realidade? Rio de Janeiro, RJ, 2005, p.1-9.

(2008). Sistemas de Drenagem na Fonte por Poços de Infiltração de Águas Pluviais. Ambiente Construído - Revista da ANTAC (Associação Nacional de Tecnologia do Ambiente Construído), v.8, n.2, p.99-117.

RICHARDS, L.A. (1931). Capillary Conduction of Liquids Through Porous Mediums. Physics-a Journal of General and Applied Physics, v.1, n.1, p.318-333.

RIGHETTO, A.M. (1998). Hidrologia e Recursos Hídricos. São Carlos, SP: Escola de Engenharia de São Carlos - Universidade de São Paulo. 819 pp

SANTOS, C.R. (2004). Análise Paramétrica da Infiltração e sua Influência na Estabilidade de Taludes em Solo Não Saturado. Dissertação de Mestrado - Escola de Engenheria de São Carlos - Universidade de São Paulo, São Carlos, SP, 2004. 104 $\mathrm{pp}$

SCHOLZ, M.; GRABOWLECKI, P. (2007). Review of Permeable Pavement Systems. Building and Environment, v.42, n.11, p.3830-3836.

SILVEIRA, A.L.L.; LOUZADA, J.A.; BELTRAME, L.F.S. (2004). Infiltração e Armazenamento no Solo. In: C.E.M. TUCCI. Hidrologia Ciência e Aplicação. 3.ed. Porto Alegre: ABRH Editora da UFRGS, 2004. Capítulo 9, p.335-372.

SOUZA, V.C.B. (2002). Estudo Experimental de Trincheiras de Infiltração no Controle da Geração do Escoamento Superficial. Tese de Doutorado - Universidade Federal do Rio Grande do Sul, Porto Alegre, RS, 2002. 137 pp

SWARTZENDRUBER, D. (1969). The Flow of Water in Unsaturated Soils. In: R.J.M. WIEST. Flow Through Porous Media. New York: Academic Press, 1969. Capítulo 6, p.215-292.

VAN GENUCHTEN, M.T. (1980). A Closed-Form Equation for Predicting the Hydraulic Conductivity of Unsaturated Soils. Soil Science Society of America Journal, v.44, n.5, p.892-898. 
VANAPALLI, S.K.; FREDLUND, D.G.; PUFAHL, D.E. (1999). The Influence of Soil Structure and Stress History on the Soil-Water Characteristics of a Compacted Till. Géotechnique, v.49, n.2, p.143-159.

VAUCLIN, M.; KHANJI, D.; VACHAUD, G. (1979). Experimental and numerical study of a transient, 2-dimensional unsaturated-saturated water table recharge problem. Water Resources Research, v.15, n.5, p.1089-1101.

VILAR, O.M. (2002). Resistência ao Cisalhamento. Apostila - Escola de Engenharia de São Carlos - Universidade de São Paulo, São Carlos, SP, 2002. 